Vera Lúcia Conceição de Gouveia Santos

\title{
Cuidando do estomizado: análise da trajetória no ensino, pesquisa e extensão
}

Tese apresentada à Escola de Enfermagem da Universidade de São Paulo para inscrição no Concurso de Livre Docência, junto ao departamento de Enfermagem Médico-Cirúrgica 


\section{Catalogação na publicação (CIP) \\ Biblioteca "Wanda de Aguiar Horta" da EEUSP}

Santos, Vera Lúcia Conceição de Gouveia

Cuidando do estomizado: análise da trajetória no ensino, pesquisa e extensão. / Vera Lúcia Conceição de Gouveia Santos. - São Paulo: V. L. C. de G. Santos, 2006. $205 \mathrm{p}$.

Tese (Livre-docência) - Escola de Enfermagem da Universidade de São Paulo.

1. Enfermagem em estomaterapia 2. Epidemiologia 3. Especialidades da enfermagem 4. Qualidade de vida 5. Políticas públicas. I. Título. 
"Se os teus sonhos estiverem nas nuvens, não te preocupes pois estão no lugar certo. Agora começa a construir os alicerces."

(autor desconhecido) 


\section{DEDICATÓRIA}

Neste momento, não se trata de dedicar ou agradecer acerca da realização de um trabalho mas, como será percebido pelo leitor, dedicar e agradecer por uma vida de trabalho e de realizações. É nesse sentido que me dedico e à minha vida, em primeiro lugar, a Deus pelos dons, pela inteligência, pela obstinação e, enfim, por tudo. Em seguida, à minha família e, especialmente, aos homens de minha vida, meus amores. 


\section{AGRADECIMENTOS}

Agradecer às pessoas que estiveram comigo, durante a minha trajetória profissional, nos melhores momentos e naqueles não tão bons, torna-se muito difícil porque são muitas, o tempo é longo e há, além do mais, o risco do esquecimento.

Mesmo assim alguns nomes, locais ou serviços precisam ser mencionados. Desse modo, agradeço:

A esta universidade e a esta escola, nas quais construí meu desenvolvimento profissional, desde suas bases.

À enfermeira Alice Martins Gomes, meu primeiro modelo profissional.

Às minhas orientadoras Professoras Maria Sumie Koizumi e Bader Burihan Sawaia, que me acolheram e muito me ensinaram.

À Profa Dra Angelita Habr-Gama, pelo carinho e energia no início de minha caminhada.

Aos alunos de graduação e de pós-graduação, sensu latu e sensu stritu, com os quais muito aprendi e espero ter contribuído para a sua formação.

Aos pacientes estomizados, primeira motivação desta especialidade.

Aos colegas do departamento ENC: os muitos que ainda estão, os novos que chegaram e os poucos que já se foram, pelo companheirismo e parcerias.

Aos profissionais do Núcleo de Assistência a Ostomizados do Hospital das Clínicas da FMUSP, pelos anos de atividades conjuntas e amizade. 
Às queridas amigas, de tanto tempo - Lena, Li, Fá, Bebel, Marcinha e àquelas mais recentes - Rê, Cássia, Soninha, Mimi, Eli e Silvinha, pela amizade.

Aos amigos conquistados nesta jornada "especializada". Àqueles de perto como Tania, Rita, Ângela, Bia, Su, Gisele, Diba, Noemi e ... E àqueles mais distantes, como Nancy, Louise, Liz, Julia, Heidi, Pilar(s), Carmen, Berta, Cadi, Montserrat e ... Lu e Andréia (Expansão) e Vivi (BCC Tur), vocês também estão aqui!

Ao amigo Afonso, por compartilhar comigo o sonho da implantação da estomaterapia no Brasil.

Às "secretárias" do Departamento de Enfermagem Médico-Cirúrgica Rose, Marisa, Bete, Dorinha e Fátima. A Marisinha e Rose, em especial, pela paciência na digitação e formatação final de meu memorial tese.

À Débora, pela gentileza em formatar esta tese!

Ao Rufo, pela beleza e arte que adicionou a este trabalho (tese e memorial).

Ao Carlos da Tesouraria, pelo apoio constante.

Às secretárias do Serviço de Cultura e Extensão Maria Helena, Silvana (agora "pós"), Ana e Marcela, pelo apoio durante estes mais de quinze anos de extensão.

Ao Serviço de Biblioteca e Documentação, muito especialmente à Nadir pelo cuidado com que reviu e corrigiu as referências bibliográficas aqui utilizadas. E à Juliana, pela orientação na elaboração da ficha catalográfica e dos descritores empregados.

À SOBEST - orgulho de nossa especialidade! 
Aos amigos do CORALUSP, pela oportunidade de conhecê-los e de cantar a vida.

Às INSAnas, pelo maravilhoso re-encontro. 


\section{RESUMO}

Santos VLCG. Cuidando do estomizado: análise da trajetória no ensino, pesquisa e extensão [livre docência]. São Paulo (SP): Escola de Enfermagem /USP; 2006.

Considerando-se o profundo engajamento com a Estomaterapia enquanto recente especialidade de Enfermagem - desde sua implementação no país, este trabalho objetivou apresentar e analisar a produção acadêmica da autora, relacionada à área de estomias, no período de 1983 a 2006. Para o desenvolvimento dessa compilação analítica, são apresentadas todas as publicações de investigações, artigos de atualização, capitulos de livros e documentos integrantes de políticas públicas, relacionados ao tema. Para o suporte teórico atualizado, realizou-se pesquisa bibliográfica de artigos indexados nos bancos de dados acessados, eletronicamente, por meio do sítio da Biblioteca Virtual em Saúde (BVS) da Biblioteca Regional de Medicina (BIREME), em pesquisa avançada, nos últimos cinco anos. Após introdução histórica da especialidade, a produção é discutida em seis capítulos que tratam dos aspectos epidemiológicos dos estomas, de alguns aspectos do cuidar e qualidade de vida de pessoas com estomas, da educação formal em estomaterapia, das políticas públicas de atenção aos estomizados e das tendências do ensino, pesquisa e assistência na área de estomas. A autora conclui a análise, apontando para a necessidade de mudanças profundas, em direção às maiores competência e autonomia do enfermeiro e do especialista. Trazendo em seu bojo condições favoráveis à ampliação e sedimentação do papel e identidade profissionais, neste milênio que se inicia, abrem-se muitas possibilidades particularmente para o enfermeiro especialista. Assumir e liderar o cuidar holístico e interdisciplinar - a presença cuidadora - com qualidade diferenciada e custo-utilidade comprovadas, fundamentado nos conhecimentos prático, estético, étnico, empírico e sócio-político - constantemente atualizados e baseados em evidências - e voltado para uma clientela diversa em suas necessidades porém única na sua humanidade, constituem algumas das transformações exigidas.

Descritores: Enfermagem em estomaterapia. Epidemiologia. Especialidades da enfermagem. Qualidade de vida. Políticas públicas. 


\section{ABSTRACT}

Santos VLCG. Caring the person with an ostomy: analysis of the trajectory in the teaching, research and extension activities [thesis]. São Paulo (SP): Escola de Enfermagem/ USP; 2006.

Considering the profound involvement with the Stomal Therapy - a recent Nursing specialty - since its implementation in Brazil, the aim of this study was to analyze the author's academic scientific production related to ostomy care (1983 to 2006). For the analysis, all published researches, updating articles, chapters and books and documents used for the development of specific health public policies were included. In order to discuss those publications, indexed articles searched in the web page of Biblioteca Virtual em Saúde (BVS/BIREME), from 2001 to 2005, were used. After a short introduction with historical aspects of the specialty, the publications were organized into six issues: epidemiology of the stomas; stoma care; quality of life; Stomal Therapy education; stoma care public policies, and perspectives of teaching, research and assistance in stoma care area. After the analysis of the publications, the author points out that Stoma Therapy needs deeply changes towards better specialists' expertise and autonomy. The new millenium brings many good opportunities favourable for the nursing professional roles and identity. Some of those necessary changes are related to the assumption of the caring presence towards persons which have different demands but are unique on their humanity. It means a care with the following characteristics: qualified; costeffective; holistic and interdisciplinary; and based on practical, esthetic, ethnic, empirical and socio-political knowledge - updated and evidenced.

Descriptors: Stoma Therapy Nursing. Epidemiology. Nursing specialties. Quality of life. Health public policies. 


\section{TABELA}

Tabela 1 - Instituições habilitadas por nível de complexidade. 132

\section{LISTA DE QUADROS}

Quadro 1 - Características demográficas e clínicas dos pacientes estomizados em algumas publicações (período 1986 a 2006). 27

Quadro 3 - Publicações acerca dos cuidados gerais às pessoa com estomas, no período 1993 a 2003. 49

Quadro 4 - Publicações acerca das complicações do estoma e pele periestoma, no período 1989 a 2003. 60

Quadro 5 - Publicações acerca da irrigação e sistema oclusor de colostomia, no periodo 1984 a 2000. 67

Quadro 6 - Publicações acerca dos equipamentos coletores para estomizados, no período 1986 a 2003. 79

Quadro 7 - Publicações acerca da qualidade de vida dos estomizados, no período 1994 a 2006. 89 
Quadro 8 - Publicações acerca da qualidade de vida dos estomizados, no período 1990 a 2004

Quadro 9 - Publicações referentes à organização de Serviços e Políticas Públicas de Atenção ao Estomizado, no período 1989 a 2005 133

Quadro 10 - Conferências cujos temas versaram sobre as perspectivas da Estomaterapia (1999 a 2004). 144

Quadro 11 - Características das práticas especializadas e avançadas. 161 


\section{SUMÁRIO}

INTRODUÇÃ

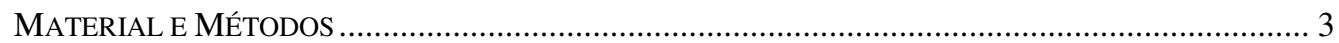

ASPECTOS HISTÓRICOS DA ESTOMATERAPIA MUNDIAL E BRASILEIRA..................... 5

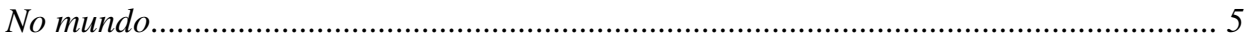

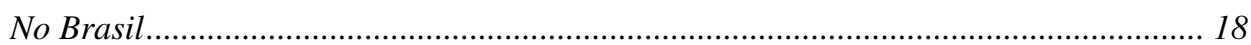

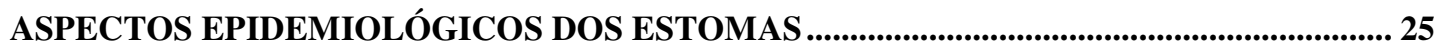

ALGUMAS PARTICULARIDADES DO CUIDAR DE PESSOAS COM ESTOMAS................. 46

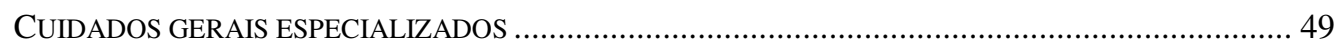

COMPLICAÇÕES DO ESTOMA E PELE PERIESTOMA.................................................................. 58

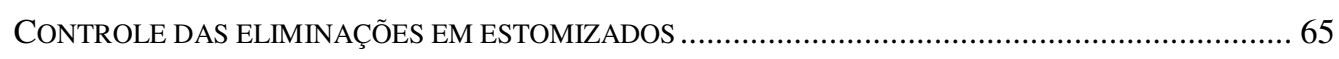

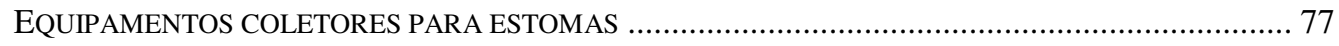

QUALIDADE DE VIDA DE PESSOAS COM ESTOMAS ............................................................. 86

EDUCAÇÃO EM ESTOMATERAPIA ................................................................................ 1132

POLÍTICAS PÚBLICAS DE ATENÇÃO AO ESTOMIZADO ............................................... 125

PERSPECTIVAS DO ENSINO, PESQUISA E ASSISTÊNCIA EM ESTOMATERAPIA.... $143 \underline{1}$

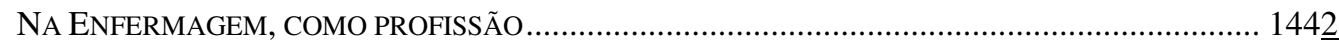

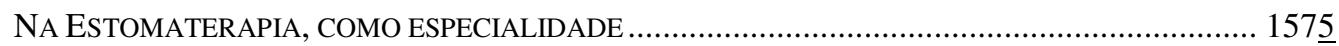

REFERÊNCIAS BIBLIOGRÁFICAS..................................................164 


\section{INTRODUÇÃO}

A estomaterapia é uma especialidade estabelecida para a enfermagem pelo World Council of Enterostomal Therapists - WCET, a partir de 1980 e o seu especialista é denominado estomaterapeuta (ET).

Apesar do termo estomaterapia referir-se, etimologicamente, à terapia ou cuidados dos estomas, segundo o mesmo Conselho, sua definição envolve o "cuidado de pessoas com estomas, incontinências, feridas drenantes, fistulas e alterações reais ou potenciais da integridade tissular" (WCET 2005; WCET 2006). E o estomaterapeuta é, portanto, aquele com conhecimento, treinamento e habilidade para o cuidado de qualquer tipo de estomizado e de portadores de fistulas, feridas agudas e crônicas e incontinências anal e urinária (Lenneberg 1971; Mahoney 1976; Vukovich, Grubb 1977; Sredl, Wilhite 1980; Jackson, Broadwell 1982; Foulkes 1987; Faller 1997; Santos 2000; WCET 2006).

No Brasil, pode-se dizer que a especialidade iniciou-se oficialmente após a implantação do primeiro curso de especialização, na Escola de Enfermagem da USP, em 1990. Dezesseis anos e quinze edições depois, o curso formou cerca de 190 enfermeiros, de quase todos os estados do país. Alguns desses acabaram por replicar os programas em seus estados de origem e outros continuaram sua formação em nível de pósgraduação sensu stritu, melhorando a produção científica nessa área, o que tem contribuido para o estabelecimento de algumas evidências 
fundamentais para o momento em que se encontra a enfermagem brasileira e mundial.

Em 1992, os poucos estomaterapeutas existentes (cerca de 20) reuniram-se e fundaram a Sociedade Brasileira de Estomaterapia SOBEST, o que tem promovido grande impulso para o desenvolvimento científico da especialidade no Brasil bem como sua projeção internacional, ao tornar-se sede do congresso mundial do WCET - pela primeira vez na América Latina - em 2004.

Como participante ativa de todos esses movimentos, em prol da Estomaterapia Brasileira, seja como coordenadora do primeiro curso de especialização do país; como membro fundador e presidente da SOBEST, em suas primeiras gestões; como presidente de quatro dentre seis congressos nacionais e como presidente do congresso mundial do WCET no Brasil - certamente favorecida pelo vínculo com a docência na Universidade de São Paulo - ao longo de 24 anos, venho desenvolvendo ensino, pesquisa e extensão nas áreas da estomaterapia: estomas, feridas, incontinências e desenvolvimento profissional, concorrendo para o estabelecimento de consistentes linha de pesquisa e produção acadêmica.

Frente a essas considerações, este trabalho objetiva analisar a produção acadêmica da autora acerca da Estomaterapia, na área do cuidado em estomas. Para tanto, a apresentação desenvolve-se nos seguintes capítulos: 
- Capítulo 1: Aspectos históricos da Estomaterapia mundial e brasileira.

- Capítulo 2: Aspectos epidemiológicos dos estomas.

- Capítulo 3: Algumas particularidades do cuidar de pessoas com estomas.

- Capítulo 4: Qualidade de vida de pessoas com estomas.

- Capítulo 5: Educação em Estomaterapia.

- Capítulo 6: Políticas Públicas de Atenção às Pessoas com Estomas.

- Capítulo 7: Perspectivas do ensino, pesquisa e assistência em estomaterapia.

\section{Material e Métodos}

Para o desenvolvimento desta compilação analítica, são apresentadas todas as publicações - na integra e em forma de resumos das investigações, artigos de atualização, capítulos de livros e documentos integrantes de políticas públicas, que interessam ao tema. Alguns trabalhos de pesquisa que se encontram no prelo, em julgamento ou em preparo para 
publicação também são incluídos à medida que contribuem para o aprofundamento da análise.

Para o suporte teórico atualizado das publicações apresentadas, realizou-se pesquisa bibliográfica de artigos indexados nos bancos de dados acessados, eletronicamente, por meio do sítio da Biblioteca Virtual em Saúde - BVS (http://bases.bvs.br), da Biblioteca Regional de Medicina BIREME (www.bireme.br), em pesquisa avançada, no período dos últimos cinco anos (2001 a 2005). Essa consulta incluiu publicações indexadas no MEDLINE, LILACS, ADOLEC, BBO, BDENf, BIOÉTICA, DESASTRES, HOMEOINDEX, LEYES, MEDCARIB e REPIDISCA. Além da BVS, buscaramse revisões sistemáticas por meio da biblioteca Cochrane (The Cochrane Library), também acessada eletronicamente, por meio do sítio www.cochrane.org.

Para o acesso, foram utilizados os seguintes descritores: colostomy, ileostomy e urostomy. Visto que a temática a ser explorada é bastante diversificada, não foram estabelecidos outros descritores pareados. Inicialmente, fez-se a leitura de cada título passando-se à leitura do respectivo resumo, desde que considerado pertinente ao objetivo do trabalho, isto é, atinente à produção científica a ser analisada.

O total de 1001 trabalhos foram identificados, sendo 573 para o descritor colostomy, 412 para ileostomy e 16 para urostomy, dos quais cerca de 200 foram incluídos neste trabalho. 


\section{ASPECTOS HISTÓRICOS DA ESTOMATERAPIA MUNDIAL E BRASILEIRA*}

"A vida só pode ser compreendida olhando-se para atrás; mas só pode ser vivida, olhando-se para a frente"

(Kierkgaard)

\section{No mundo}

A estomaterapia começa na História da Medicina - Medicina em Estomias.

Estoma ou estomia - termos adequados para a língua portuguesa no Brasil, segundo a Academia Brasileira de Letras* - são designativos oriundos do grego que significam boca ou abertura, utilizados para indicar a exteriorização de qualquer víscera oca através do corpo por causas variadas. Dependentemente do segmento corporal de onde provém, recebe nomes diferenciados. Assim, para os estomas intestinais temos as colostomias, as ileostomias e jejunostomias (Martins, Rocha 1997;HabrGama, Araújo 2000). Quanto aos estomas urinários, são denominados

Baseado em: Santos VLCG. A estomaterapia através dos tempos. In: Cesaretti IUR. Assistência em estomaterapia: cuidando do ostomizado. 1ed. São Paulo (SP): Atheneu; 2000. p.1-17. 
genericamente de urostomias ou derivações urinárias, dependentemente da técnica cirúrgica adotada (Rodrigues 2000). Embora sejam esses os tipos de estomas de eliminações fecais e urinárias, respectivamente, mais freqüentes na prática clínica, há outros como as gastrostomias, traqueostomias, esofagostomias, com diferentes finalidades e indicações.

Historicamente, durante muitos anos, a evolução da Veterinária foi maior que a da Medicina, visando à proteção aos animais, como fontes de subsistência ou elementos sagrados. Em função disso quando, em muitas ocasiões, explorararam-se os resultados obtidos em animais para o homem, a experiência foi desastrosa (Vukovich e Grubb 1977; Anderson 1982).

As primeiras operações abdominais, conhecidas por meio dos escritos de Aurelianus Caelius, ocorreram cerca do ano 300 aC, sendo efetuadas por Praxágoras que interveio sobre o íleo, abrindo-o, evacuando-o e fechando-o novamente, em alguns casos de trauma abdominal (Vukovich e Grubb 1977; Anderson 1982; Zampieri e Jatobá 1997).

Na Idade Média, a Medicina, especialmente a Anatomia Humana, teve sua evolução prejudicada pelos conceitos eclesiáticos do corpo sagrado, vigentes na época. Já a partir da Renascença, essa área passou a ter um

* Consulta à Academia Brasileira de Letras, feita pela Sociedade Brasileira de Estomaterapia, em 2005 
novo impulso pois os médicos novamente puderam proceder à autópsia. No entanto, uma vez que a maioria desses procedimentos era efetuada em jovens saudáveis assassinados, os conhecimentos acerca das doenças não se desenvolveram significativamente (Vukovich e Grubb 1977; Anderson 1982).

Segundo Zampiere e Jatobá (1997), já no século XVI, Paracelsus falava de sua preferência pelo que chamava de "anus artificial", como intervenção em intestino traumatizado.

Quanto aos estomas propriamente ditos, Alex Littré é considerado o pai da colostomia pois, mesmo sem confeccioná-la, foi seu idealizador, em 1710, ao realizar a autópsia de um recém-nascido com mal formação retal e descobrir que poderia exteriorizar as alças intestinais à parede abdominal (Vukovich e Grubb 1977; Anderson 1982). Na mesma época, Heister teria fixado as lesões intestinais à parede abdominal, em soldados feridos na Guerra de Flandres, as quais não constituíam, no entanto, estomias verdadeiras (Zampiere e Jatobá 1997).

Em relação à primeira colostomia realizada, existem controvérsias na literatura. Há relatos de que tenha sido feita em 1750, na esposa de um pescador com uma hérnia encarcerada. Outra referência é atribuída a C. Duret, professor de Cirurgia no Hospital Militar da Marinha de Brest, que teria efetuado uma derivação fecal ilíaca esquerda em um bebê de 3 dias com ânus imperfurado. Este teria vivido até a idade de 45 anos (Vukovich e Grubb 1977; Anderson 1982). O nome desse cirurgião é 
controverso, assumindo alguns autores que teria sido Dubois - cirurgião de Napoleão - e não Duret, o autor dessa operação (Zampiere e Jatobá 1997). Outros ainda atribuem a Pillore a realização com sucesso da primeira estomia, em 1776.

Para as variantes dos estomas terminais, a colostomia em alça com bastão de apoio foi introduzida por Maydl em 1883 (Zampiere e Jatobá 1997), enquanto a colostomia em duas bocas, separadas por segmento de pele, foi proposta por Block, em 1892, e por Witzel em 1894 (Zampiere e Jatobá 1997). Similarmente a essa técnica, Paul e Miculicz, independentemente, propuseram, na virada do século, a colostomia em "cano de espingarda", em que as alças distal e proximal ficam dispostas paralelamente entre si e perpendicularmente à parede abdominal (Zampiere e Jatobá 1997).

Nessa época, as estomias em intestino delgado eram raramente praticadas pois, embora julgadas também como viáveis, havia grandes fatores limitantes como a difícil manipulação posterior pelo paciente, além dos importantes distúrbios nutricionais e metabólicos. Assim, a primeira ileostomia de que se tem registro foi confeccionada por Baum, em 1879, mais de cem anos após as colostomias. O cirurgião alemão a realizou como forma de derivação provisória em paciente com câncer obstrutivo no cólon ascendente, que veio a falecer após o seu fechamento, em função de deiscência da anastomose íleo-colônica (Mc Garity 1993a). O primeiro paciente a sobreviver após procedimento para ileostomia foi reportado por 
Maydl, da Áustria, em 1883, também operado por câncer de cólon (Mc Garity 1993a).

A partir daí, mesmo sendo reduzida a freqüência de operações para confecção de estomias, diversas técnicas eram tentadas buscando-se a melhor maneira de exteriorizar as alças intestinais, principalmente o íleo, objetivando a maior facilidade no manejo do estoma pelo paciente, após a alta hospitalar. Ainda assim, essas operações eram acompanhadas de altos indices de mortalidade e morbidade (Mc Garity 1993a; Turnbull e Turnbull 1993).

De qualquer maneira, essa situação perdurou até 1930, quando Mc Burney exteriorizou a ileostomia separadamente da incisão cirúrgica principal, abrindo espaço para novas e promissoras idéias (McGarity 1993a). Ainda nessa década - o que se pode também considerar um avanço importante - ocorre a primeira tentativa de confecção de uma bolsa coletora para ileostomizados, engendrada por Alfred A. Strauss, de Chicago, cujo modelo foi melhorado por Koenig - ileostomizado e estudante de química. O dispositivo era de borracha aderente que cobria o estoma, impedindo vazamento do conteúdo para a pele, e fixado a esta com um preparado de látex, além de conter um artifício para a colocação de um cinto que aumentava a segurança. Em torno de 1940, esse sistema ficou conhecido como Bolsa de Strauss Koenig Rutzen e já possuía ampla aceitação, apesar de suas grandes limitações (McGarity 1993a). 
A respeito dessas bolsas, como praticamente a única e melhor alternativa para o estomizado até cerca de 1960, Gill-Thompson (1990) diz: ".bolsas de borracha compridas que eram grosseiramente cimentadas no corpo ou seguras com correias, ataduras ou curativos e até latas de atum eram usadas".

A década de 1950 constituiu um marco no desenvolvimento da área de estomias, não só em cirurgia mas também em equipamentos. É quando surge a técnica cirúrgica de eversão total da mucosa ileal, proposta quase que simultaneamente por Turnbull, em Cleveland, e Brooke, em Londres. Essa técnica é utilizada até os dias atuais e veio contribuir sobremaneira para a melhoria da qualidade de vida do ileostomizado (GillThompson 1990; McGarity 1993a; Weakley 1994).

Os anos 50 passaram a caracterizar-se, também, por grande número de publicações sobre técnicas cirúrgicas, cuidados pós-operatórios, balanços hídrico e eletrolítico, manuseio de bolsas e controle de odor, incluindo aspectos da sexualidade, gravidez, ajustamento psicológico ao estoma e reabilitação. "O campo médico, finalmente, tornou-se inteirado e consciente das reais necessidades do paciente ostomizado" (Turnbull e Turnbull 1993). Somente em 1961, como conseqüência do elevado número de publicações, o termo ileostomia passou a compor o Cumulated Index Medicus (Turnbull e Turnbull 1993).

A importante proposta de Turnbull e Brooke impulsionou ainda a busca de novas técnicas objetivando a continência para todos os tipos de 
estomias, como os reservatórios continentes de Kock, para as urostomias, e a implantação de anéis musculares e anéis magnéticos, para as colostomias. Essas estimularam, por sua vez, o desenvolvimento das técnicas de preservação esfincteriana, atualmente empregadas, por meio das quais são evitadas as derivações externas e toda a problemática que acarretam. Têm-se como exemplos as bolsas ileais com anastomose íleoanal, as ampliações vesicais, as derivações uretero-sigmoideanas e outras.

No campo dos dispositivos coletores, talvez o maior avanço para o desenvolvimento tecnológico daqueles atualmente utilizados, foi a descoberta acidental do pó de Karaya, por Turnbull, em 1952. A Karaya goma extraída de uma árvore existente na Índia, com poder absorvente e restaurador do $\mathrm{pH}$ da pele - após utilizada em vários dos pacientes de Turnbull, mostrou excelentes resultados, levando-o a contatar o engenheiro químico Leonard Fenton, para a produção industrial do produto, acoplado em bolsa coletora. Instituía-se, assim, a primeira barreira protetora de pele periestoma, revolucionando o cuidado de estomizados (Mc Garity 1993a; Turnbull e Turnbull 1993).

De modo geral, verifica-se que os acontecimentos, pelo menos até a década de 50, estavam muito mais relacionados à evolução da Cirurgia do Estoma do que, propriamente, aos seus cuidados, embora a literatura reitere que a baixa freqüência na confecção de estomias, até então, muito se devia às precárias condições de cuidado, especialmente para os ileostomizados e, de forma marcante, pela deficiência de sistemas coletores adequados. Segundo alguns autores, os sobreviventes dessas cirurgias 
eram infelizes, incapazes de trabalhar, tidos como inválidos crônicos e, muitas vezes, rejeitados pela própria família, isolavam-se socialmente (Mc Garity 1993a; Turnbull e Turnbull 1993).

A primeira publicação referente aos cuidados a estomizados foi feita em 1930, por Du Bois, no American Journal of Nursing. Nele, o autor considera o estoma como deficiência e descreve alguns aspectos individuais e ambientais, predominantemente sobre a alimentação e a localização da estomia, como critérios para o procedimento cirúrgico e o cuidado (Vukovich e Grubb 1977; Anderson 1982). Nessa época, o controle do efluente era tentado com o uso de drogas, alimentação e irrigação, possivel principalmente para os colostomizados (Vukovich e Grubb 1977; Anderson 1982)

Até os anos 50, a enfermagem utilizava-se mais do método empírico para o cuidado, com escassas publicações científicas na área (Vukovich e Grubb 1977; Anderson 1982).

A década de 1950 foi ainda fundamental para a pessoa com estoma, em função do surgimento das primeiras Associações de Estomizados e início das atividades hoje conhecidas e reconhecidas como Estomaterapia (Gill-Thompson 1990; Mc Garity 1993a; Turnbull e Turnbull 1993; Weakley 1994).

A visão de que o estomizado necessitava muito mais do que uma boa e efetiva técnica cirúrgica para a reabilitação - como empatia, 
informação e instruções personalizadas no autocuidado - levou o cirurgião Rupert Turnbull a convidar uma de suas pacientes, Norma Gill, para auxiliá-lo nessa atividade. Ileostomizada após uma Retocolite Ulcerativa, Norma Gill, já na fase de convalescença, havia se mostrado interessada em ajudar outros pacientes estomizados, principalmente porque, além das próprias dificuldades que antevia, convivera com sua avó, colostomizada por câncer de reto, durante dois anos (Gill-Thompson 1990). Em 1958, Turnbull contratou-a para atuar na Cleveland Clinic Foundation como técnica em estomia. Nascia então, oficialmente, a posteriormente chamada Estomaterapia - Enterostomal Therapy, onde entero $=$ intestino e stomal $=$ stoma - considerando-se Norma Gill como a primeira estomaterapeuta (ET) e Turnbull, como o pai da Estomaterapia (Gill-Thompson 1990; Mc Garity 1993a; Turnbull e Turnbull 1993; Santos e Sousa Jr 1993; Weakley 1994).

Fator importante na constituição da especialidade e no suporte social ao estomizado - a partir da parceria entre pacientes e profissionais de saúde - eram as reuniões entre pacientes, durante as longas hospitalizações, e que prosseguiam após a alta hospitalar. Há referências de que, já no início da década de 50, no Hospital Monte Sinai, em Nova Iorque, os pacientes ali estomizados, reuniam-se sistematicamente para troca de experiências e informações sobre a problemática de ter um estoma. Esses pacientes foram estimulados a estabelecerem uma organização oficial denominada QT Alumni, posteriormente QT New York $(Q$ e $T$ eram as designações das enfermarias onde ficavam durante a internação hospitalar), pela enfermeira Lucy Neary e pelo cirurgião Albert Lyons (Gill-Thompson 1990; Turnbull e Turnbull 1993; Lyons 2001). Paralelamente à publicação 
sobre o grupo, no Journal of the American Medical Association, em 1952, e à sua exposição junto à American Medical Association (AMA), outros grupos formaram-se, em diversos pontos do país, como em Boston e Pensilvânia. Em 1956, representantes de oito grupos reuniram-se em Nova Iorque e criaram dois boletins informativos: Ileostomy Quarterly e Colostomy Quarterly (Turnbull e Turnbull 1993). Em 1960, novo encontro reuniu representantes, não só dos EUA como também do Canadá, estabelecendo-se os objetivos organizacionais e os procedimentos operacionais para a oficialização da United Ostomy Association (UOA), em 1962, em Cleveland. Sua primeira Convenção Anual ocorreu em 1963, onde foram fixadas a continuidade da edição da Ostomy Quarterly e as taxas de afiliação (GillThompson 1990; Turnbull e Turnbull 1993; Mc Garity 1993b; Cullen 1999).

Cleveland tornou-se, então, importante centro decisório e de treinamento em cuidados para estomizados. Em 1961, é aí que surge o primeiro Curso de Estomaterapia oficial no mundo, tendo como primeiros e principais alunos os próprios pacientes, mas também algumas enfermeiras. Esse programa inicial era bastante rudimentar e feito, individualmente, por Gill e Turnbull, com ênfase nos aspectos práticos (Vukovich e Grubb 1977; Anderson 1982; Turnbull e Turnbull 1993; Gard 1999; Gray 1999a). Nesse mesmo ano, a criação do Departamento de Estomaterapia Abdominal no Ferguson-Droste-Ferguson Hospital contribui para o avanço no conceito de especialidade em cuidar dessas pessoas (Cesaretti e Leite 2000).

Sete anos mais tarde, em 1968, ainda por sugestão do Dr Turnbull, e tendo à frente Norma Gill, constituiu-se a primeira organização 
de estomaterapeutas através da North American Association of Enterostomal Therapists (NAAET) que, em 1970, passou a chamar-se American Association of Enterostomal Therapists (AAET) e, em 1971, International Association for Enterostomal Therapy (IAET), atualmente Wound, Ostomy and Continence Nursing Society - WOCNS (Gill-Thompson 1990; Turnbull e Turnbull 1993; Gard 1999; Gray 1999a; Mc Garity 1993b; Cullen 1999). Foi a organização americana que estabeleceu os primeiros critérios para a implantação de novos cursos de estomaterapia e as diretrizes para a assistência de enfermagem. Em 1973, formaram-se 351 especialistas, em cinco programas educacionais (Cesaretti e Leite 2000).

Nesse înterim, surge também a International Ostomy Association (IOA), em 1975, como a organização que congrega não só a UOA mas, atualmente, 62 associações existentes em 57 países, sendo orientada para a promoção do cuidado em saúde a estomizados, ajuda à sua reabilitação e melhora de sua qualidade de vida (IOA 1975; Aukett 1991).

Paralelamente, constituiam-se outros cursos, nesse momento destinados somente aos profissionais de saúde, não só em outros pontos dos Estados Unidos (Pensilvânia, Michigan, Harrisburg), como fora, na Austrália e Inglaterra (Gill-Thompson 1990; Turnbull e Turnbull 1993).

Com o desenvolvimento de novos cursos, investimentos em pesquisas de novos produtos e o aumento do interesse pela especialidade em 1975, já eram 600 membros efetivos da IAET (Anderson 1982) - passouse à organização de Conferências Anuais e Congressos, nos quais eram 
discutidos não só aspectos referentes à evolução da cirurgia como também aos dispositivos coletores e protetores de pele (Vukovich e Grubb 1977; Anderson 1982), mais específicos para a esfera do cuidar. Nessa época, o número expressivo de enfermeiros, técnicos em estomaterapia, tornou possível a regionalização da organização norte-americana, acarretando o reconhecimento crescente do caráter profissional da especialidade bem como da figura do estomaterapeuta na equipe multiprofissional (Anderson 1982).

Cada vez mais o interesse pela Estomaterapia extrapolava os limites dos grandes países como EUA, Canadá, Inglaterra e França, surgindo, então, a idéia da constituição de um órgão representativo, em nível internacional, novamente por estímulo e liderança de Norma Gill, o que acabou efetivando-se em 1978, por meio do WCET. O órgão tem como objetivos promover a identidade da estomaterapia no mundo e intercâmbio internacional entre os especialistas, possibilitando o desenvolvimento técnico e científico na área, além da padronização de condutas, buscando, na melhoria da qualidade do desempenho do especialista, a melhoria da qualidade assistencial ao estomizado (segundo sua origem), aos indivíduos com feridas agudas e crônicas, reais ou potenciais, além daqueles com incontinências anal e urinária (Gill-Thompson 1990; Turnbull e Turnbull 1993; Gard 1999; Cullen 1999; WCET 2006).

Após quase meio século de existência da especialidade, desde a sua origem, e com um escopo bem mais abrangente - não apenas a área das estomias - existem atualmente cerca de 1150 associados ao WCET (Smits 
2005), inúmeras associações ou sociedades de especialistas ao redor do mundo e 46 Cursos de Especialização ou Programas de Educação em Enfermagem em Estomaterapia (Enterostomal Therapy Nursing Education Program - ETNEP) - 34 dos quais credenciados junto ao WCET - em 26 países de todos os continentes, que formaram mais de 5000 especialistas, nesse período (Santos e Sousa Jr 1994; Santos 2004; WCET 2006).

Em recente trabalho desenvolvido por Santos (2004), não publicado, que objetivou conhecer a situação da especialidade no mundo, a autora enviou questionário (13 perguntas abertas e fechadas) aos delegados internacionais de todos os 54 países membros do WCET. Obteve $25(46,3 \%)$ devoluções, 5 de países do continente americano, 11 do europeu, 8 do asiático e 1 do africano. Desses, cerca de metade (12 ou 48\%) possuía ETNEPs, 21 dos quais credenciados pelo WCET. Sessenta porcento dos países respondentes possuíam associações de especialistas (em quaisquer das áreas da especialidade); nove (36\%) dispunham de políticas públicas relacionadas à estomaterapia e, em três deles - Hong Kong, Espanha e EUA - para as 3 áreas (estomias, feridas e incontinências). Em 63,1\% deles, os estomaterapeutas atuavam em hospitais, destacando-se $18,3 \%$ em que os especialistas prestavam atendimento domiciliário. $\mathrm{Na}$ maioria dos países $(76,7 \%)$, os ETs atuavam principalmente junto aos pacientes estomizados. Os delegados internacionais relataram o aumento das pesquisas e de cursos bem como a necessidade da maior divulgação da especialidade, com ampliação do papel profissional, como perspectivas. 


\section{No Brasil}

No Brasil, pode-se dizer que a Estomaterapia teve início, formalmente, com a implantação do Curso de Especialização em Enfermagem em Estomaterapia da Escola de Enfermagem da Universidade de São Paulo (EEUSP), em 1990 (Sousa Jr, Santos e Habr Gama 1990; Santos e Sousa Jr 1993; Santos e Sousa Jr 1994; Santos e Sousa Jr 1996) Certamente, no entanto, foi antecedida por diversos movimentos no exterior, conforme descritos anteriormente, e no próprio país, que contribuíram para o seu desenvolvimento.

À semelhança de muitos outros países, inclusive EUA e Canadá, a organização dos estomizados, a partir da década de 1970, ao criar demanda para a melhor qualidade assistencial, a democratização do atendimento e a existência de equipamentos coletores, quantitativa e qualitativamente mais adequados, mobilizaram profissionais, especialmente enfermeiros, médicos e assistentes sociais, a procurar maior e mais profundo conhecimento técnico - científico na área.

A partir daí, já nos anos 80, alguns enfermeiros partiram para o exterior em busca de formação especializada, em países como Estados Unidos, Colômbia e Espanha contribuindo, após seu retorno, para a reciclagem de outros profissionais, na atualização acerca da evolução da especialidade no mundo e, consequentemente, para a motivação de outros enfermeiros na organização e implementação de Serviços de Assistência, em Hospitais e Ambulatórios, principalmente da rede pública. 
Paralelamente a esses acontecimentos, o movimento das Associações de Estomizados fortalecia-se com a criação da Sociedade Brasileira de Ostomizados (SBO) - hoje Associação Brasileira de Ostomizados (ABRASO) - que alcançava alguns intentos junto ao Governo Federal, relacionados a compra e distribuição de equipamentos coletores, em função do momento propício da instalação do Sistema Unificado e Descentralizado de Saúde (SUDS), posteriormente Sistema Único de Saúde (SUS).

Todas essas forças associadas a uma conscientização maior dos profissionais de saúde, particularmente das classes médica e de enfermagem, também impulsionada pela maior divulgação do tema e pelo crescente número de estomizados nos Serviços, além da formação especializada de profissionais no exterior acarretaram a implantação do primeiro Curso de Especialização no Brasil, em 1990, segundo na América Latina, antecedido somente pela Colômbia, alguns meses antes.

O Curso de Especialização em Enfermagem em Estomaterapia, em nivel de pós-graduação sensu latu, desde sua primeira edição, tem seu conteúdo programático e carga horária teórico-prática baseados nos critérios de credenciamento estabelecidos pelo Comitê de Educação do WCET e, por cuja entidade, vem sendo reconhecido a cada quatro anos, desde sua implantação. Sua missão e finalidades têm direcionado o conteúdo e as estratégias educacionais para a capacitação especializada dos enfermeiros, buscando atender à amplitude das funções do ET - 
assistencial e de apoio especializado, educativa ou docente, investigativa, administrativa ou gerencial e de desenvolvimento profissional.

Em 1992, após três edições do curso de especialização, Santos et al (1993) realizaram um inquérito sobre o desempenho de 40 estomaterapeutas, formados no Brasil e no exterior. Os autores constataram que todos desenvolviam atividades assistenciais, conforme esperado, enquanto $54 \%$ atuavam no ensino, formal ou não; $45,9 \%$ envolviam-se em atividades administrativas, relacionadas a organização de Serviços e Programas Assistenciais, assessoria e consultoria e somente $27 \%$ desenvolviam investigação.

Ao detectar atuação tão limitada na área da pesquisa, os mesmos autores (Santos e Sousa Jr 1994) decidiram levantar a produção científica nacional, no período de 1970 a 1992, e a contribuição respectiva dos ETs. A partir de 1990, após a instalação do primeiro Curso de Especialização, mostrava-se já uma tendência a discreto aumento e regularidade das publicações, o que não ocorria até 1988 com, pelo menos, uma dissertação ou tese e duas publicações em periódicos ao ano, a maioria elaborada por ETs. Para a participação em Congressos Brasileiros de Enfermagem e de Colo-Proctologia - uma vez que ainda não existiam os específicos de estomaterapia - verificou-se aumento significativo do número de resumos sobre estomias. Em ambas situações, havia predominio da temática do assistir/cuidar, contribuindo para o direcionamento da própria Enfermagem como profissão. 
À época, Faller (1997) encontrou resultados similares, ao buscar estabelecer relações entre o ET e o enfermeiro clínico especialista, nos EUA. Identificou que a maioria dos ETs desenvolvia, principalmente, o papel clínico assistencial, parecendo ignorar as demais funções e referindo dificuldades, especialmente no que se referia ao desenvolvimento de trabalhos de investigação, publicações e apresentações formais em público. Por outro lado, preocupavam-se, sobremaneira, com o próprio desenvolvimento profissional.

Mais recentemente, Souza et al (2004) realizaram pesquisa bibliográfica acerca das dissertações e teses em estomaterapia, desenvolvidas no país, no período de 1970 a 2004, incluindo-se todas as suas áreas de abrangência. Por meio de bancos de dados como o DEDALUS e o Banco de Teses da ABEn, as autoras encontraram 121 estudos, dos quais 106 dissertações de Mestrado, 12 Teses de Doutorado e 3 teses de Livre-Docência, a maioria descritivos $(73,5 \%)$ e com abordagem quantitativa $(61,2 \%)$. Ressalta-se que $9,1 \%$ eram experimentais, $4,1 \%$ correlacionais e $2,5 \%$ casos controle, conferindo-lhes possibilidades de obtenção de resultados com melhor nível de evidências. O período 1996 a 2000 foi aquele com o maior número de estudos (42 ou 34,7\%) e as amostras de 30 a 60 sujeitos predominaram $(32,4 \%)$, apesar de identificarem-se também amostras superiores a 150 individuos (20,3\%); em atendimento hospitalar $(57,1 \%)$ ou ambulatorial (34,9\%). Os temas mais freqüentes foram prevenção e fatores de risco $(23,1 \%)$ e Sistematização da Assistência de Enfermagem - SAE (12,4\%). Somente $23,1 \%$ dos estudos relacionaram-se às estomias, principalmente as intestinais $(82,1 \%)$. 
Um outro efeito imputável, em grande parte, aos cursos de especialização e que constitui um marco na história da estomaterapia brasileira, foi a fundação da Sociedade Brasileira de Estomaterapia (SOBEST), em dezembro de 1992, denominada Sociedade Brasileira de Estomaterapia: ostomias, feridas e incontinências, a partir de 1997 e, atualmente, Associação Brasileira de Estomaterapia: estomias, feridas e incontinências. Embora antecedida pela organização de alguns enfermeiros não ETs em um Grupo de Interesse Clínico (GICEE e GEE), vinculado à Associação Brasileira de Enfermagem (ABEn), desde 1984, o aumento rápido do número de especialistas e a constituição de massa crítica dentro da especialidade culminaram na sua criação e importante evolução.

A SOBEST, como entidade de cunho científico-cultural, é aberta a todos os profissionais que atuam na área, com direitos e deveres diferenciados, e mantém-se como uma das primeiras e ainda únicas organizações da categoria dentro da América Latina. Ademais, viabiliza a emancipação da especialidade no país e nas suas relações com o exterior, não só por meio de sua Delegada Internacional junto ao WCET (desde 1992), como da participação de seus membros como componentes de três de seus comitês, quais sejam, Education Committee e Editorial Committee, desde 1998, e Fundação Norma Gill, desde 2002. A participação ativa, junto a esse órgão internacional, permitiu-lhe organizar e sediar o $15^{\text {th }}$ Biennial Congress of the World Council of Enterostomal Therapists, em Florianópolis, em 2004 - pela primeira vez na América Latina. 
Atualmente, a SOBEST conta com mais de 200 associados, em cinco diferentes categorias, entre estomaterapeutas e enfermeiros não especialistas, profissionais da saúde em geral, alunos de graduação e pessoal auxiliar e técnico de enfermagem, além de empresas fabricantes ou distribuidoras de materiais e equipamentos específicos. Realiza inúmeras atividades científicas durante o ano - reuniões, simpósios e jornadas - além de seu congresso nacional bienal. Estabeleceu a Semana Nacional de Estomaterapia (25 a 31 de outubro), desde 2003 e edita a Revista Estima, em fase de indexação, também desde 2003. Seu sítio na rede internacional de comunicação é www.sobest.org.br. 



\section{ASPECTOS EPIDEMIOLÓGICOS DOS ESTOMAS}

"A verdadeira filosofia é reaprender a ver o mundo."

(Merleau Ponty)

Tratar da epidemiologia dos estomas, em nosso país, é tão dificil quanto de qualquer outro tema que demande registro sistematizado de informações. A dimensão continental, as falhas de registro, as dificuldades de comunicação - apesar da disseminação dos meios eletrônicos de comunicação - constituem apenas alguns dos aspectos envolvidos na sistematização de dados e informações em saúde. Por outro lado, os estomas constituem seqüelas ou conseqüências de doenças ou traumas morbidade - e não causas ou diagnósticos, o que dificulta sua informação.

Informações diretas acerca da prevalência dos estomas podem ser obtidas nas próprias publicações sobre essa clientela - por meio de sua caracterização demográfica e clínica - ou ainda de organismos nacionais ou internacionais relacionados ao tema, principalmente as associações de estomizados como a Associação Brasileira de Ostomizados - ABRASO, no Brasil, e a International Ostomy Association (IOA) e United Ostomy Association (UOA), mundial e norte-americana (EUA e Canadá), respectivamente. Informações indiretas provêm dos dados epidemiológicos das causas dos estomas, principalmente as neoplasias malignas particularmente as colorretais e vesicais - além das doenças inflamatórias 
intestinais - Doença de Crohn e Retocolite Ulcerativa Inespecífica - e dos traumas ou causas externas - acidentes de trânsito e ferimentos por armas brancas ou de fogo.

Atendendo ao objetivo desta tese, a seguir, são apresentadas as principais características demográficas e clínicas (Quadro 1) dos pacientes estomizados, incluídos em alguns de nossos estudos, produzidos ao longo de mais de 20 anos de atividades junto a essa clientela. Ressalta-se que foram selecionados apenas aqueles com amostras numericamente mais representativas e que continham a descrição de seus perfis. Desse modo, eles são exibidos conforme apresentados nos estudos originais e, a seguir, discutidos à luz da pesquisa bibliográfica mais recente. 
Quadro 1 - Características demográficas e clínicas dos pacientes estomizados em algumas publicações (periodo 1986 a 2006).

\begin{tabular}{|c|c|c|c|c|c|c|c|}
\hline \multirow{2}{*}{ Publicação } & \multirow{2}{*}{ Amostra } & \multicolumn{3}{|c|}{ Caracteristicas demográficas ${ }^{\#}$} & \multicolumn{3}{|c|}{ Caracteristicas clinicas } \\
\hline & & Sexo & Idade & Diagnóstico & Tipo de Estoma & $\begin{array}{c}\text { Caráter do } \\
\text { estoma }\end{array}$ & $\begin{array}{l}\text { Tempo de } \\
\text { estoma }\end{array}$ \\
\hline $\begin{array}{l}\text { Santos et al. Rev } \\
\text { Paul Enf 1986; } \\
\text { 6(2):60-66. }\end{array}$ & \begin{tabular}{|l|}
$\mathrm{N}=173$ (pacientes \\
internados / Jan \\
1985 a Jan 1986) \\
\end{tabular} & $\mathrm{S} / \mathrm{D}$ & $\mathrm{S} / \mathrm{D}$ & $\mathrm{S} / \mathrm{D}$ & $\begin{array}{|ll|}- & \text { Colostomias }(65,8 \%) \\
\text { - } & \text { Ileostomias }(8,7 \%) \\
& \text { Urostomias }(25,5 \%) \\
\end{array}$ & $\begin{array}{c}\text { Temporário } \\
(21,4 \%) / 1 \\
\text { ano } \\
\end{array}$ & $\mathrm{S} / \mathrm{D}$ \\
\hline $\begin{array}{l}\text { Sousa Jr et al. Rev } \\
\text { Bras Coloproctol } \\
\text { 1989; } 9 \text { supl 1: } 56- \\
56 .\end{array}$ & $\begin{array}{l}\mathrm{N}=164 \text { (pacientes } \\
\text { ambulatoriais/ } \\
\text { Jul } 1986 \text { a Jul } \\
\text { 1989) }\end{array}$ & $\begin{array}{c}\text { Feminino } \\
(56,1 \%)\end{array}$ & $\begin{array}{l}\text { Predomínio: } \\
\text { 3a, } 5^{\mathrm{a}} \text { e } 6^{\mathrm{a}} \\
\text { décadas }\end{array}$ & $\begin{array}{l}\text { Câncer de cólon e reto }(40,8 \%) \\
\text { Doenças Inflamatórias } \\
\text { intestinais }(15,2 \%) \\
\text { Megacólon Chagásico }(8,5 \%) \\
\end{array}$ & $\begin{array}{ll} & \text { Colostomias }(79,9 \%) \\
-\quad & \text { lleostomias }(20,1 \%)\end{array}$ & $\mathrm{S} / \mathrm{D}$ & $\mathrm{S} / \mathrm{D}$ \\
\hline $\begin{array}{l}\text { Santos e Koizumi. } \\
\text { Rev Esc Enf USP } \\
\text { 1992; 26(3):303- } \\
314 .\end{array}$ & \begin{tabular}{l|}
$\mathrm{N}=40$ \\
(colostomizados \\
submetidos a \\
auto irrigação da \\
colostomia) \\
\end{tabular} & $\begin{array}{c}\text { Feminino } \\
(60 \%)\end{array}$ & $\begin{array}{c}56 \text { a } 65 \text { anos } \\
(47,5 \%)\end{array}$ & Câncer de reto (100\%) & - Colostomias $(100 \%)$ & $\begin{array}{l}\text { Definitivo } \\
(100 \%)\end{array}$ & Até 4 meses \\
\hline $\begin{array}{l}\text { Nogueira et al. Rev } \\
\text { Esc Enf USP 1994; } \\
\text { 28(3): } 309-320 . \\
\\
\text { Boccardo et al. Rev } \\
\text { Esc Enf USP 1995; } \\
\text { 29(1): } 59-71 .\end{array}$ & $\mathrm{N}=45$ & $\begin{array}{c}\text { Masculin } \\
\text { o } \\
(51,1 \%)\end{array}$ & $\begin{array}{c}58 \text { a } 78 \text { anos } \\
(40 \%)\end{array}$ & $\begin{array}{l}\text { Neoplasias intestinais e } \\
\text { urinárias } \\
(77,8 \%)\end{array}$ & $\begin{array}{l}\text { - Colostomias } \\
(82,2 \%)\end{array}$ & $\begin{array}{l}\text { Maioria } \\
\text { definitivo }\end{array}$ & $\begin{array}{l}\bullet<3 \text { meses } \\
(15) \\
i 3 \text { a } 12 \text { meses } \\
(15) \\
(15) \\
(15)\end{array}$ \\
\hline $\begin{array}{l}\text { Andrade et al. Rev } \\
\text { Paul Enf 1999; } \\
\text { 18(1/3):35-49. }\end{array}$ & $\mathrm{N}=58$ & $\begin{array}{c}\text { Feminino } \\
(58,6 \%)\end{array}$ & $\mathrm{S} / \mathrm{D}$ & $\begin{array}{l}\text { Câncer de cólon, reto e bexiga } \\
(63,8 \%) \\
\text { Doenças Inflamatórias } \\
\text { Intestinais }(19 \%)\end{array}$ & 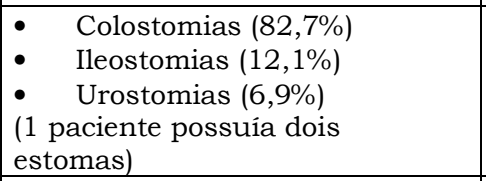 & $\begin{array}{l}\text { Maioria } \\
\text { definitivo }\end{array}$ & $\begin{array}{l}\cdot 3 \text { meses a } 1 \\
\text { ano }(34,5 \%) \\
\cdot>5 \text { anos } \\
(34,5 \%)\end{array}$ \\
\hline $\begin{array}{l}\text { Paula e Santos. Rev } \\
\text { Bras Coloproctol } \\
\text { 1999a; 19(3): } 155- \\
163 . \\
\\
\text { Paula e Santos. Rev } \\
\text { Esc Enf USP 1999b; } \\
33 \text { n esp: 63-73. }\end{array}$ & $\begin{array}{l}\mathrm{N}=483 \\
\text { (prontuários) }\end{array}$ & $\begin{array}{l}\text { Masculin } \\
\text { o }(50,8 \%)\end{array}$ & $\begin{array}{c}\text { Até } 19 \text { anos } \\
(57,1 \%) \\
\text { homens } \\
\\
45 \text { a } 64 \text { anos } \\
(52,8 \%) \\
\text { mulheres }\end{array}$ & $\begin{array}{l}\text { Câncer de cólon, reto, bexiga e } \\
\text { ginecológico }(63,2 \% \text { e } 72,9 \% \text {, } \\
\text { respectivamente para } 45 \text { a } 64 \\
\text { anos e }>65 \text { anos) } \\
\text { Traumas / urgências }(42,1 \% \\
\text { para idade até } 19 \text { anos) }\end{array}$ & \begin{tabular}{|l|}
$\quad$ Colostomias predominam \\
segundo diagnóstico (câncer, \\
trauma/urgência e megacólon) \\
com p<0,05; e a partir de 45 \\
anos, independentemente do \\
sexo $(47,5 \%$ e $52,5 \%$ \\
respectivamente para homens e \\
mulheres) \\
- Ileostomias predominam nas \\
doenças inflamatórias $(75 \%) ;$ e \\
entre 20 a 44 anos para homens \\
(62,1\%) e entre 45 a 64 anos, \\
para mulheres $(81,2 \%)$, com \\
\end{tabular} & $\mathrm{S} / \mathrm{D}$ & $\begin{array}{l}\text { Tempo de } \\
\text { seguimento } \\
\text { ambulatorial } \\
(27,3 \pm 40,7 \\
\text { meses })\end{array}$ \\
\hline
\end{tabular}


ASPECTOS EPIDEMIOLÓGICOS DOS ESTOMAS

\begin{tabular}{|c|c|c|c|c|c|c|c|}
\hline & & & & & $\mathrm{p}<0,05$ & & \\
\hline $\begin{array}{l}\text { Silva et al. Rev Esc } \\
\text { Enf USP 1999; } 33 \\
\mathrm{n}^{0} \text { esp: } 55-62 .\end{array}$ & $\begin{array}{l}\mathrm{N}=29 \\
\text { (colostomizados } \\
\text { com e sem } \\
\text { irrigação) }\end{array}$ & $\begin{array}{l}\text { Masculin } \\
\text { o }(62,1 \%)\end{array}$ & $\begin{array}{l}34 \text { a } 70 \text { anos } \\
(61,4 \pm 13,9 \text { e } \\
58,5 \pm 9,4, \\
\text { respectivamen } \\
\text { te sem e com } \\
\text { irrigação) }\end{array}$ & Câncer de reto $(96,5 \%)$ & Colostomia (100\%) & $\begin{array}{l}\text { Definitivo } \\
(100 \%)\end{array}$ & $\begin{array}{l}6 \text { a } 256 \text { meses } \\
(59,9 \pm 72,3 \text { e } \\
82,7 \pm 61,6 \\
\text { meses } \\
\text { respectivamente } \\
\text { sem e com } \\
\text { irrigação) }\end{array}$ \\
\hline $\begin{array}{l}\text { Batista et al. Rev } \\
\text { Bras Coloproctol } \\
2003 a ; 23 \text { supl } \\
1: 40-40 .\end{array}$ & $\begin{array}{l}\mathrm{N}=102 \text { adultos e } \\
52 \text { crianças }\end{array}$ & $\begin{array}{l}\text { Masculin } \\
\text { o }(62,3 \%)\end{array}$ & $\begin{array}{l}54,9 \text { anos } \\
\text { (adultos) e } 5,1 \\
\text { anos } \\
\text { (crianças) }\end{array}$ & $\begin{array}{l}\text { Câncer }(73,6 \%) \text { para adultos e } \\
\text { doenças congênitas }(73,1 \%) \\
\text { para crianças }\end{array}$ & Colostomias $(63,6 \%)$ & $\begin{array}{c}\text { Definitivo } \\
(51 \%) \text { para } \\
\text { adultos e } \\
\text { provisório } \\
(86,6 \%) \text { para } \\
\text { crianças }\end{array}$ & \\
\hline $\begin{array}{l}\text { Santos, Kimura e } \\
\text { Chaves. Rev Bras } \\
\text { Coloproct 2003a; } 23 \\
\text { supl 1: 44-44. } \\
\text { Santos, Kimura e } \\
\text { Chaves. Quality of } \\
\text { Life Research } \\
2003 b ; 12(7): 821- \\
821 . \\
\text { Santos, Kimura e } \\
\text { Chaves. WOCN J } \\
2006 \text { (em } \\
\text { julgamento). }\end{array}$ & $\mathrm{N}=114$ & $\begin{array}{l}\text { Masculin } \\
\text { o }(63,2 \%)\end{array}$ & $\begin{array}{l}59,6 \pm 3 \text {, para } \\
\text { pacientes com } \\
\text { estomas } \\
\text { definitivos, e } \\
44,7 \pm 5,2 \\
\text { para estomas } \\
\text { temporários } \\
(\mathrm{p}<0,001)\end{array}$ & $\begin{array}{l}\text { Câncer }(81,4 \%) \text { em pacientes } \\
\text { com estomas definitivos e } \\
\text { trauma }(43,9 \%) \text {, para } \\
\text { pacientes com estomas } \\
\text { temporários }(\mathrm{p}<0,001)\end{array}$ & $\begin{array}{l}\text { Colostomias }(57,1 \% \text { e } 69 \% \text {, } \\
\text { respectivamente para pacientes } \\
\text { com estomas temporários e } \\
\text { permanentes) }\end{array}$ & $\begin{array}{c}\text { Definitivo } \\
(63,2 \%)\end{array}$ & $\begin{array}{l}70,1 \pm 18,4 \\
\text { meses para } \\
\text { pacientes com } \\
\text { estomas } \\
\text { definitivos }\end{array}$ \\
\hline
\end{tabular}




\begin{tabular}{|c|c|c|c|c|c|c|c|}
\hline $\begin{array}{l}\text { Vasconcellos et al. } \\
2006 \text { (em fase de } \\
\text { preparo para } \\
\text { publicação) }\end{array}$ & $\begin{array}{l}\mathrm{N}=635 \\
\text { (prontuários) }\end{array}$ & $\begin{array}{l}\text { Feminino } \\
(51 \%)\end{array}$ & $\begin{array}{l}\geq 60 \text { anos } \\
(59,1 \%)\end{array}$ & $\begin{array}{l}\text { Câncer de colo, reto e bexiga } \\
(68,6 \%)\end{array}$ & $\begin{array}{ll}\text { - } & \text { Colostomias }(79,6 \%) \\
\text { - } & \text { Ileostomias }(13,6 \%) \\
\text { - } & \text { Urostomias }(6,9 \%)\end{array}$ & $\begin{array}{l}\text { Definitivo } \\
(64,5 \%)\end{array}$ & $\begin{array}{l}76,5 \pm 99,0 \\
\text { meses }\end{array}$ \\
\hline
\end{tabular}

"A maioria dos estudos não continha informações sobre raça/etnia e/ou escolaridade e/ou ocupação, sendo excluidas da apresentação.

"Vasconcellos ACLP, Santos VLCG, Secoli SR, Boness AS, Paula CAD, Barros ECC. Estomizado adulto no município de São Paulo: um estudo sobre o custo do consumo de equipamentos especializados [trabalho de conclusão de curso]. São Paulo: Especialização em Estomaterapia, Escola de Enfermagem da USP; 2006. 
O Quadro 1 mostra as principais características demográficas e clínicas de 1895 pacientes, predominantemente atendidos em serviços ambulatoriais de assistência especializada, na cidade de São Paulo. Certamente, ao constituírem os mesmos centros, em diferentes estudos, pode haver sobreposição dos dados, o que reduziria a amostra final. No entanto, deve-se considerar que se tratam de períodos distintos para as coletas de informações além de serem quatro investigações retrospectivas, entre onze trabalhos exibidos.

Nos estudos, praticamente não há diferença entre os estomizados no que se refere ao sexo, com o predomínio eqüitativo de mulheres e homens (apenas em uma publicação não há esse dado). Porém, quando prevalece o sexo feminino, a diferença de porcentagens é menor comparativamente ao masculino. Isto é, o predomínio de mulheres ocorre para pouco mais de $50 \%$ enquanto, para os homens, esses percentuais sobem para mais de $60 \%$, exceto em dois dos estudos realizados com a mesma amostra (Nogueira et al 1994; Boccardo et al 1995).

Em relação à idade, certamente varia de acordo com a clientela estudada quanto ao diagnóstico, tipo de estoma e tempo de pós-operatório. Verifica-se, porém, que a maioria encontra-se na faixa acima dos 50 anos.

Embora não existam dados definitivos sobre o número de estomizados no país, conforme já mencionado no início deste capítulo, algumas estimativas podem ser feitas a partir de informações publicadas 
pelo Ministério da Saúde e em boletins ou revistas das associações dos estomizados, brasileiras e internacionais.

Desse modo, segundo Vladimir Kleinwachter ${ }^{*}$, vice-presidente da International Ostomy Association, há cerca de 1 estomizado para cada 1000 habitantes, em países com um bom nivel de assistência médica, podendo ser bem inferior nos países menos desenvolvidos. Essa estimativa foi baseada em coleta de dados feita junto aos países membros da organização, constatando-se ausência de muitas respostas. Projetando-se essa estimativa para o nosso país e tendo-se como base o censo de $2000^{* *}-$ quando a população total era de 169799170 pessoas - teriamos cerca de 170 mil estomizados.

Em publicação recente, na Revista da Associação Brasileira de Ostomizados - ABRASO (2005), a respeito dos relatórios de alguns países, exibidos na Conferência Anual da United Ostomy Association, no Canadá, em 2005, têm-se: a Sérvia com 4000 estomizados, clientela que ocupa o terceiro lugar no país, somente após diabéticos e hemofilicos; a Ucrânia, com 50 mil e a Rússia com 120 mil pessoas com estomas. Além disso, a associação japonesa contava, em 2005, com 12 mil membros, com média etária de 61 anos.

* Informação prestada, após consulta à IOA, por email, em 6 de fevereiro de 2006.

** Disponivel em www.ibge.gov.br, em 15 de fevereiro de 2006. 
Para a ABRASO (2004a), em 2003 havia 42627 estomizados, em 23 estados brasileiros, cadastrados junto às associações estaduais, dos quais 53\% eram mulheres. Nessa mesma edição da Revista da ABRASO (2004b), publicou-se o número de "procedimentos de colostomia" terminologia empregada na Portaria nº 1230 de 4/10/1999, para designar dispositivos coletores e protetores de pele para estomias - pagos pelo Ministério da Saúde, em 2003, totalizando 2501119 itens. Embora seja um número subestimado - pela falta de registro ou pelo financiamento parcial com verbas estaduais - e inclua protetores de pele, além dos equipamentos coletores, pode-se efetuar uma estimativa grosseira do número de pessoas atendidas. Dividindo-se esse valor pelo número médio de equipamentos usados por uma pessoa ao ano (total de dias do ano dividido pela durabilidade média do equipamento $+20 \%$ ), tem-se, aproximadamente, 34262 pessoas, número considerado bastante abaixo não só das estimativas internacionais quanto na comparação com outros países, com nível de desenvolvimento similar.

Se, de um lado verifica-se ausência ou escassez dessas estatísticas, por outro lado reconhece-se que é no diagnóstico ou nas causas dos estomas que se encontra o maior respaldo da literatura.

Os dados do Quadro 1 mostram o amplo predominio das neoplasias malignas, principalmente intestinais, como origem da confecção da maioria dos estomas. 
Segundo Secoli (2005), os dados do Instituto Nacional do Câncer (INCa) indicavam a incidência de quase 470 mil casos de câncer no país, em 2005, dos quais 14 mil colorretais. Ainda conforme os dados do INCa, a mesma autora menciona ser esse o segundo em prevalência no mundo, com 945 mil casos novos ao ano, principalmente em países desenvolvidos. Esse perfil projeta-se na realidade brasileira à medida de sua maior ocorrência nos Estados de São Paulo e Rio de Janeiro, ou seja, estados da região sudeste, a mais desenvolvida do país. Conforme o DATASUS ${ }^{\star \star \star}$, em 2003, houve 22,36 e 21,90 casos de cânceres colorretais para 100 mil homens e mulheres, respectivamente, em São Paulo, e 23,45 e 23,97 casos para 100 mil homens e mulheres, respectivamente, no Rio de Janeiro, constituindo as maiores taxas nacionais. No país como um todo, esse tipo de câncer ocupa o quarto lugar, tanto entre homens como mulheres. Para os homens, primeiramente estão os cânceres de pele, incluindo os melanomas $(47,3 \%)$, seguidos pelos de próstata $(40,5 \%)$ e de pulmões, traquéia e brônquios $(17,4 \%)$. E, para as mulheres, além dos de pele $(50,2 \%)$, estão os de mama $(46,3 \%)$ e de colo de útero $(18,3 \%)$, nessa ordem.

Os traumas ou causas externas também têm representado percentual importante como causas dos estomas, principalmente no meio urbano. No Quadro 1, verifica-se que eles constituíram mais de 40\% das condições clínicas, conforme a idade e tipo de estoma nos estudos de Paula

${ }^{* * *}$ Disponivel em http://tabnet.datasus.gov.br/cgi/idb2004, em 15 de fevereiro de 2006. 
e Santos (1999a,b) e de Santos, Kimura e Chaves (2003a, 2003b, 2006). No último trabalho apresentado, no entanto, essas causas não atingiram os $7 \%$ (Vasconcellos et al 2006).

Evidentemente, as causas geralmente determinam o tipo e o caráter do estoma. Desse modo, constata-se a inequívoca predominância das colostomias definitivas, independentemente da idade e sexo, na maioria dos estudos. Considerando-se que esse tipo de estoma foi critério de seleção para os estudos que tratam da irrigação da colostomia (Santos e Koizumi 1992; Silva et al 1999), nos demais o diagnóstico principal foi o câncer colorretal ou de bexiga que, muitas vezes, demanda o estoma permanente.

É exatamente nesse sentido que as investigações mais recentes têm sido desenvolvidas, ou seja, desde o estabelecimento de diretrizes para o tratamento do câncer colorretal ao aperfeiçoamento das técnicas cirúrgicas visando à preservação esfincteriana. Inovações tecnológicas em cirurgia também têm sido testadas seja para evitar o estoma temporário ou, nas situações em que ele é indispensável, qual deles implicaria em menor morbidade. O uso da cirurgia laparoscópica na cirurgia colorretal também é um tema explorado.

O tratamento de escolha para o câncer colorretal é o cirúrgico e, dentre seus objetivos principais, está a preservação esfincteriana (HabrGama e Araújo 2000). 
Em revisão de literatura para identificação dos métodos cirúrgicos de preservação esfincteriana e os respectivos resultados oncológicos e funcionais, McNamara e Parc (2003) concluíram que esse tipo de operação é possivel para a maioria dos pacientes com câncer retal. Ademais, resultados funcionais ótimos podem ser obtidos nos cânceres de reto médio e baixo com o emprego de técnicas de preservação nervosa e de um reservatório colônico na reconstrução do trajeto.

Saito et al (2004) por sua vez, ainda visando à preservação esfincteriana, propõem a ressecção inter-esfinctérica, com ou sem ressecção parcial adicional do esfincter externo, para adenocarcinomas na junção ano-retal. Testada em 35 pacientes, estudados prospectivamente, os autores verificaram recorrência tumoral em 5 pacientes $(23$ meses em média) e resultados funcionais considerados satisfatórios. Apenas um dos pacientes submeteu-se, posteriormente, à colostomia definitiva. Esses resultados apontam para a possibilidade de sua utilização em pacientes candidatos à amputação abdômino-perineal do reto, evitando o estoma.

Casos avançados de recorrências tumorais pélvicas, após radioterapia e quimioterapia, têm sido tratados por meio da exenteração pélvica ou extirpação das vísceras pélvicas - descrita por Brunschwig, em 1948 - cirurgia altamente mutiladora que objetiva maximizar a sobrevida com a menor alteração anatômica possível. Em revisão de literatura, Salom e Penalver (2003) mencionam os avanços da cirurgia, principalmente da fase reconstrutora, em que já é possível evitar o estoma - por meio de anastomoses colorretais baixas; realizar a construção de neovagina - 
permitindo a intimidade sexual e fortalecer o soalho pélvico, reduzindo a morbidade.

Dentre outras razões - como o diagnóstico precoce, o uso de antibiotioticoprofilaxia e melhora da técnica cirúrgica - a preservação esfincteriana tornou-se possivel, também, graças ao desenvolvimento das suturas mecânicas (Habr-Gama e Araújo 2000). Apesar de constituir estratégia cirúrgica bastante empregada, mesmo em centros menores, recente revisão Cochrane mostra que não há evidências suficientes que demonstrem a superioridade dessa técnica comparada à sutura manual, para anastomoses colorretais, independentemente do seu nível. Após metanálise feita com nove ensaios randomizados controlados, Lustosa et al (2006) verificaram diferença estatisticamente significativa somente para a estenose, mais freqüente na sutura mecânica, e para o tempo de confecção da anastomose, maior para a sutura manual.

Aspectos importantes, presentes em algumas das publicações levantadas, referem-se à necessidade de utilização de estoma temporário e, quando necessário, qual estoma empregar (colostomia ou ileostomia), seja nas cirurgias de eleição para tumores retais baixos - ressecção anterior seja na proteção anastomótica em geral. Para ambos aspectos, a literatura recente tem mostrado resultados controversos.

Estoma de proteção reduziu a taxa de deiscências de anastomose colorretal - que demandaram intervenções reparadoras - e as suas conseqüências em amplo estudo prospectivo com 881 pacientes $(32,3 \%$ de 
2729 pacientes atendidos no período), realizado por Gastinger et al (2005). Embora também empregado por Bailey et al (2003), como medida de proteção anastomótica, os autores detectaram que $8 \%$ de 59 pacientes mantinham-se estomizados, após seguimento de 4 anos. Esses autores concluem que tal resultado não é adequado, à medida que a ressecção anterior baixa constitui exatamente uma alternativa ao estoma definitivo.

Já os resultados de Koperna (2003) sugerem um benchmark de $10 \%$ ou menos para a realização de estomas protetores e para a ocorrência de deiscências de anastomoses, em cirurgias de ressecção anterior, o que limitaria os custos totais a 12 mil Euros por paciente tratado, estimulando a implantação de programas especiais voltados para a redução de ambos índices (estomas temporários e deiscências). O autor ainda afirma que elevadas taxas de deiscências, apesar do alto número de estomas, depende muito mais da habilidade do cirurgião do que das características dos pacientes, exigindo mudanças nas estratégicas cirúrgicas.

No que tange ao tipo de estoma temporário a ser empregado colostomia ou ileostomia - os estudos também mostram resultados distintos quanto à sua morbidade, durante a permanência e após o fechamento. Nesse sentido, Law, Chu e Choi (2002) e Gastinger et al (2005) são favoráveis às colostomias, enquanto Rullier et al (2001), Edwards et al (2001), Kuijpers (2001), Tocchi et al (2002) e Platell, Barwood e Makin (2005) preferem as ileostomias. Os estudos de Sakai et al (2001) e Robertson et al (2005) mostraram percentuais gerais semelhantes entre ambos tipos de estomas. Enquanto os primeiros sugerem a realização de 
estudos futuros que investiguem e comparem a percepção dos pacientes sobre a qualidade de vida; os segundos apontam diferenças quanto à morbidade entre os dois tipos de estomas, ao longo de dois anos. Ressaltase que todas as investigações mencionadas apresentam desenhos metodológicos diferentes.

Em revisão Cochrane, também recente, acerca da comparação entre as complicações de colostomias e ileostomias temporárias, Lertsithichai e Rattanapichart (2004) realizaram metanálise com cinco estudos randomizados controlados. Constataram que as colostomias foram significativamente mais propensas à ocorrência de complicações dos estomas em pacientes com câncer colorretal, submetidos a cirurgias eletivas; enquanto as ileostomias mostraram maiores tendências para complicações após o fechamento. Os autores concluem que há necessidade de maior número de estudos e mais amplos para a indicação do tipo de estoma temporário mais adequado nessas condições.

A discussão acerca da necessidade de estoma provisório não ocorre, no entanto, somente para as cirurgias no tratamento do câncer retal. Conforme constatado no Quadro 1, os estomas também podem ser devidos às causas traumáticas e aqui reside outra grande polêmica acerca da cirurgia reparadora primária - com ou sem estoma de proteção? Revisão Cochrane (2006), realizada por Singer e Nelson (2002), em que se procedeu à metanálise de seis estudos acerca do tratamento de lesões penetrantes do cólon, conclui que a técnica do reparo primário é superior à derivação fecal. Apesar das evidências existentes, autores como Miller et al (2002) discutem 
o uso de um algoritmo no qual pacientes com lesões destrutivas do cólon e presença de doença importante e de transfusão sangüinea devem ser submetidos à derivação fecal, em função do alto risco de mortalidade. Adesanya e Ekanem (2004) apregoam o uso mais liberal das reparações primárias em lesões destrutivas do cólon, tendo em vista a ausência de diferenças estatisticamente significativas entre os pacientes com e sem colostomia, apesar da morbidade (21\%) e mortalidade (5,3\%) após fechamento do estoma provisório.

Além do tipo mais adequado de estoma temporário, encontram-se inúmeros outros estudos referentes a propostas técnicas para a sua confecção, novas ou revisitadas, como a derivação urinária e fecal combinada, sem anastomose intestinal (Costa, Kreder e Howe 2003); a ileostomia blow-hole (exteriorização do íleo através do cólon, com ou sem ileostomia em alça) para pacientes com megacólon tóxico ou grandes obstruções intestinais (Remzi et al 2003); a ileostomia com preservação da válvula íleo cecal (Nio et al 2004); a ileostomia em alça sem suporte de fixação (Papachristou e Papachristou 2004); a simplificação da técnica de colostomia, por meio de tubo plástico subcutâneo (Bancu 2003), e as colostomias (Blanco Díez et al 2003) e ileostomias (Guimarães et al 2005) úmidas, que evitam a exteriorização de estoma duplo. Todas essas inovações visam a facilitar a técnica operatória, à sua manipulação pelo paciente ou, posteriormente, ao seu fechamento.

Nessa linha, encontra-se o emprego da cirurgia laparoscópica, como alternativa eficiente para a exteriorização de estomas. É o que 
mostram os estudos de Olmi et al (2002) e Swain e Ellis (2002), respectivamente com 55 (23 colostomias terminais de Miles, 21 colostomias terminais de Hartman, 9 colostomias em alça e 3 ileostomias em alça) e 53 (ileostomias em alça) procedimentos, que resultaram em baixa morbidade, com tempo operatório bastante menor (Olmi et al 2002; Swain e Ellis 2002), principalmente para pacientes distendidos e obstruídos (Olmi et al 2002).

Esses resultados apoiam-se, de certa maneira, nas recomendações resultantes de uma revisão Cochrane, realizada por Schwenk et al (2006), que reuniu 25 ensaios randomizados controlados acerca dos resultados imediatos da cirurgia laparoscópica em ressecções colorretais. Esse tipo de procedimento mostrou vantagens clínicas relevantes comparativamente à técnica tradicional, em pacientes selecionados. Os autores recomendam que, se os resultados oncológicos de longo prazo forem equivalentes para ambas técnicas, futuramente deve-se preferir a via laparoscópica. Em nosso meio, as diretrizes para tratamento do câncer colorretal recomendam que esse tipo de procedimento, para o tratamento paliativo, deve ser realizado somente em centros especializados (Codeiro et al 2001).

Em estudo prospectivo de coorte (Kienle et al 2003), 59 pacientes consecutivos não oncológicos - com retocolite ulcerativa e polipose familiar submeteram-se à cirurgia laparoscópica para realização de bolsa ileal, com e sem ileostomia de proteção. Embora considerada factível, o Índice de Massa Corporal (IMC) elevado foi identificado como fator de risco para o insucesso. Além disso, a cirurgia laparoscópica não inibe a necessidade de 
ileostomia protetora em pacientes selecionados - o que ainda não se encontra claramente estabelecido.

Para pacientes mais graves, sem indicação cirúrgica, Mattingly et al (2003) propõem uma forma não invasiva para efetuar a derivação fecal, por meio de colonoscopia. Em revisão retrospectiva de 15 casos, em que foi utilizada somente anestesia local ou regional, não foram detectadas complicações.

Aspecto interessante nos trabalhos levantados - que também concorrem para a redução da prevalência de estomas provisórios - são os aspectos relacionados ao seu fechamento. Embora não se possa ter uma referência adequada a esse respeito, nos dados apresentados no Quadro 1 uma vez que os tempos de seguimento referem-se, principalmente, às pessoas com estomas definitivos, que constituem a maioria - em nosso meio, os estomas temporários acabam permanecendo durante longos períodos, de até um a dois anos, seja na etiologia traumática seja nas doenças inflamatórias ou oncológicas. Infelizmente, não são as condições clínicas e preferências dos pacientes que determinam a reconstrução do trânsito intestinal, mas a "fila" cirúrgica estabelecida pela precariedade do sistema de atenção à saúde, que prioriza evidentemente os casos mais graves, particularmente as neoplasias malignas, o que retarda os processos de fechamento dos estomas.

De qualquer maneira, as publicações internacionais têm investigado o fechamento precoce, ainda durante a hospitalização (Bakx et 
al 2003); modificações para simplificar a abordagem pré-operatória, sem exame contrastado (Cowan e Hill 2005), ou a intra-operatória (Cantele, Méndez e Leyba 2001; Keating, Kelly e Hunt 2003); morbidade após o fechamento (Kuijpers 2001; Bakx et al 2004; Wong et al 2005) - em torno de $10 \%$ a $18 \%$, conforme a doença de base, tipo de estoma e de fechamento, além das condições do paciente - e ainda estudos funcionais acerca do impacto do estoma temporário na musculatura do esfincter anal (Sailer et al 2001) ou na mucosa intestinal (Oh et al 2005).

Embora se tenha tratado de preservação esfincteriana, como tendência mesmo para o tratamento do câncer de reto baixo, há as condições em que o estoma definitivo torna-se imperativo, seja com finalidade curativa ou paliativa. Segundo as diretrizes nacionais para a abordagem do câncer de reto - inseridas no Projeto Diretrizes AMB - CFM elaboradas pela Sociedade Brasileira de Coloproctologia, em 2001 - "sempre que houver lesão esfincteriana, para lesão tumoral ou margem distal insuficiente, faz-se obrigatória uma cirurgia de amputação abdôminoperineal", que implica na exteriorização de um estoma permanente.

Estudo de coorte interessante, desenvolvido por Hodgson et al (2003), objetivou associar o porte do hospital com o número de colostomias realizadas e a taxa de sobrevivência de pacientes com câncer de reto, durante três anos consecutivos. Os autores concluiram que os pacientes operados em hospitais de grande porte possuiam menos colostomias permanentes e melhor taxa de sobrevida comparativamente àqueles operados em hospitais de menor porte. Finalizam recomendando a revisão 
dos processos de cuidar que contribuem para tais diferenças, visando à melhora dos resultados, em todos os serviços.

Certamente, ao discutir-se sobre o câncer colorretal - como uma das principais causas dos estomas, particularmente os definitivos - é fundamental ressaltar que os estudos têm versado sobre o tema da prevenção. Evidentemente, a prevenção também interessa à epidemiologia dos estomas, à medida da possibilidade de evitar sua confecção, seja por meio do diagnóstico precoce e ressecções mais econômicas seja na evitação da própria doença, o que ainda é bastante discutivel. Corroborando essas suposições, em revisão Cochrane recente, em que se fez metanálise com estudos que envolveram casuística importante (mais de 10 mil sujeitos), Towler et al (2006) concluíram que existem beneficios do rastreamento, por meio do teste de sangue oculto nas fezes - hemoccult - que incluem redução da mortalidade e possível redução da incidência de câncer - seja por intermédio da detecção e remoção precoces de adenomas seja, potencialmente, pelo tratamento de lesões com cirurgias menos invasivas. No entanto, também ocorrem efeitos indesejáveis como as complicações físicas das colonoscopias, a ruptura do estilo de vida, estresse e desconforto conseqüentes à investigação e à ansiedade causada pelos resultados falsos positivos. Desse modo, embora os beneficios superem os danos para a população com risco aumentado, são ainda necessárias mais informações sobre tais efeitos deletérios, sobre as respostas da comunidade e sobre os custos envolvidos, em diferentes sistemas de saúde, antes que o hemoccult possa ser estabelecido como recomendação. 
Ainda no que se refere às medidas preventivas do câncer colorretal, duas outras revisões Cochrane tratam de aspectos dietéticos acerca, respectivamente, de fibras e de suplementação de cálcio. Analisando cinco estudos randomizados ou quase randomizados, junto a pacientes com adenomas e sem história de câncer, mostraram que não há evidências indicativas de que o aumento de fibras na dieta acarrete diminuição da incidência ou recorrência de pólipos adenomatosos, no período investigado, de 2 a 4 anos (Asano e McLeod 2006). Na outra revisão, que incluiu dois estudos randomizados com placebo controle ( $\mathrm{n}=1346$ indivíduos), Weingarten, Zalmanovici e Yaphe verificaram que, embora a suplementação de cálcio na dieta contribua moderadamente para a prevenção de pólipos adenomatosos colorretais, essa também não constitui evidência suficiente para transformá-la em recomendação.

Outros estudos tratam da indicação de estomas em condições pouco usuais como a constipação idiopática crônica grave (Scarpa, Barollo, Keighley 2005; El-Tawil 2004) ou em paraplégicos após Lesão Medular Traumática (La Fuente et al 2003; Safadi et al 2003), com resultados satisfatórios principalmente para o segundo grupo. Em estudo de caso, Münch et al (2005) indicam o uso da ileostomia temporária para um paciente com colite colagenosa - doença pouco freqüente e de etiologia desconhecida - com redução importante do processo inflamatório mucoso, normalização da degeneração epitelial e da permeabilidade da mucosa.

\footnotetext{
Finaliza-se este capítulo, reconhecendo-se a escassez de literatura específica e, principalmente, de estatísticas nacionais e
} 
internacionais que dêem suporte ao que se denominou epidemiologia dos estomas. O tema acabou sendo discutido muito mais à luz da literatura médica em cirurgia voltada para o estoma como conseqüência da impossibilidade do alcance de uma das metas mais importantes, qual seja a preservação esfincteriana. Atualmente, essa é muito mais factível na Urologia - através das ampliações vesicais, neo bexigas e esfincteres artificiais - o que foi possivel depreender pela ausência de publicações que tratam, especificamente, das urostomias ou derivações urinárias. Como tendências, podem-se apontar algumas inovações na cirurgia de ressecção anterior baixa, para o tratamento cirúrgico dos tumores retais baixos, e as indicações e tipos de estomas temporários, para proteção de anastomoses, no câncer e trauma.

Esses temas, certamente, encontram-se relacionados à epidemiologia dos estomas, à medida que repercutem não somente no número de pessoas com estomas permanentes e definitivos, em diferentes condições clínicas, como no processo de cuidar, desde uma etapa diagnóstica precoce, durante o perioperatório até etapas mais tardias. Algumas particularidades desse cuidado são apresentadas e discutidas no próximo capítulo. 


\section{ALGUMAS PARTICULARIDADES DO CUIDAR DE PESSOAS COM ESTOMAS}

"Tudo o que existe e vive precisa ser cuidado para continuar a existit e a viver."

(Boff 2000)

O cuidar em Estomaterapia, voltado para as pessoas com estomias, embora com suas raizes fincadas ainda na Antigüidade, tem sua primeira publicação somente em 1930 (ver Capítulo 1), com substancial incremento posterior, ainda na década de 50, quando é oficializada como especialidade.

De lá para cá, muitos livros foram publicados sobre o tema - até para subsidiar os cursos de especialização que proliferaram nos anos seguintes - criaram-se sociedades e revistas específicas e alguns temas foram sendo mais explorados, de acordo com as tendências internacionais, como os psicossociais e a qualidade de vida.

Nos últimos 40 anos, os dispositivos coletores e as barreiras protetoras de pele periestoma passaram daqueles permanentes e reutilizáveis de borracha e do óxido de zinco, respectivamente, para produtos de alta tecnologia que cumprem adequadamente suas funções de coleta e armazenamento de efluentes com segurança, conforto e maior proteção contra possiveis complicações (Turnbull e Erwin-Toth 1999; Van Rijwisjk (2000). Disseminaram-se algumas técnicas, como a demarcação 
pré-operatória do estoma; o teste de hipersensibilidade aos componentes do equipamento coletor; a irrigação colônica e o uso do sistema oclusor de colostomia, para controle das exonerações intestinais; o auto cateterismo intermitente, para os estomas continentes; o uso precoce de cintas elásticas, para prevenção de hérnias para estomais e tantas outras até hoje empregadas.

Nesse período, marcado pelo maior cientificismo da Enfermagem, estabeleceram-se princípios para as suas ações, o que também ocorreu para a estomaterapia, os quais, entretanto parecem não ter evoluído. O que se constata, na atualidade, é uma prática baseada na tradição desses principios (Turnbull e Erwin-Toth 1999; Van Rijwisjk (2000), dificultando, muitas vezes, o maior investimento em pesquisas na área, o que inibe o conhecimento, cerceia as evidências e, dessa maneira, o acesso da clientela - especialistas, profissionais da saúde e pacientes - a intervenções e recursos mais adequados às maiores complexidade e exigência do mercado e do consumidor, nos dias de hoje.

Corroborando essas afirmações, em 1999 e após revisão de literatura, Turnbull e Erwin-Toth (1999) indicaram a profunda escassez de pesquisas sobre os cuidados com estomas - o que se repetia em nosso meio - embora muito se escrevesse e se publicasse sobre o tema. As autoras acrescentam que a efetividade de muitos cuidados preconizados, como a demarcação pré-operatória do estoma, a seleção dos dispositivos e a prevenção de complicações do estoma e pele periestoma, encontravam-se ricos de evidências empíricas porém sem comprovação investigativa que 
lhes desse suporte. Outros temas como o uso de convexidade; as vantagens, benefícios e indicações de sistemas de uma e de duas peças; o uso de bolsas fechadas para ileostomias e colostomias; o emprego de barreiras protetoras em pasta; o tempo de uso dos equipamentos coletores; as recomendações dietéticas; a acidificação urinária com Vitamina C, em urostomias; e o impacto psicossocial do estoma na qualidade de vida do indivíduo, com diferentes características demográficas e clínicas, constituiam alguns exemplos de práticas, tradicional e empiricamente aceitas, que mereciam investigações futuras (Turnbull e Erwin-Toth, 1999). Ainda nesse sentido, Gray (1998) afirmava que “. a base da pesquisa para o cuidado de estomias está sendo tristemente perdida e parece que muitas das questões a ele relacionadas permanecem não respondidas...”.

Infelizmente, esse cenário não se modificou muito, desde essas publicações, ou seja, nos últimos cinco anos. Embora já possam ser encontrados alguns consensos estabelecidos pelas sociedades de especialistas, eles ainda são muito poucos. Além disso, na pesquisa bibliográfica por nós realizada, são raros os ensaios clínicos randomizados controlados bem como as revisões sistemáticas ou metanálises que tratam dos cuidados específicos com as estomias. Esses e outros estudos são apresentados a seguir, dando suporte às nossas publicações sobre o tema, geradas no período e que se encontram subdivididas em tópicos: cuidados gerais especializados; complicações do estoma e pele periestoma; controle das eliminações em estomizados e equipamentos coletores para estomas. 


\section{Cuidados gerais especializados}

Desde 1992, publicamos três capitulos, em três livros diferentes, além de quatro artigos sobre os cuidados específicos a serem ministrados às pessoas com estomas, desde a etapa pré-operatória precoce à tardia ambulatorial ou domiciliária (Quadro 2).

\section{Quadro 2 - Publicações acerca dos cuidados gerais às pessoas com estomas, no periodo 1993 a 2003.}

1. Santos VLCG. Reabilitação do ostomizado: em busca do ser saudável. Texto contexto Enf 1992; 1(2): 180-190.

2. Santos VLCG. Buscando o lugar certo. Rev Paul Enf 1993; 12(3):103-106.

3. Viana NM, Moritaka L, Pelicia R, Roncaratti E, Marx LC, Santos VLCG. Técnica da demarcação do local do futuro estoma: determinante da adaptação do ostomizado. . [Resumo] Rev Bras Coloproctol 1995; 15 supl 1:101-101.

4. Cezaretti IUR, Santos VLCG, Filippin MJ, Lima SRS, Ribeiro AM. A enfermagem e o processo de cuidar de estomizados. In: Crema E, Silva R. Estomas: uma abordagem interdisciplinar. Uberaba: Editora Pinti; 1997. P.125144.

5. Cesaretti IUR, Santos VLCG, Filippin MJ, Lima SRS. O cuidar de enfermagem na trajetória do ostomizado: pré \& trans \& pós-operatórios. In: Santos VLCG, Cesaretti IUR. Assistência em estomaterapia: cuidando do ostomizado. São Paulo: Atheneu; 2000. P. $113-131$.

6. Santos VLCG. Fundamentação teórico-metodológica da assistência aos ostomizados na área da saúde do adulto. Rev Esc Enf USP 2000b; 34(1): 59-63.

7. Santos VLCG. Estomias abdominais. In: Velasco IT (ed). Propedêutica na emergência. São Paulo: Atheneu; 2003. p. 607-612.

8. Batista RF, Viana RM, Santos MC, Schiftane SS, Guimarães RP, Cesaretti IUR, Santos VLCG. Crianças e adultos com ostomias: um perfil da clientela. [Resumo] Rev Bras Coloproctol 2003a; 23 supl 1: 40-40.

9. Yamada BFA, Peres CSV, Santos VLCG. Granuloma em gastrostomia: uma alternativa inovadora de tratamento tópico. Rev Estima 2005; 3(3 n esp): 61-61. 
Fundamentando-nos em clássicos autores internacionais como Mahoney (1976); Vukovich e Grubb (1977); Broadwell e Jackson (1982), em seu livro Principles of ostomy care - à época, considerado a bíblia da estomaterapia - Breckman (1990) e Hampton e Bryant (1992), além de nossa experiência clínica junto a essa clientela, esses documentos foram escritos reiterando as diretrizes práticas vigentes.

Desse modo - e sempre enfatizando a necessidade do planejamento individual e sistematizado, ou seja, sem estabelecer fórmulas assistenciais - esses cuidados têm sido divididos conforme a etapa operatória em que o paciente se encontra.

Na etapa pré-operatória, ressalta-se a avaliação específica incluindo as abordagens fisica, psicológica e social, cultural, espiritual e educacional - não só do paciente como de sua família, nos aspectos que a ela se relacionam. Essa avaliação, feita por meio de exame físico e entrevista, subsidia a identificação e interpretação das demandas de cuidar, o estabelecimento dos diagnósticos de enfermagem e o futuro planejamento das intervenções, gerais e específicas (Santos 1992; Cezareti et al 1997; Cesaretti et al 2000; Santos 2000b). Nas situações emergenciais, ao preverse a construção iminente de um estoma e desde que as condições gerais do paciente o permitam, tais cuidados devem ser sumarizados e priorizados, mas não abandonados (Santos 2003).

Dentre os cuidados físicos específicos nessa etapa operatória que repercutem sobremaneira nas etapas posteriores - destacam-se o 
preparo colônico e a demarcação do local para exteriorização do futuro estoma.

Quanto ao preparo colônico, nas últimas décadas, tem evoluído do preparo mecânico e microbiano - enteroclisma e antimicrobiano profilático - para o emprego de soluções orais como o Manitol a 10\%, polietileno glicol ou fosfato de sódio, além de controle alimentar. Apesar das pequenas variações, segundo os protocolos institucionais, ele sempre foi advogado para a prevenção de complicações pós-operatórias, principalmente as infecciosas. No entanto, em recente revisão Cochrane, em que se analisaram nove ensaios clínicos $(n=1592$ pacientes em cirurgia colorretal eletiva), Guenaga et al (2006) não encontraram evidências convincentes de que esse tipo de preparo associa-se à redução das deiscências de anastomoses. Contrariamente, os autores verificaram que houve associação significativa com o aumento não só desses índices, mas também das complicações da ferida operatória. A ausência de diferenças estatisticamente significativas nos demais resultados - mortalidade, peritonite, re-operações, complicações infecciosas e não infecciosas extraabdominais e infecção do sítio cirúrgico - reforçaram os resultados obtidos. Estudo isolado de Ahmad, Abbas e Asghar (2003), junto a 47 pacientes - 16 dos quais em cirurgia de urgência - sem preparo colônico prévio e com controle antibiótico, mostrou baixa morbidade.

A demarcação do estoma consiste em uma técnica bastante simples, apesar de especializada, e visa ao estabelecimento do local mais adequado à exteriorização do futuro estoma. Conforme mencionado, no 
início deste capítulo, trata-se de um dos cuidados tradicionalmente preconizados, como um dos mais importantes na etapa pré-operatória. No entanto, dotado de inúmeras evidências empíricas, carece de evidências científicas. Mesmo assim, em julho de 2004, a Joint Commission on Accreditation of Healthcare Organizations (JCAHO), nos EUA, por similaridade, oficializou esse procedimento em seu National Patient Safety Guides, no protocolo universal para prevenção de local errado, procedimento errado e paciente errado em cirurgia. Baseando-se nessa norma, a Wound, Ostomy and Continence Nursing Society (WOCN) sociedade norte americana e canadense de enfermagem em estomaterapia: ferida, estoma e continência - posiciona-se em consonância com a JCAHO e com a Association of Operating Room Nurses (AORN), também envolvida na elaboração dessas normas (WOCNS 2006a).

Tema de uma de nossas primeiras publicações (Santos 1993), o artigo descreve os principais aspectos a serem considerados no procedimento, desde os locais - tipo de cirurgia, localização do músculo reto abdominal, manutenção de área adesiva suficiente, distância adequada de acidentes anatômicos críticos (cicatriz umbilical, rebordos ósseos, dobras de pele e de gordura, futura incisão cirúrgica, linha da cintura, cicatrizes anteriores) - como os mais gerais - possibilidade de visualização pelo paciente, presença de órteses e próteses, alterações sensoriais ou motoras, déficit visual e outros - além de condições outras como obesidade ou magreza excessivas, necessidade de dois estomas, aspectos culturais e religiosos, dentre outros (Santos 1993; Cezaretti et al 1997; Cesaretti et al 2000). Novamente, em situações de emergência, em que se prevê a 
construção de um estoma, recomenda-se revisão sumária das condições abdominais, com particular atenção as características da pele, proeminências ósseas e presença de distensão colônica e/ou lesões da parede abdominal e, se possivel, alterações motoras ou sensoriais que possam interferir no futuro auto cuidado (Santos 1993; Santos 2003). A importância desse tema levou-nos à confecção de um vídeo educativo, apresentado em 1995 (Viana et al, 1995).

Apesar de pouco empregada em nosso meio, em um de nossos estudos recentes (Batista et al 2003a) junto a 154 estomizados (102 adultos e 52 crianças), verificamos que a maioria dos estomas estava adequadamente localizada. Essa conclusão pôde ser inferida à medida que os estomas localizaram-se predominantemente em superficie plana da parede abdominal $(85,1 \%)$, com distâncias superiores a $3 \mathrm{~cm}$ em relação aos pontos considerados críticos: proeminências ósseas $(84,4 \%$ e $81,1 \%)$, cicatriz umbilical $(83,4 \%$ e $85,1 \%)$ e cicatriz cirúrgica $(82,45$ e $68,8 \%)$, percentuais respectivos para adultos e crianças.

Em se tratando da etapa perioperatória, como cuidados específicos ressaltam-se o respeito à zona demarcada para exteriorização do segmento intestinal pelo cirurgião, sempre que possível, e a colocação de equipamento coletor adequado, uma vez confeccionado o estoma, ainda na sala cirúrgica. Certamente, o controle rigoroso das complicações do estoma e efluente traduz o principal objetivo específico na fase imediata (Santos 1992; Cezaretti et al 1997; Cesaretti et al 2000; Santos 2003). 
Nas etapas pós-operatórias mediata e tardia, as intervenções específicas estão voltadas basicamente para o ensino do auto cuidado relacionado ao manuseio do estoma, pele periestoma e equipamento coletor, técnicas de controle do hábito intestinal, cateterismo intermitente e controle de complicações; o controle da doença de base - necessidade de tratamentos adjuvantes com radioterapia e/ou quimioterapia e medicamentos; e a re-inserção gradativa às atividades e hábitos de vida diária - sono e repouso, dieta/ hidratação, vestuário, locomoção e movimentação; bem como às sociais - trabalho, lazer, sexualidade, relações com família e amigos (Santos 1992; Cezaretti et al 1997; Cesaretti et al 2000). A amplitude de tais intervenções exige um trabalho em equipe interdisciplinar e baseia-se na participação ativa da pessoa estomizada e da família, visando à superação dos limites impostos pela doença e pelo estoma, ao re-dimensionamento de metas e ao desenvolvimento das potencialidades remanescentes.

Tratamento tópico específico de granuloma em gastrostomia utilizando gel de Cloreto de Sódio 20\% - foi por nós reportado recentemente (Yamada, Peres e Santos 2005), por meio de estudo de cinco casos, bem sucedidos. Embora se trate de gastrostomias, não discutidas nesta tese, o acúmulo de evidências empíricas acerca do emprego desse tipo de tratamento encaminha para o mesmo procedimento nessas complicações, também presentes em colostomias e ileostomias.

As publicações mais recentes sobre os aspectos do cuidar de pessoas que ficaram estomizadas resumem-se a estratégias de seguimento 
da doença - particularmente o câncer colorretal; a descrições gerais sobre o cuidar, similares às nossas - na forma de estudos de casos e cuidados paliativos; a dieta e metabolismo - especialmente em ileostomizados; ao uso de medicamentos e aos grupos de auto-ajuda.

Em revisão Cochrane acerca das estratégias de seguimento de pacientes tratados de câncer colorretal não metastático, cinco estudos mostraram que há benefícios em intensificarem-se tais estratégias, no período de cinco anos após a cirurgia curativa, embora a variedade dos programas impeça definir qual ou quais seriam as melhores quanto às freqüências das consultas, dos testes de sangue, dos procedimentos endoscópicos e radiológicos. Também não foi possível estimar qual seria a abordagem com melhor custo-efetividade (Jeffery, Hickey e Hider 2006).

A educação para o auto cuidado, como fonte de suporte social e emocional, também constitui tema de algumas das publicações levantadas, seja como referência do cuidado especializado de enfermagem em geral (Schultz 2002; Comb 2003; Burch 2005; WOCNS 2006b) - incluindo a avaliação de custo-beneficio no primeiro ano de pós-operatório (Pringle e Swan 2001) - ou no cuidado paliativo (Doughty 2005; O`Brian, Baddi e Benson 2005), também em estomizados oncológicos com incapacidades importantes para o aprendizado (Black e Hyde 2004); seja no cuidado em casos especiais como o manejo de ileostomias próximas a feridas complicadas (Braun 2003; Jones, Harbit e Anderson 2003) ou em obesos (Sadler e Froiland 2002; Jones, Harbit e Anderson 2003). 
A questão alimentar é outro aspecto importante do cuidado específico para pacientes com estomas. Em estudo do tipo survey, Floruta (2001) recebeu respostas de 604, dentre 40 mil membros da UOA, para os quais foram enviados questionários contendo 14 questões sobre recomendações e restrições dietéticas individuais. A autora verificou que $88,4 \%$ não seguiam qualquer dieta específica, mas muitos apresentavam problemas devidos a alguns alimentos. Dos $11,8 \%$, que modificaram sua alimentação, $55 \%$ eram aderentes à dieta modificada e a usavam indefinidamente. Os alimentos evitados incluíam frutas frescas, grãos, coco e alguns vegetais e os maiores problemas referidos foram bloqueio e flatulência. Metade dos respondentes informa ter recebido orientação alimentar principalmente de estomaterapeutas, durante a hospitalização. A autora conclui que a educação pré e pós-operatória deve incluir orientação sobre a seleção de alimentos.

Temas, ainda sobre a alimentação e hidratação e sua relação com a morbidade do estoma, referem-se à avaliação hídrica - perdas (Chambrier et al 2001) e água corporal (Carlsson, Bosaeus e Nordgren 2002) - além do metabolismo do colesterol (Nissinen et al 2004), na presença de ileostomia em pacientes com doenças inflamatórias intestinais ou síndrome do intestino curto.

Visto que pacientes estomizados podem apresentar problemas na absorção de medicamentos além de alterações na consistência ou coloração fecal, em conseqüência de seu emprego, Turnbull (2005) descreve algumas orientações importantes que devem interessar ao enfermeiro, especialista 
ou não, no processo de cuidar dessas pessoas. Desse modo, embora os colostomizados sejam considerados quase como pessoas que possuem o cólon e o reto íntegros, deve-se atentar para medicamentos programados para absorção gradativa em todo o trajeto. Para pacientes com aumento ou redução do tempo de trânsito intestinal ou com ressecções intestinais, pode-se orientar que, antes de ingerir o medicamento, proceda a um teste simples: se o medicamento levar mais de 30 minutos para dissolver em um copo com água, provavelmente será melhor absorvido. Além disso, deve-se também orientar para nunca cortar os comprimidos, o que pode inativá-los. A autora recomenda ainda que as formulações mais adequadas para as pessoas ileostomizadas são as soluções, suspensões e cápsulas de gelatina ao invés dos revestidos. Esses pacientes devem ser orientados, particularmente, a observar a presença dos medicamentos nas fezes. Devem também evitar os medicamentos orais para o controle do odor das fezes, já que esses podem provocar obstipação e escurecimento dos excretas (carvão - sem evidência clínica de efetividade) ou diarréia e coloração esverdeada das fezes (clorofila - com evidência de sua efetividade). A autora finaliza recomendando que pessoas com ileostomia não devem usar laxativos e seu preparo intestinal deve ser feito apenas com restrição de líquidos e alimentos.

Encerrando-se este tópico acerca dos cuidados gerais especializados ao paciente com estoma, já em uma etapa pós-operatória tardia, não se pode deixar de mencionar os grupos de auto-ajuda, representados principalmente pelas associações de estomizados. Já inseridas historicamente no Capítulo 1 deste trabalho, Lyons (2001) 
ressalta duas funções fundamentais desses grupos como a psicológica relacionada ao reconhecimento da existência de outras pessoas com problemas similares, que se encontram re-inseridas socialmente, e a como lidar com as próprias dificuldades, na ótica de seus pares - e educacional na troca de informações entre estomizados mas também para os cirurgiões e público em geral.

Algumas vezes, grupos de auto-ajuda podem ter caráter terapêutico profissional. Nesse sentido, Paegle e Silva (2005) apresentam os resultados de um estudo qualitativo que objetivou analisar a freqüência de comportamentos eficientes e não eficientes, de cinco pacientes estomizados operados de câncer de reto há mais de oito meses, durante cinco reuniões coordenadas por enfermeira. As autoras verificaram o predominio de rigidez e competitividade nas relações intra-grupais, determinando paralisia e estereotipia na interação, provavelmente por baixa afetividade entre eles. Isso tornou o grupo pouco operativo e efetivo.

Ambos exemplos tipificam resultados ainda não plenamente explorados na literatura nacional e internacional acerca dos grupos de auto-ajuda, apesar de serem indicados como forma importante de suporte social complementar.

\section{Complicações do estoma e pele periestoma}

A qualidade de vida e a adaptação do indivíduo com estomas, especialmente de caráter definitivo, estão condicionadas, muitas vezes, às 
complicações de seu estoma ou pele periestoma (Black 2002). Diante da profunda alteração do esquema corporal a que o estomizado é submetido, as dificuldades para a aceitação do estoma podem estar exacerbadas na presença de uma ou mais complicações, constituindo um agravante na busca de um nível ótimo de qualidade de vida*.

As complicações físicas do estoma podem ocorrer no pósoperatório imediato (complicações precoces) ou no decorrer da vida do estomizado (complicações tardias), destacando-se, respectivamente, a deiscência mucocutânea, o edema e o sangramento - entre as primeiras - e a estenose, as fistulas, os granulomas, as úlceras, os prolapsos, as hérnias, a impregnação do estoma ou pele periestoma com cristais de fosfato, as diarréias, as cólicas abdominais, o desequilíbrio hidroeletrolítico, o abscesso periestoma, a foliculite, a lesão pseudoverrucosa, a infecção por fungos e outras. Os estudos junto a populações diversificadas contêm dados estatísticos bastante variáveis, mas que apontam, como complicações mais freqüentes, as dermatites (18 a 57\%), as hérnias (3 a 21\%), os prolapsos (3 a $38 \%$ ) e as retrações (9 a 35\%)*.

* Baseado em Santos VLCG, Cesaretti IUR. Dermatites periestoma: da prevenção ao tratamento. In: Jorge SA, Dantas SRPE (org). Abordagem multiprofissional no tratamento de feridas. 1ed. São Paulo: Atheneu; 2003. p. 299-308. 
Como aspecto fundamental do cuidado - nem sempre prevenível as complicações do estoma e da pele periestoma vêm fundamentando algumas de nossas publicações, desde 1989. Essas encontram-se no Quadro 3.

\title{
Quadro 3 - Publicações acerca das complicações do estoma e pele periestoma, no periodo 1989 a 2003.
}

\author{
1. Sousa Jr AHS, Santos VLCG, Mileo LF, Delatorre GA, Nahas P, Pinotti HW, \\ Habr-Gama A. Equipe multiprofissional no cuidado de ostomizados: 164 casos \\ seguidos no Núcleo de Assistência a Ostomizados. [Resumo] Rev Bras \\ Coloproctol 1989; 9 supl 1: 56-56.
}

2. Santos VLCG. Como eu trato as dermatites periestoma. Rev Esc Enf USP 1994; 28 (1):67-71.

3. Paula RAB, Santos VLCG. Estudo retrospectivo sobre as complicações do estoma e da pele periestomal. Rev Bras Coloproctol 1999a; 19 (3):155-163. Paula RAB, Santos VLCG. Estudo retrospectivo sobre as complicações do estoma e da pele periestoma em ostomizados da cidade de São Paulo. Rev Esc Enf USP 1999b; 33 no esp: 63-73.

4. Santos VLCG, Cesaretti IUR. Dermatites periestoma: da prevenção ao tratamento. In: Jorge SA, Dantas SRPE (org). Abordagem multiprofissional no tratamento de feridas. 1ed. São Paulo: Atheneu; 2003. p. 299-308.

Das quatro publicações, excetuando-se o capítulo de livro (Santos e Cesaretti 2003) e a compilação bibliográfica (Santos 1994) - ambos acerca das dermatites periestoma - as duas outras referem-se a estudos retrospectivos sobre as complicações gerais dos estomas, incluindo também as dermatites. 
No primeiro estudo (Sousa Jr et al 1989) - em que avaliamos prontuários de 164 pacientes, atendidos no Núcleo de Assistência a Ostomizados do Hospital das Clínicas da Faculdade de Medicina da USP, após os primeiros anos de funcionamento do serviço - constatamos dermatites periestoma em quase um terço dos pacientes $(31,1 \%)$, prolapsos em $6,7 \%$, hérnias em $5,5 \%$ e estenoses em apenas $1,2 \%$ deles.

No segundo estudo (Paula e Santos 1999a, 1999b), analisando retrospectivamente 483 prontuários de estomizados atendidos em dois Serviços de Assistência Especializada da cidade de São Paulo, verificamos 779 complicações $(1,6 \pm 1,4$ por paciente). Dentre essas, predominaram as dermatites periestoma $(43,3 \%)$ - principalmente as irritativas $(57,9 \%)$ e as alérgicas $(23,7 \%)$ - as retrações $(9,2 \%)$, os prolapsos $(8,1 \%)$ e as hérnias paracolostômicas $(7,1 \%)$. Houve associações estatisticamente significativas entre a idade e o número de complicações $(p=0,003)$, e o tipo de complicações como as dermatites, hérnias, retrações e prolapsos $(p<0,001)$, ou seja, essas foram mais freqüentes em pacientes mais velhos. Além disso, as dermatites, hérnias e retrações predominaram entre as mulheres enquanto os prolapsos, entre os homens $(p<0,02)$.

Ao analisarem-se os artigos, tanto os mencionados nessas publicações como aqueles levantados para esta tese, pode-se verificar que ainda ocorre importante morbidade física relacionada à presença dos estomas, apesar de todos os avanços quer nas técnicas cirúrgicas quer no suporte pré e pós-operatório, educacional e psicossocial. 
Desse modo, autores como Matuliková e Hoch (2001) falam de morbidade superior a $50 \%(n=88)$, com a presença de complicações em 9,7\% dos colostomizados e risco aumentado de distúrbios metabólicos em $80,8 \%$ dos ileostomizados que apresentaram débito ileal superior a 1000ml/ 24 horas. Persson et al (2005) também identificaram índices elevados, com $71 \%$ de complicações em 49 colostomizados e 43\%, em 42 ileostomizados. Para Kuijpers (2001), por sua vez, principalmente as dermatites, retrações, prolapsos, estenoses e hérnias ocorreram em 30 a $60 \%$ de seus casos. Essas freqüências foram, no entanto, bastante mais baixas para Ratliff e Donovan (2001) que, em estudo prospectivo com 161 novos pacientes, atendidos após dois meses de cirurgia, identificaram somente 10 (6\%) com complicações (5 urostomizados e 4 ileostomizados). Todos apresentaram retração e a dermatite irritativa foi detectada em 8 pacientes (80\%), dois deles com infecção por Candida albicans.

Em outro estudo retrospectivo, no periodo de três anos, Duchesne et al (2002) encontraram 25\% de 164 pacientes com complicações, $39 \%$ delas já no primeiro mês de pós-operatório. As complicações incluíram necrose (22\%), prolapso (22\%), estenose (17\%), dermatite $(17 \%)$, infecção (15\%), sangramento e retração ( $5 \%$ cada uma). A localização e tipo do estoma bem como o diagnóstico e sexo não apresentaram associação significativa com a ocorrência das complicações, sendo as doenças inflamatórias (odds ratio $=4,49$ ) e a obesidade (odds ratio $=2,66)$, os únicos preditores de risco. O estudo destaca ainda o papel do estomaterapeuta na prevenção dessas complicações (odds ratio $=0,15$ ). 
Mais recentemente, em seguimento prospectivo (até dois anos após a cirurgia) de 408 pacientes consecutivos, Robertson et al (2005) verificaram 10 a 70\% de complicações, algumas das quais piorando com o tempo (hérnias, para colostomizados e ileostomizados, e esvaziamento noturno para os ileostomizados). Os resultados mostraram hérnia ( 0 a $40 \%$, entre colostomizados; e 0 a $22 \%$, entre ileostomizados), retração (8 a 22\%), prolapso (1 a $3 \%$ ) e estenose (1 a $2 \%$ ). As dermatites foram mais freqüentes entre os ileostomizados.

Especificamente voltado para os estomas temporários, o estudo de Bakx et al (2004) menciona complicações em 42\% de 69 pacientes com ileostomia em alça; enquanto Edwards et al (2001) observaram 10 ocorrências ( $\mathrm{n}=70$ pacientes) - hérnias, prolapsos e fistula fecal - apenas entre os pacientes com colostomias de transverso em alça.

Dentre as complicações do estoma, as hérnias e os prolapsos estão entre as mais freqüentes e recorrentes, suscitando o maior número de trabalhos voltados, principalmente, para a melhoria das técnicas de reparação.

Segundo Carne, Robertson e Frizelle (2003), a revisão de literatura mostra que as hérnias ocorrem em 4 a $48,1 \%$ e 0 a 30,8\% das colostomias terminais e em alça, respectivamente; e em 1,8 a 28,3\% e 0,6 a $2 \%$ das ileostomias terminais e em alça, respectivamente. As incidências variam conforme o tempo de seguimento dos pacientes e não foram encontrados fatores técnicos cirúrgicos de prevenção para o seu 
desenvolvimento. Pringle e Swan (2001) verificaram que 20\% de seus pacientes, colostomizados operados de câncer retal, desenvolveram hérnias para-estomais, após 1 ano de seguimento.

Essas condições tornam o reparo das hérnias para estomais como um verdadeiro desafio para o cirurgião frente às necessidades cosméticas, de auto cuidado e, às vezes, de urgência (nos casos de encarceramento ou estrangulação) e que exigem sua correção (Le Blanc et al 2005). Por outro lado, a abordagem cirúrgica controversa e a presença de resultados desapontadores - com taxas gerais de recorrências, em torno dos 45\% - pioram o desafio (Cheung, Chia e Chiu 2001). Nesse sentido, os estudos propõem como alternativas: o reparo fascial, com ou sem reforço com tela com ou sem re-alocação do estoma - conforme o tamanho da hérnia (Cheung, Chia e Chiu 2001); o emprego de tela, com ou sem variantes técnicas (Amin et al 2001; Kasperk et al 2002; Jänes, Cengiz e Israelsson 2004; Longman e Thomson 2005; Le Blanc et al 2005); e variações sem o uso da tela, por complicações (Aldridge e Simson 2001; Saclarides, Hsu e Quiros 2004).

Com tema menos freqüente, dois estudos acerca da correção ou redução dos prolapsos sugerem sutura mecânica (Maeda et al 2004) ou hialuronidase (Chaudhuri e Prasai 2003), respectivamente.

Poucos estudos mencionam as complicações dos estomas urinários, cada vez menos confeccionados. Das duas publicações encontradas, desde 2001, em uma delas (Mirhashemi et al 2004) os autores 
comentam sobre a avaliação retrospectiva dos resultados da Bolsa de Miami - derivação urinária continente - realizada em 77 pacientes, em até seis semanas de seguimento. Com elevada mortalidade peri-operatória $(11,7 \%)$, $5 \%$ dos pacientes desenvolveram complicações diretamente relacionadas ao reservatório, principalmente fistulas. No segundo estudo, Alonso Gracia et al (2004) constataram, precocemente, necrose isquêmica (7\%) e, tardiamente, dermatite (18\%), hérnia (12\%), estenose $(9 \%)$ e granuloma $(6 \%)$

Finalmente, outras publicações tratam de ocorrências menos freqüentes, relacionadas muito mais às doenças causais do estoma do que propriamente às suas complicações. Desse modo, encontram-se um estudo de caso sobre o pioderma gangrenoso periestoma (Mancini, Floyd e Solla 2002) e outro, retrospectivo, acerca da recorrência da Doença de Crohn no estoma ou no íleo pré-estoma, exigindo re-operações (Ecker et al 2001). Além desses, três outros estudos referem-se à presença, também rara, de adenocarcinoma no estoma, seja colostomia (Shibuya et al 2002) ou ileostomia (Achneck et al 2005; Agabiti et al 2005), precoce ou tardiamente, após câncer retal e Retocolite Ulcerativa Inespecífica, respectivamente.

\section{Controle das eliminações em estomizados}

Uma vez que a preservação esfincteriana é uma das metas mais importantes no tratamento das doenças colorretais e urinárias, oncológicas ou não - conforme mencionado no Capítulo 2 - e visto que ela nem sempre é possivel, os autores têm desenvolvido, desde a década de 20 e 
principalmente nos últimos 30 anos, métodos para a obtenção da continência ou, minimamente, do controle dos próprios estomas. Embora nem sempre essas alternativas consigam solucionar definitivamente o problema da incontinência nessa clientela e à luz do conceito de Koch para incontinência como "o controle voluntário e domínio do momento da eliminação", esses estudos têm gerado recursos para reduzir ou abrandar o impacto do estoma na vida das pessoas.

Os procedimentos que objetivam o controle das exonerações, intestinais ou urinárias, em estomizados incluem os não cirúrgicos e os cirúrgicos.

A. Os procedimentos não cirúrgicos constituem parte das intervenções cuidativas em Estomaterapia e, para os estomas intestinais incluem o método natural - dieta obstipante associada ou não a medicamentos; a irrigação da colostomia e o sistema oclusor de colostomia.

A facilidade de uso desses métodos e do treinamento dos estomizados, os custos relativamente baixos, a inexistência de procedimento invasivo e a efetividade que têm demonstrado no que tange ao controle das exonerações intestinais em colostomizados, com poucas desvantagens e limitações, tornam tais procedimentos, principalmente os dois últimos, fundamentais no processo de reabilitação da clientela, em busca da melhor qualidade de vida possivel. 
Essa motivação orientou parte das nossas publicações (Quadro 4), incluindo o desenvolvimento da dissertação de mestrado. 


\section{Quadro 4 - Publicações acerca da irrigação e sistema oclusor de colostomia, no periodo 1984 a 2000.}

1. Santos VLCG. Estudo sobre o método de irrigação intestinal em colostomizados. [Nota prévia] Rev Esc Enf USP 1984; 18(1):93-94.

2. Santos VLCG. Relato da experiência no treinamento da irrigação intestinal de uma paciente colostomizada. Rev Paul Enf 1985; 5(2): 73-75.

3. Habr-Gama A, Santos VLCG, Sousa Jr AHS, Oya T, Pinotti HW. Importância do método de irrigação para o colostomizado. [Editorial] Rev Bras Coloproctol 1989; 9(2):49-51.

4. Santos VLCG. Estudo sobre os resultados da irrigação em colostomizados submetidos a um processo de treinamento sistematizado. [dissertação]. São Paulo (SP): Escola de Enfermagem/ USP; 1989.

5. Santos VLCG, Koizumi MS. Processo de auto - irrigação em colostomizados: avaliação de resultados. [Resumo] ABCD Arq Bras Cir Dig 1990; 5(2): 11-11.

6. Habr-Gama A, Santos VLCG, Sousa Jr AHS. Importance of the bowel irriogation method for the colostomized patient. [Editorial] ABCD Arq Bras Cir Dig 1991; 6(2): 31-32.

7. Santos VLCG, Koizumi MS. Sentimentos e sugestões manifestados por colostomizados que se auto-irrigam. Rev Esc Enf USP 1992a; 26(2):161-172.

8. Santos VLCG, Koizumi MS. Estudo sobre os resultados da irrigação em colostomizados submetidos a um processo de treinamento sistematizado. Rev Esc Enf USP 1992b; 26(3):302-314

9. Santos VLCG, Habr-Gama A, Ribeiro AM, Roncaratti E, Sousa Jr AHS. Utilização do sistema oclusor de colostomia: resultados preliminares. [Resumo] Rev Bras Coloproctol 1992; 12 supl1: 59-59.

10. Santos VLCG, Habr-Gama A, Ribeiro AM, Nishida CSI, Roncaratti E, Sousa Jr AHS, Pinotti HW. Usage of colostomy plug system: preliminary results. ABCD Arq Bras Cir Dig 1993; 8(1): 16-21.

11. Santos VLCG, Cezareti IUR, Ribeiro AM, Filippin MJ, Lima SRS. Métodos de controle do hábito intestinal em estomizados: auto-irrigação e sistema oclusor. In: Crema E, Silva R (org) Estomas: uma abordagem interdisciplinar. 1ed. Uberaba: Editora Pinti; 1997. p.145-162.

12. Silva ED, Arruda MEM, Martins SS, Santos VLCG. Colostomia e irrigação: significados psicológicos atribuídos por colostomizados. Rev Esc Enf USP 1999; 33 n esp: 55-62. 
13. Santos VLCG, Cesaretti IUR, Ribeiro AM. Métodos de "controle" intestinal em ostomizados: auto-irrigação e sistema oclusor. In: Santos VLCG, Cesaretti IUR. Assistência em estomaterapia: cuidando do ostomizado. 1ed. São Paulo: Atheneu; 2000. Pp. 245-262.

O Quadro 4 mostra 13 publicações, entre artigos na integra e resumos, além da dissertação de mestrado, dois capitulos de livros e dois editoriais, nove dos quais exclusivamente sobre a irrigação da colostomia.

Embora as publicações sobre a irrigação da colostomia datem de 1927 (Santos 1989; Santos et al 1997; Santos et al 2000), não se conhece quando esse método foi introduzido no Brasil. Apesar de reconhecer-se que ele já era empregado nos anos 70, tratava-se de iniciativa pessoal de alguns coloproctologistas com especialização, estágios ou visitas técnicas nos EUA, país em que o método surgiu e nunca foi abandonado. A falta de publicações brasileiras sobre o tema na época, quer seja em revistas médicas ou de enfermagem, leva a crer que, de fato, fomos responsáveis por sua introdução, pelo menos de maneira sistematizada, em nosso meio.

Nesse sentido, encontram-se os primeiros artigos, desde uma nota prévia (Santos 1984) - futuro tema de nossa dissertação de mestrado de um relato da experiência inicial com o método (Santos 1985) aos seus resultados propriamente ditos, no final dos anos 80 e início dos 90 (Santos 1989; Habr-Gama et al 1989; Santos e Koizumi 1990, 1992a, 1992b; HabrGama, Santos e Sousa Jr 1991), junto a cujos pacientes, sistematizamos um processo de treinamento, ainda inexistente no país. 
Objetivando sistematizar o processo de treinamento da autoirrigação da colostomia em nosso meio, Santos (1989) e Santos e Koizumi (1990, 1992 a, 1992b) constataram que a maioria dos 40 pacientes investigados - treinados pela autora principal - irrigava-se há até um ano $(52,5 \%)$, diariamente $(62,5 \%)$ e pela manhã $(72,5 \%)$, utilizava cerca de $1000 \mathrm{ml}$ de água morna $(57,5 \%)$, em periodo de 40 a 60 minutos para completar o procedimento. Oitenta porcento dos colostomizados apresentaram ausência ou perdas fecais esporádicas entre as irrigações; ausência e redução dos gases (62,5\%) e redução ou abolição do uso do equipamento coletor (70\%). Sentimentos de bem estar, segurança e normalidade foram mencionados pela maioria dos pacientes.

Similarmente a esses resultados, em estudo retrospectivo dos prontuários de 100 pacientes com colostomia definitiva, operados de câncer colorretal, em que foi indicada a irrigação da colostomia, Habr-Gama et al (1989) e Habr-Gama, Santos e Sousa Jr (1991) verificaram que, após um ano de treinamento, $80 \%$ deles não apresentavam dificuldades e o utilizavam regularmente; dois terços irrigavam-se diariamente, usando de 30 a 80 minutos para o procedimento completo. Nos intervalos das irrigações, mais de $80 \%$ dos pacientes não apresentavam perdas fecais ou essas eram esporádicas, dispensando o uso de equipamento coletor a não ser em ocasiões especiais (diarréia ou viagem). A maioria dos estomizados relatou sentimentos positivos frente à irrigação, considerando-o como o melhor método para a solução de seu problema físico. Em seguimento mais tardio, apenas cinco pacientes abandonaram a irrigação devido a complicações no estoma (hérnia e estenose). 
Os aspectos positivos da auto-irrigação da colostomia foram reforçados em um de nossos estudos (Silva et al 1999), que comparou os significados atribuídos à palavra "colostomia", por colostomizados que utilizavam $(n=14)$ e não a irrigação $(n=15)$. Empregando-se a técnica do Diferencial Semântico de Osgood, os colostomizados selecionavam o adjetivo que melhor correspondia às suas opções, entre 21 pares de adjetivos bipolares. Os resultados mostraram que, apesar da palavra "colostomia" ser percebida positivamente por todos os pacientes, sem diferenças entre os grupos, parece que aqueles que se irrigavam atribuíram significados de maior bem estar e normalidade. Além disso, os pacientes que não se irrigavam apresentaram os maiores índices de contradição interna quanto aos fatores valorativo e simplicidade. As autoras sugerem que a irrigação pode ter contribuído para as diferentes percepções.

O processo de treinamento do método da auto-irrigação da colostomia - assim denominado por Santos e Koizumi - além de suas indicações, cuidados, vantagens e desvantagens bem como os principais resultados obtidos em estudos internacionais, encontram-se descritos em dois capítulos de livros (Santos et al 1997; Santos et al 2000), cujas referências também estão no Quadro 4.

Advogando o método, como importante alternativa para o controle das exonerações em pessoas com colostomias e o positivo impacto na qualidade de vida, seja por meio das publicações realizadas seja na educação formal em estomaterapia, certamente contribuímos para sua maior divulgação no país. No entanto, verifica-se que esse método, 
infelizmente, ainda é muito pouco utilizado em nosso meio. Diversos fatores têm contribuído para tal realidade, destacando-se o desconhecimento - não só dos enfermeiros generalistas como dos médicos responsáveis por sua indicação - e a falta de uma política nacional de atenção aos estomizados atualmente em julgamento no Ministério da Saúde - que inclua o procedimento como uma técnica especializada e favoreça os recursos físicos, materiais e humanos necessários para a sua implementação e disseminação.

Visto tratar-se de método consagrado no exterior, principalmente nos EUA, as poucas publicações encontradas versam, principalmente, sobre o uso de soluções alternativas para irrigação, visando a torná-la ainda mais efetiva no controle intestinal. Assim, O`Bichere et al (2001) compararam os resultados da irrigação em 15 colostomizados que utilizaram água morna com e sem o trinitrato gliceril - droga relaxante da musculatura lisa durante 30 sessões consecutivas (15 para cada solução). Ao final, os autores observaram reduções significativas dos tempos de infusão $(p=0,001)$ e total $(p<0,001)$ de irrigação, das perdas fecais nos intervalos $(p=0,02)$ e elevada satisfação dos pacientes com a utilização da solução experimental, porém com muitos efeitos adversos como cólicas e cefaléias (ambos com $\mathrm{p}<0,001$ ), concluindo que novos colonoplégicos devem ser testados.

Similarmente a esse estudo, O`Bichere, Green e Phillips (2004) testaram o uso do polietilenoglicol (PEG) em 41 pacientes randomizados para ambos programas, ou seja, a irrigação com e sem PEG. Trinta e três pacientes completaram o estudo totalizando 352 sessões, com metade para 
cada solução. Os resultados mostraram que a maioria dos pacientes irrigava-se a cada 24 horas (51,5\%), com $1000 \mathrm{ml}(48,5 \%)$ ou $1500 \mathrm{ml}$ $(33,3 \%)$, infundidos em cerca de 6 minutos, independentemente da solução empregada. Houve diferenças estatisticamente significativas quanto ao tempo de esvaziamento $(p=0,01)$, perdas fecais nos intervalos $(p<0,001)$, escore de satisfação $(p<0,001)$ e uso de dispositivos coletores $(p=0,008)$, sempre favoráveis ao PEG, o que o indica como uma possibilidade melhor.

Apenas duas outras publicações versaram especificamente sobre os cuidados relacionados à irrigação. Turnbull (2003) discute a necessidade do estabelecimento de alguns critérios para o atendimento de colostomizados que se irrigam, em residências de enfermagem ou domicílio nos EUA, uma vez que o atendimento é realizado por enfermeiros não especialistas. Dessa maneira, sugere a necessidade de sistematização quanto ao equipamento, treinamento da equipe e documentação clara e específica que gerem resultados fidedignos para compor o panorama nacional. Na única publicação brasileira encontrada, Costa e Maruyama (2004) descrevem um estudo de caso acerca da implementação e avaliação de um plano de ensino para a auto-irrigação da colostomia.

Quanto à oclusão da colostomia, como outro método de controle das exonerações intestinais em colostomizados, exige um sistema tampão feito de espuma de poliuretano, descartável, que permanece no estoma durante períodos variáveis, com limite de 48 horas. Idealizado por Burcharth et al, pesquisadores escandinavos, um primeiro estudo foi publicado na revista Lancet, em 1986 (Burcharth et al, 1986). No Brasil, o 
primeiro estudo foi também desenvolvido por nós e seus resultados foram apresentados durante o $41^{\circ}$ Congresso Brasileiro de Coloproctologia, em 1992 (Santos et al, 1992), sendo publicados no ano seguinte (Santos et al 1993). Utilizado em 15 pacientes colostomizados (7 em uso de irrigação), que atendiam aos critérios de indicação, os resultados foram comparados após processos de treinamento de 3 e 4 semanas, respectivamente para os pacientes com e sem irrigação. Os períodos de utilização variaram conforme o uso ou não da irrigação, sendo de $8 \mathrm{~h}$ a $11 \mathrm{~h} 8 \mathrm{~min}$ e de $3 \mathrm{~h} 47 \mathrm{~min}$ a 7h46min, respectivamente. Obteve-se um período máximo de aplicação de 46 horas para um dos pacientes que se irrigava. Somente $20 \%$ das trocas foram devidas a intercorrências e 17 respostas relacionaram-se a aspectos positivos como segurança e conforto. Alguns aspectos negativos também foram mencionados como "sensação de intestino cheio", perdas fecais e dor. A maioria dos pacientes (12) manifestou a intenção de continuar utilizando o sistema oclusor.

O processo de treinamento desse sistema, suas indicações, cuidados, vantagens e desvantagens bem como os principais resultados obtidos em estudos internacionais, também se encontram descritos nos capítulos (Santos et al 1997; Santos et al 2000) cujas referências estão no Quadro 4.

Utilizado principalmente na Europa, não foram encontradas publicações atuais sobre o sistema oclusor de colostomia. 
B. Dentre os procedimentos cirúrgicos para controle das exonerações em estomizados, encontram-se: as derivações urinárias continentes, realizadas com diversas técnicas cirúrgicas, principalmente em crianças; as ileostomias continentes de Koch, oriunda da urologia e retomada mais recentemente em função dos avanços nas técnicas de construção dos mecanismos valvulares; os neo-esfincteres, musculares e artificiais, também atualmente retomados; oclusores ou obturadores intestinais, do tipo luminal (tampão) ou de balão circunferencial (esfincter) - desenvolvidos em estudos experimentais e publicados como relatos de casos, deram origem aos sistemas oclusores descartáveis; operações que retardam o trânsito intestinal, tais como a implantação de anel muscular no estoma ou as técnicas de angulação e desnervação colônicas, as quais também têm sido acompanhadas de dificuldades técnicas e complicações por infecção, além da necessidade de utilização de enema para estimular a evacuação; e os transplantes intestinais, ainda em caráter experimental.

Embora não incluam atividades especificas da Enfermagem em Estomaterapia, exceto nas fases pré e pós-operatórias, constituem a maioria das publicações encontradas em nossa pesquisa bibliográfica.

Dentre cinco artigos, que tratam da ileostomia continente, três deles são retrospectivos e visam à avaliação dos resultados a médio e longo prazo.

De um total de 133 pacientes, com seguimento superior a seis anos, operados de retocolite ulcerativa ou polipose familiar, com ou sem 
bolsa ileal prévia, a maioria manteve-se continente ao final de períodos variáveis, com morbidade também diversa. Lepistö e Järvinen (2003) obtiveram $71 \%$ de continência total após 29 anos de seguimento, embora o sucesso tenha reduzido conforme o tempo. Para Börjesson, Oresland e Hultén (2004), esse percentual foi de $76,9 \%$; sendo de $90 \%$ para Castillo et al (2005). Em todos os estudos, as taxas de revisões e reconstruções, principalmente valvulares, foram elevadas. Para os autores, apesar desses indices negativos, a presença de resultados funcionais satisfatórios torna a ileostomia continente uma opção viável para o tratamento das doenças mencionadas, principalmente após complicações da bolsa ileal, desde que realizada em pacientes adequadamente selecionados e motivados.

Dois outros estudos propõem mudanças técnicas cirúrgicas, ambas relacionadas ao mecanismo valvular da ileostomia continente - fator de maior complicação a longo prazo - em humanos (Kaiser, Stein e Beart 2002) e em modelo animal (Nessar, Remzi e Wu 2004), com resultados promissores.

No que tange às colostomias, algumas variações técnicas também têm sido testadas para melhorar seu controle, geralmente associadas ao método da irrigação colônica. Assim são os estudos de Lasser et al (2001) colostomia perineal pseudo-continente, usando a técnica de Schmidt, realizada em 40 pacientes, com seguimento de 45 meses; de Zherlov, Bashirov e Krasnoperov (2002) - reservatório pré-colostomia simulador da sensação de evacuação à estimulação do peritôneo parietal por distensão, testado em 17 pacientes; de Hetzer et al (2003) - esfincteroplastia dinâmica 
do reto abdominal ao redor do estoma, em modelo animal; e de Kostov et al (2004) - esfincteroplastia muscular no estoma, também testada em humanos e seguimento de dois anos. Apesar de não se tratar propriamente de estoma perineal, deve-se mencionar o estudo retrospectivo em que Sato et al (2005) avaliaram os resultados de longo termo (> 2 anos) de 19 pacientes submetidos à construção de neo-ânus, a partir de porção do glúteo máximo com anastomose de inervação pudenda, simultaneamente à cirurgia de Miles. Apesar dos bons resultados alcançados, os estudos mencionados são isolados e carecem de mais evidências.

Apenas o estudo de Wedderburn et al (2001) apresenta avaliação retrospectiva de 46 casos, em que foram associados a reconstrução vesical pela técnica de Mitrofanoff, em 58\% dos casos - e o enema anterógrado para obtenção da continência fecal. Ambos procedimentos são bastante empregados principalmente em Pediatria, para tratamento das malformações congênitas urinárias e anorretais.

\section{Equipamentos coletores para estomas}

O equipamento coletor, em suas várias possibilidades - bolsa coletora, acessórios ou adjuvantes, barreiras protetoras, equipamento para irrigação da colostomia, sistema oclusor de colostomia e outros - constitui aspecto fundamental do cuidar em estomaterapia. Em nossa tese de doutorado (Santos 1996), já escreviamos que a bolsa é o fator patognomônico para o estomizado, assim como a insulina o é para o diabético. Ela constitui a extensão de uma parte corporal perdida, mesmo 
que os pacientes nem sempre a utilizem, como para aqueles que se irrigam, por exemplo.

Criada, como componente indispensável, no início do século passado (Santos 2000a), atualmente ela quase “esbarra” na perfeição. Em diferentes estilos, tamanhos, aberturas, com ou sem diversos tipos de barreira protetora de pele, plana ou convexa, aberta ou drenável, tamanho normal ou pediátrico ou neonatal, uma ou duas peças, a bolsa coletora não se apresenta sozinha, dispondo de inúmeros adjuvantes e acessórios.

Apesar disso e de que conste como um dos dez direitos do estomizado (IOA), ela nem sempre é "democrática", isto é, nem sempre é acessivel a todos os que a demandam. Ao tratar-se de material caro, fabricado por grandes companhias multinacionais, ela acaba não se tornando disponivel e acessivel ao estomizado, principalmente nos países menos desenvolvidos os quais, geralmente, também não dispõem de políticas públicas específicas de atenção, abrangentes e inclusivas.

A preocupação com o equipamento coletor acarretou algumas publicações (Quadro 5), já no início de nossas atividades com estomizados. 


\title{
Quadro 5 - Publicações acerca dos equipamentos coletores para estomizados, no período 1986 a 2003.
}

\begin{abstract}
1. Santos VLCG, Silva MAT, Oya T, Gutierrez ECV. Previsão de equipamentos específicos para a assistência a pacientes portadores de estomas intestinais e urinários, no Hospital das Clínicas da Faculdade de Medicina da Universidade de São Paulo. Rev Paul Enf 1986; 6(2): 60-66.
\end{abstract}

2. Santos VLCG. Avaliação do equipamento disponível para ostomizados. Rev Paul Enf 1986; 6(3): 116-119.

3. Batista RF, Schiftane SS, Santos MC, Guimarães RP, Viana RM, Cesaretti IUR, Santos VLCG. Avaliação do equipamento coletor para uso em ostomias na ótica do cliente e enfermeiro. [Resumo] Rev Bras Coloproct 2003b; 23 supl 1: 3939.

4. Batista RF, Santos MC, Schiftane SS, Viana RM, Guimarães RP, Cesaretti IUR, Santos VLCG. Avaliação do equipamento coletor para uso em crianças ostomizadas na ótica do cliente e enfermeiro. [Resumo] Rev Bras Coloproct 2003c; 23 supl 1: 78-78.

Em 1986, publicamos dois artigos (Santos et al 1986; Santos 1986) nos quais buscávamos estabelecer algumas bases teóricas que dessem suporte à futura padronização tanto qualitativa como quantitativa dos equipamentos coletores, à época, ainda bastante restritos em nosso meio. Esses trabalhos, de alguma forma, contribuíram para a descrição dos procedimentos incluídos, posteriormente, nas políticas públicas tanto do Estado de São Paulo, em 1993, como do Ministério da Saúde, mais recentemente, em 2005.

Conforme mencionado no início deste capítulo, os cuidados ou o uso dos equipamentos coletores para estomizados inserem-se dentro dos tópicos que exigem mais evidências científicas, principalmente no que se 
refere a algumas de suas caraterísticas como ser aberta ou fechada, ter ou não barreira protetora e qual tipo de barreira, ter ou não convexidade, tempo de uso em diferentes tipos de estomas entre outras.

Nesse sentido, além da apresentação dos produtos, novos (Davenport e Sica 2003) ou já existentes (Burch e Sica 2004), encontramos apenas um estudo prospectivo, experimental e controlado em que Nielsen et al (2005) objetivaram comparar as alterações na pele provocadas por duas diferentes barreiras protetoras - óxido de zinco e hidrocolóide - em 11 voluntários saudáveis. Enquanto o óxido de zinco acarretou aumento de perda transepidérmica de água, redução do conteúdo de água na pele, aumento da espessura epidérmica, escamas e paraqueratose, como uma dermatite atópica; o hidrocolóide apenas aumentou a perda transepidérmica de água e reduziu o seu conteúdo na pele, sem acarretar alterações epidérmicas. Os autores concluíram que a natureza da barreira desempenha importante papel nas respostas da pele à aplicação repetida desses produtos. Certamente a replicação desse desenho metodológico, utilizando diferentes barreiras, será fundamental para a melhoria das evidências, respeitando-se e avaliando-se as diferenças entre saudáveis e estomizados.

Posicionamento da WOCNS (2006c), acerca do tempo de uso de equipamento coletor intestinal e urinário, também foi encontrado por nós no sítio dessa sociedade. Apesar de ser considerado como possivelmente desatualizado, não sendo estabelecido como consenso ou recomendação, baseia-se em referências atualizadas como uma revisão de literatura, 
publicada no Journal of Clinical Nursing (2005); análise prospectiva de complicações relacionadas ao estoma, publicada no Colorectal Diseases (2005) e auditoria prospectiva acerca dos fatores de risco para as complicações dos estomas, também no Colorectal Diseases (2003). O documento descreve o tempo mínimo aceitável para uso - três dias - e os fatores que interferem nessa manutenção, como consistência e quantidade do efluente; integridade da pele periestoma; características do estoma e da pele; tipo de barreira utilizada; e preferências, atividades, necessidades e recursos financeiros do paciente.

Ao falar-se na indicação e seleção dos equipamentos, a participação do estomaterapeuta, embora reputada como fundamental pelos especialistas, tem sido bastante questionada pelos usuários. O parecer técnico torna-se indispensável também nos processos de planejamento e compra, atendendo à sua função gerencial do cuidar. No entanto, sua validade passa a ser duvidosa quando se baseia somente em opinião, mesmo que formulada a partir da vivência clínica. Nesse sentido, é imprescindível a realização de estudos de avaliação dos equipamentos coletores, embasados em critérios como segurança, aderência, conforto, durabilidade, resistência a odor e ruído, flexibilidade, facilidade de manejo, discrição e disponibilidade, entre outros, devidamente definidos operacionalmente além de consensuados, se possivel, entre os próprios especialistas.

Infelizmente, esses estudos são bastante escassos seja na literatura nacional como internacional. 
Em 2003, realizamos dois estudos objetivando avaliar a percepção sobre os equipamentos coletores na ótica do usuário - adulto e criança - e de enfermeiros, segundo alguns critérios previamente estabelecidos. Para os 102 adultos, que participaram do estudo (Batista et al 2003b), verificamos que houve correlações positivas $(r>0,50)$ e estatisticamente significativas $(p<0,05)$ entre os escores obtidos por ambos grupos, estomizados e enfermeiros, para a maioria dos critérios analisados. Além disso, correlações nesse nível também foram constatadas entre o critério conforto, avaliado pelo paciente, e segurança e aderência, avaliados pelo enfermeiro. Quanto às crianças $(n=52)$, os resultados foram similares. Além das correlações positivas e estatisticamente significativas para a maioria dos critérios, essas também foram observadas entre conforto, percebido pelo usuário, e aderência e durabilidade, avaliadas pelo enfermeiro (Batista et al 2003c).

Alguns desses critérios foram empregados em dois estudos internacionais recentes, que visavam ao teste de novo equipamento (White e Berg 2005) e à comparação de equipamentos similares, já disponíveis, porém de companhias diferentes (Berg e Sidler 2005).

Assim, White e Berg (2005) testaram a performance de um sistema de duas peças, sem anel de acoplamento (Esteem synergy system ${ }^{\circledR}$ da Convatec), por meio da avaliação da facilidade de aplicação e remoção, segurança, conveniência e preferência individual, entre usuários habituais de sistemas de uma peça; e conforto, flexibilidade, segurança e preferências 
individuais entre usuários habituais de sistemas de duas peças. Os autores concluíram que o produto reuniu os atributos de ambos tipos de sistemas.

Já Berg e Seidler (2005), em estudo prospectivo, randomizado e cross over, ao compararem dois sistemas similares de empresas diferentes, avaliaram 17 atributos e 7 critérios finais, dentre os quais conforto, flexibilidade, tempo de uso, facilidade de remoção e performance geral. Apresentando performances distintas quanto aos atributos mais favoráveis para um e outro sistema, os autores concluem sobre a importância deste tipo de estudo para subsidiar o processo de avaliação, seleção e indicação de equipamentos para estomias.

Para finalizar este Capitulo, consideramos interessante incluir dois trabalhos que tratam da avaliação do cuidado, na perspectiva dos pesquisadores (Hodgson, Fuchs e Ayanian 2001) e dos pacientes (Persson et al 2005).

No primeiro estudo, ao considerarem que não são somente os fatores clínicos - como o estágio tumoral - que influenciam o tratamento e seus resultados bem como o prognóstico de pacientes com câncer colorretal, Hodgson, Fuchs e Ayanian (2005) realizaram revisão de literatura sobre o tema. Verificaram associações consistentes entre o nível de especialização dos cirurgiões e o controle tumoral; entre o volume de cirurgias (instituição e médico) e número de colostomias definitivas; idade dos pacientes e tratamento adjuvante pós-operatório; raça e agressividade do tratamento; raça e mortalidade relacionada à doença e nível sócio 
econômico e mortalidade relacionada à doença. Os autores consideram que as variações no tratamento podem ocorrer devido ao conhecimento médico inadequado acerca de diretrizes estabelecidas, às decisões baseadas em fatores clinicos não avaliados ou às preferências dos pacientes. Concluem que um melhor conhecimento e entendimento sobre os mecanismos das associações obtidas, entre as características do provedor e do usuário, podem melhorar a qualidade do cuidado aos pacientes com câncer de cólon e reto, que incluem os estomizados.

No segundo estudo, especificamente voltado para os cuidados com estomizados, Persson et al (2005) aplicaram o questionário previamente validado Quality of care from the patient's perspectives a 42 ileostomizados e 49 colostomizados. A maioria dos pacientes considerou muitos dos aspectos apresentados como insatisfatórios. Um terço dos colostomizados e metade dos ileostomizados estavam insatisfeitos com a informação recebida sobre os resultados dos exames médicos e laboratoriais e proporções maiores de pacientes estavam insatisfeitas com a participação no processo de tomada de decisões em geral bem como na discussão dos problemas sexuais. Apesar de percentuais importantes de complicações relacionadas aos estomas $143 \%$ em colostomizados e $71 \%$ em ileostomizados), essas não acarretaram impacto sobre os resultados da qualidade do cuidado. Os autores concluem que as informações e o aconselhamento, realizados tanto por estomaterapeutas como por cirurgiões, estão deficitários apontando para a necessidade de avaliação contínua e revisão dos padrões de qualidade existentes. 
Ambos estudos indicam fragilidades, sejam institucionais sejam profissionais, que comprometem a qualidade do cuidar e promovem algumas indicações das modificações a serem implementadas em busca da melhoria da satisfação da clientela atendida. 


\section{QUALIDADE DE VIDA DE PESSOAS COM ESTOMAS}

"Poderão cortar todas as flores, mas não poderão deter a primavera!"

(Pablo Neruda)

Historicamente, concepções relativas ao conceito de qualidade de vida estão presentes desde a Antigüidade, embora os termos utilizados não fossem exatamente os mesmos da atualidade (Zhan 1992; Nordenfelt 1994). $\mathrm{Na}$ sociedade moderna, a expressão qualidade de vida teve sua retomada a partir da Segunda Guerra Mundial. Começou a ser utilizada no vocabulário norte-americano ao ser incluída como uma das metas de governo do presidente Lyndon Johnson, para realçar que uma vida boa requer mais do que a afluência de bens materiais (Meeberg 1993). A partir de então, inúmeros pesquisadores, das mais diversas áreas do conhecimento, têm estudado diferentes aspectos do bem-estar e qualidade de vida, contribuindo para uma crescente compreensão dos seus significados e abrangência .

No campo da saúde, a incorporação da qualidade de vida, como um novo objetivo a ser alcançado, resultou de uma percepção crescente

\footnotetext{
*Fragmento do trabalho Quality of life and coping for people with temporary and permanent stomas de Santos, Chaves e Kimura, ainda em julgamento para publicação no WOCN Journal 2006.
} 
entre os profissionais da área, assim como entre o público em geral, de que o fim último da assistência não poderia mais se restringir à cura da doença ou à prorrogação da morte (Nordenfelt 1994). Assistência efetiva e humanizada deveria estar centrada na pessoa, num sentido mais ampliado, mais do que no seu organismo biológico, o que tem implicado na incorporação da qualidade de vida e bem-estar - enquanto conceitos revisitados - no desenvolvimento e avaliação de políticas e programas sociais e de tecnologias em saúde, ao lado de parâmetros tradicionalmente utilizados como os índices de morbi-mortalidade, expectativa de vida e controle dos sintomas.

No que concerne especificamente ao estomizado, o número de estudos tratando desse tema vem aumentando gradativamente nos últimos 15 anos. Apesar disso, até os dias de hoje, as publicações nacionais e internacionais tratam principalmente do impacto da sua problemática sobre a qualidade de vida (Thompson 1990; Martinsson, Josefsson e Ek 1991; Köhler et al 1991; Awad et al 1993; Griffero 1998; Gooszen et al 2000; Carlsson, Berglund e Nordgren 2001; Persson e Hellström 2002; Brown e Randle 2005), com escassa utilização de instrumentos genéricos ou específicos de avaliação. Na década de 80, surgiram os primeiros instrumentos específicos para essa avaliação, como o Quality of Life Index de Padilla e Grant que, embora tenha sido pouco empregado e pouco adaptado para outros idiomas (Winnie 2001), constituiu a base para o desenvolvimento de inúmeras outras escalas; e o Ostomy Adjustment Scale (OAS), desenvolvido por Olbrisch (1983) e já adaptado em algumas culturas como a sueca (Brydolf et al 1994) e a japonesa (Kataoka et al 2003). Mais 
recentemente, Marquis, Marrel e Jambon (2003) publicaram importante estudo prospectivo multicêntrico europeu, em que validaram o Stoma Care QOL Index, resultante do Montreux Study. E em 2004, um novo instrumento - The City of Hope Quality of Life: Ostomy Questionnaire (COH$Q O L)$ - foi publicado por Grant et al (2004), tendo confirmado suas principais propriedades de medida (validade de construto, validade discriminante e confiabilidade). Além desses, em algumas outras publicações, a qualidade de vida tem sido utilizada como indicador de avaliação de intervenções, ainda principalmente relacionadas à área médica, como às técnicas operatórias continentes e incontinentes; ao manuseio da Retocolite Ulcerativa Inespecífica e outras doenças inflamatórias (Probert, Jayanthi e Mayberry 1996; Tan et al 1997; Litle et al 1999; Behrens, Paris e Luttrell 1999; Seidel, Newman e Sharp 2000; Camilleri-Brennan e Steele 2001); dos cânceres colorretal (O`Leary et al 2001) e vesical (Conde Redondo et al 2001) ou do trauma medular (Craven e Etchells 2002); ao desenvolvimento de novos equipamentos coletores (Sanchez-Crisol 1998; Centellas Morral 2000); e à utilização de métodos de controle do hábito intestinal em colostomizados definitivos (Armenta Galán 1999), entre outros.

Essa breve introdução teórica, constante em recente estudo por nós desenvolvido*, possibilita ao leitor compreender a importância que esse tema vem adquirindo nas últimas décadas e como vem sendo tratado não só na área da saúde, em geral, como especificamente na Estomaterapia relacionada ao estomizado. Embora os instrumentos específicos de avaliação sejam escassos e ainda não disponiveis em nosso meio, ou seja, 
ainda não adaptados e validados transculturalmente, o estudo do impacto do estoma na vida dos sujeitos, a reabilitação e algumas variáveis psicossociais correlatas - sexualidade, auto estima, estigma e estratégias de enfrentamento - têm constituído objetos de nossas publicações, desde 1994. Essas encontram-se no Quadro 6.

\section{Quadro 6 - Publicações acerca da qualidade de vida dos estomizados, no período 1994 a 2006.}

1. Nogueira SA, Santos ER, Boccardo LM, Santos VLCG, Miyadahira AMK. Autocuidado do ostomizado: dificuldades percebidas após a alta hospitalar. Rev Esc Enf USP 1994; 28(3): 309-320.

2. Boccardo LM, Nogueira SA, Santos ER, Miyadahira AMK, Santos VLCG. Aspectos da reinserção social do ostomizado. Rev Esc Enf USP 1995; 29(1): 5971.

3. Hashimoto H, Guedes SL, Pereira VC, Santos VLCG, Kimura M, Sousa Jr AHS. O ostomizado e a qualidade de vida: abordagem fundamentada nas dimensões propostas por Flanagan. [Resumo] Rev Bras Colo-Proct 1996; 16 supl 1: 74-74.

4. Andrade V, Ferreira AM, Barco RS, Escorse PR, Santos VLCG. A sexualidade do ostomizado: uma trajetória de transformações. Rev Bras Colo-Proct 1996; 16 supl 1: 74-74.

5. Andrade V, Ferreira AM, Barco RS, Santos VLCG. A sexualidade do ostomizado na visão do parceiro. Rev Paul Enf 1999; 18(1/3): 35-49.

6. Almeida MCS, Santos VLCG. Qualidade de vida de clientes com estomas intestinais definitivos e provisórios. [Resumo] Rev Esc Enf USP 1999; 33 n esp: $88-88$.

7. Aron S, Carrareto R, Prazeres SMJ, Cerqueira APB, Santos VLCG. Selperceptions about having an ostomy: a postoperative analysis. O/W Manage 1999; 45(4): 46-62.

8. Santos VLCG. Representações do corpo e a ostomia. Estigma. In: Santos VLCG, Cesaretti IUR (orgs). Assistência em estomaterapia: cuidando do ostomizado. 1ed. São Paulo: Atheneu; 2000c. p. 89-102. 
9. Santos VLCG, Kimura M. Qualidade de vida e a reabilitação do ostomizado. In: Santos VLCG, Cesaretti IUR (orgs). Assistência em estomaterapia: cuidando do ostomizado. 1ed. São Paulo: Atheneu; 2000. p.453-475.

10. Santos VLCG. The cancer patient: some reflections about the interface between rehabilitation and quality of life. World Counc Enterostom Ther $\mathrm{J}$ 2000d; 20(3):30-38.

11. Michelone APC, Santos VLCG. Qualidade de vida de adultos com câncer colorretal, com e sem ostomia. [Resumo] Rev Bras Colo-Proct 2002; 22 supl 1: 66.

12. Barreire SG, Oliveira OA, Kazama W, Kimura M, Santos VLCG. Qualidade de vida de crianças ostomizadas na ótica das crianças e das mães. J Pediatr 2003; 79(1):55-62.

13. Santos VLCG, Kimura M, Chaves EC. Qualidade de vida e coping de pessoas com ostomias provisórias e definitivas. [Resumo] Rev Bras Colo-Proct 2003a; 23 supl 1: 44-44.

14. Santos VLCG, Kimura M, Chaves EC. Quality of life and coping of people with temporary and permanent stomas. [Abstract] Quality of Life Research 2003b; 12(7): 821-821.

15. Santos VLCG, Oliveira ACB. Qualidade de vida e auto-estima de adultos jovens com ostomias. [Resumo] Rev Bras Colo-Proct 2004; 24 supl 1: 64-64.

16. Michelone APC, Santos VLCG. Qualidade de vida de adultos com câncer colorretal com e sem ostomia. Rev Latin-amer Enf 2004; 12(6): 875-83.

17. Ferreira MCT, Souza DMST, Resende MMC, Santos VLCG, Silva AC. A autoestima de pessoas portadoras de ostomia com o uso de peça íntima com bolso acoplado, para suporte da bolsa coletora. [Resumo] Revista Estima 2005; $3 \mathrm{n}^{\circ}$ esp:32-32.

18. Santos VLCG, Kimura M, Chaves EC. Quality of life and coping of persons with temporary and permanent stomas. WOCN J 2006 (em julgamento).

Assim como os demais autores internacionais, nossos primeiros trabalhos relacionaram-se à problemática do estomizado. Desse modo, em 1994 e 1995, publicamos dois estudos, realizados com alunos de graduação em enfermagem, acerca das dificuldades percebidas pelos pacientes 
estomizados, após a alta hospitalar, relativas ao auto cuidado (Nogueira et al 1994) e à reinserção social mais tardia (Boccardo et al 1995). Realizados com 45 estomizados ambulatoriais, em diferentes fases pós-operatórias, verificou-se que apenas cerca de metade deles (23) recebeu orientações durante a hospitalização, referentes, principalmente, a higiene e troca do equipamento coletor, predominantemente em um dos dois serviços investigados, o qual recebia apenas pacientes atendidos na própria instituição hospitalar. Quanto às dificuldades apresentadas, a maioria das respostas referiu-se à falta de habilidade para o manuseio do estoma e equipamento, principalmente entre os pacientes com até um ano de operados. Problemas associados a higienização do estoma e pele periestoma e do equipamento coletor relacionaram-se mais aos aspectos psicológicos do que propriamente aos físicos, como o medo e a depressão, além de sensações desagradáveis - nojo, dor e odor - respectivamente e independentemente da fase operatória em que se encontravam. Inúmeras dificuldades foram ainda mencionadas quanto à aquisição e custos do equipamento coletor (Nogueira et al 1994). No que tange à reinserção social, a maioria desses pacientes não retornou, total ou parcialmente, às suas atividades prévias - domésticas, de lazer e de trabalho - principalmente por problemas fisicos. A insegurança predominou entre as justificativas para o distanciamento das atividades de lazer e 11 pacientes encontravam-se aposentados ou em licença médica, motivando o afastamento do trabalho (Boccardo et al 1995).

A sexualidade foi um outro aspecto explorado nesse último estudo (Boccardo et al 1995), identificando-se que 31 dentre os 45 
pacientes não retomaram as atividades sexuais após a cirurgia, melhorando de acordo com o tempo de pós-operatório (13, 10 e 8 pacientes, respectivamente, para $<3$ meses, de 3 a 12 meses e $>12$ meses de pósoperatório). Embora novamente predominassem os problemas físicos, como respostas para aqueles que retornaram a essas atividades (parcialmente ou com dificuldades), a vergonha, os problemas com o equipamento coletor e a não aceitação pelo parceiro constituíram outras justificativas importantes. Esses resultados levaram-nos ao desenvolvimento de dois outros estudos, onde a questão da sexualidade foi mais profundamente investigada.

Buscando conhecer os significados da sexualidade e as mudanças e suas causas ocorridas após a confecção de um estoma, 66 estomizados ambulatoriais foram entrevistados. Significando a sexualidade principalmente como ato sexual $(58,1 \%)$, os pacientes mencionaram mudanças, predominantemente negativas, envolvendo comportamentos e sentimentos $(40,8 \%)$ além de ausência ou redução de relações sexuais (59,2\%). Motivadas pelas condições físicas globais para 54,3\% dos estomizados, também ocorreram de maneira independente do período pósoperatório (Andrade et al 1996). Ao investigarmos as percepções de 58 pessoas acerca da sexualidade de seus parceiros estomizados, novamente o ato sexual foi o significado mais freqüentemente atribuído (39\% das respostas). Para eles, 66\% das mudanças referiram-se a ausência ou diminuição das relações sexuais, causadas pelas condições psicológicas desfavoráveis (64\%), com alterações de auto-imagem e auto-estima (Andrade et al 1999), discordante das percepções dos pacientes, nesse aspecto. 
Em nossa pesquisa bibliográfica, encontramos somente dois estudos mais recentes tratando de um dos aspectos da sexualidade - a função sexual - e, ainda, não especificamente do estomizado.

Em um deles, após revisão de literatura acerca da função sexual após ressecção retal, Keating (2004) concluiu que a impotência permanente ocorre em menos de $2 \%$ dos casos após proctocolectomia, restauradora ou com ileostomia, mediante a experiência do cirurgião; porém é superior a $40 \%$ após a amputação de reto e atinge $20 \%$ nos casos de ressecção anterior, ambas para tratamento do câncer retal. Nesse tipo de doença, a idade constituiu importante preditor de disfunção sexual pós-operatória. A disfunção ejaculatória isolada mostrou ser um problema menor nas operações para tratamento de doença benigna. Uma vez que a dissecção anatômica da pelve, com preservação das fibras autonômicas, resulta em previsível redução das taxas de morbidade sexual, o autor recomenda que o cirurgião deve discutir melhor com os pacientes os possiveis efeitos desse tipo de operação sobre a função sexual. Além disso, aponta para a necessidade de futuros estudos que avaliem os efeitos da terapia adjuvante sobre essa função.

No outro estudo Berndtsson, Oresland e Hultén (2004) avaliaram e compararam prospectivamente a sexualidade de pacientes com retocolite ulcerativa inespecífica, antes e um ano após submeterem-se à confecção de bolsa ileal. Na etapa pré-operatória, os pacientes foram divididos em dois grupos conforme tratamento apenas clínico $(n=14)$ ou cirúrgico com colectomia e ileostomia temporária $(n=29)$. A maioria dos pacientes reiniciou 
a atividade sexual até o terceiro mês após a operação. O desejo e excitação sexuais não se modificaram antes e após a cirurgia. Quatro mulheres apresentaram dispareunia na fase pré-operatória e cinco após. Entre os homens, embora a ereção e ejaculação apresentassem normalidade na fase pré-operatória, a ejaculação foi comprometida em três deles após a cirurgia. Entre os pacientes tratados clinicamente antes da cirurgia, 10 deles mostraram-se satisfeitos com a vida sexual antes e após a construção da bolsa ileal. Já, entre aqueles pertencentes ao segundo grupo, houve um aumento de 15 para 22 entre os satisfeitos após a cirurgia. Os autores concluíram que a maioria dos pacientes encontrava-se satisfeito, após a cirurgia, considerando que sua vida sexual normalizou-se consideravelmente, apesar de algumas ocorrências negativas (dispareunia e perda de ejaculação).

Imagem corporal, auto-estima e autoconceito, suas relações com as representações vigentes do corpo e do belo, em nossa sociedade, e o estigma frente ao corpo diferente do estomizado - também relacionados à sexualidade e à qualidade de vida - constituíram alguns dos conceitos por nós explorados (Santos 2000c; Ferreira et al 2005).

Visando ao re-alinhamento da imagem corporal e facilidade no autocuidado, desenvolvemos uma peça íntima com bolso acoplado para uso por estomizados, avaliado por meio de estudo prospectivo. Publicação preliminar com 18 sujeitos mostrou que, após um mês de uso da peça, apesar de não haver alterações significativas no índice de auto-estima medido pela Escala de Sentimento de Auto-Estima de Dela Coleta - essa 
promoveu mais conforto e segurança, facilitou a mobilização e higienização, promoveu maior comodidade no relacionamento sexual e não acarretou alteração na durabilidade da bolsa, segundo as percepções dos pacientes (Ferreira et al 2005).

A imagem corporal foi tema de uma das publicações encontradas na literatura mais recente, na qual Persson e Hellström (2002) - já mencionado antes - entrevistaram nove pacientes estomizados, 6 a 12 semanas após a cirurgia, acerca de seus sentimentos, atitudes e expectativas. Sete temas emergiram de seus discursos: alienação do corpo, imagem corporal alterada, influências na vida sexual e social, esportes e lazer, incerteza e problemas físicos, indicando repercussões negativas importantes - que incluíam dificuldades em lidar com o estoma - apesar de oito deles terem recebido orientação pré-operatória. Tratando ainda de imagem corporal, Tichy (2003) traz contribuição atualizada importante ao descrever o fenômeno da víscera fantasma em pacientes após amputação de reto e colostomia, mencionando não somente as alterações de esquema corporal, como a plasticidade cortical e o problema da má adaptação cortical nesses pacientes.

Em outro estudo, em que o estresse foi avaliado, Tseng et al (2004) aplicaram The Stress of Colostomy Patients Scale a amostra de conveniência de 73 pacientes ambulatoriais. Os autores identificaram cinco estressores mais importantes: problemas urinários, declínio físico, dificuldades para viajar, recorrência da doença e insônia. Outras doenças associadas e cuidadores influenciaram o estresse global desses pacientes. 
Conforme já nos referimos na parte introdutória deste capítulo, a problemática do estomizado - evidentemente também vinculada à sua doença de base - acarreta um impacto negativo sobre a sua qualidade de vida, segundo o que vem sendo reportado por dezenas de autores, nas últimas décadas (apud Santos e Kimura 2000), em recente revisão da literatura de enfermagem realizada por Brown e Randle (2005) e também em nossas publicações (Nogueira et al 1994; Boccardo et al 1995; Andrade et al 1996; Andrade et al 1999; Aron et al 1999). Em nosso meio, no entanto, talvez tenhamos sido as primeiras a avaliar a qualidade de vida dessa clientela, por intermédio de um instrumento de medida, mesmo que genérico (Hashimoto et al 1996).

Nesse estudo, realizado em nível de pós-graduação sensu latu durante o VII Curso de Especialização em Enfermagem em Estomaterapia e ainda sem preocupações com a adaptação transcultural dos instrumentos importados de outras culturas, utilizamos o Índice de Qualidade de Vida de Flanagan, após tradução livre de sua versão genérica. Embora com casuística limitada de 23 estomizados, em atendimento ambulatorial, a qualidade de vida foi inicialmente significada ( $\mathrm{n}=72$ respostas) como bem estar físico e material (34,7\%) e relações com outras pessoas $(27,8 \%)$. Quanto às mudanças após a cirurgia ( $\mathrm{n}=66$ respostas), ocorreram principalmente nas esferas das relações com os outros (31,8\%) particularmente para o relacionamento íntimo (10 respostas), corroborando os nossos achados em estudos anteriores sobre a sexualidade - e de desenvolvimento pessoal e realização $(30,3 \%)$ - particularmente para o autoconceito (10 respostas). Para a qualidade de vida, os escores totais 
foram positivos para 19 estomizados, podendo ser justificados, segundo as autoras, pelo maior tempo de pós-operatório ( $>5$ anos, para a maioria dos pacientes), pela participação em Associações de Estomizados e pela indicação da família como importante fonte de suporte social.

A partir de então, investimos em alguns estudos um pouco mais amplos, sobre a qualidade de vida, ora utilizando casuísticas similares, ou diferentes instrumentos de medida (Almeida e Santos 1999; Santos, Kimura e Chaves 2003a, 2003b e 2006; Michelone e Santos 2002 e 2004) ou abordagens metodológicas distintas (Aron et al 1999); ora associando-a a outras variáveis psicossociais, como auto-estima (Santos e Oliveira 2004; Ferreira et al 2005) e coping (Santos, Kimura e Chaves 2003a, 2003b e 2006).

Ao avaliarmos a qualidade de vida de pessoas com estomas provisórios $(n=15)$ e definitivos $(n=20)$, obtivemos mediana predominantemente superior a 70 e escores médios que variaram de 40,8 (domínio Aspectos Físicos) a 100 (domínios Aspectos Emocionais e Dor) e de 50 (domínio Aspectos Físicos) a 77 (domínio Capacidade Funcional), respectivamente, utilizando The Medical Study 36- item Short- Form Health Survey (SF-36), adaptado e validado em nosso meio. Na comparação entre os grupos, verificou-se diferença estatisticamente significativa apenas para o domínio Vitalidade $(\mathrm{p}=0,0099)$, superior para os estomizados provisórios que também eram significativamente mais jovens. As autoras concluíram que os niveis de qualidade de vida da clientela estudada eram bons, independentemente do caráter do estoma (Almeida e Santos 1999). 
Recentemente, desenvolvemos estudo similar junto a 42 estomizados provisórios e 72 definitivos, usando a versão genérica do Índice de Qualidade de Vida de Ferrans e Powers (IQVFP), também adaptado para a nossa cultura. Neste, não obtivemos diferenças estatisticamente significativas entre os grupos, para os domínios ou para o escore total. Todos os escores foram superiores a 20 pontos, em variação possível de zero a trinta, também indicando tendências positivas de avaliação da qualidade de vida, similarmente à primeira investigação. No entanto, ao analisarmos as estratégias de coping empregadas por essa clientela, identificamos diferenças estatisticamente significativas para confronto $(p=0,011)$, fugaesquiva $(p<0,001)$ e reavaliação positiva $(p=0,027)$, freqüentemente mais utilizadas pelas pessoas com estomas temporários. Visto que houve maior número de correlações significativas entre os domínios do IQVFP principalmente a família - e as estratégias usadas pelos estomizados temporários, as autoras consideraram ocorrerem maiores esforços adaptativos desse grupo para o alcance de melhor qualidade de vida, não somente pela provisoriedade do estoma como pelo menor tempo de sua construção (Santos, Kimura e Chaves 2003a, 2003b e 2006).

Objetivando ainda analisar as diferenças entre as percepções de estomizados provisórios e permanentes, desenvolvemos um estudo de caso prospectivo, sob abordagem qualitativa. Dois pacientes: uma jovem com ileostomia provisória, em primeiro tempo de cirurgia de bolsa ileal, por retocolite ulcerativa inespecífica, e um homem de 52 anos, colostomizado definitivo por câncer de reto, foram acompanhados e entrevistados nos $3^{\circ}$, $5^{\circ}$ e $7^{\circ}$ dias de pós-operatório mediato, ainda durante a hospitalização, e 
após primeiro e terceiro meses, na etapa pós-operatória tardia. Depois de analisados seus depoimentos, identificaram-se quatro categorias: suporte social - principalmente da família e em todas as fases, similar para ambos pacientes; saúde e expectativas de vida - relacionada à cura, principalmente para a pessoa com estoma provisório; sofrimento físico - principalmente nos primeiros dias após a operação; e auto-cuidado - mais evidente para a paciente com estoma temporário. Embora os discursos fossem semelhantes em muitos aspectos, foram marcadamente distintos quanto às expectativas futuras, acarretando maior motivação para a jovem estomizada no processo de reconstrução de vida (Aron et al 1999), muito mais conectada à doença de base do que ao estoma.

Visto que a maioria das pessoas com estomas temporários é constituída de jovens (ver Capítulo 2), interessou-nos não só investigar sua qualidade de vida, mas associá-la à auto-estima. Empregando a Escala para Medida do Sentimento de Auto-Estima (IAE), desenvolvida por Dela Coleta, e o Índice de Qualidade de Vida de Ferrans e Powers (IQVFP), entrevistamos 42 jovens estomizados. Os resultados mostraram escores médios de 12,2 \pm 2,7 para a auto-estima e de $24,4 \pm 3,4$ para a qualidade de vida, indicando valores bastante favoráveis; o mesmo ocorrendo para os domínios do IQVFP, com valores acima de 22 pontos. As duas medidas psicológicas apresentaram correlação apenas moderada entre seus escores totais $(\mathrm{r}=0,46)$. O IAE apresentou correlação, também moderada, com o domínio Saúde-Funcionamento do IQVFP $(\mathrm{r}=0,51)$. Não houve diferenças significativas para a qualidade de vida quando analisados idade, sexo, tipo e temporalidade do estoma. 
As publicações encontradas não se referem especificamente à comparação entre estomizados temporários e definitivos, mas a diferentes tipos de estomas provisórios e, principalmente, à qualidade de vida de pessoas com doenças inflamatórias intestinais, particularmente relacionada à confecção da bolsa ileal.

Silva, Ratnayake e Deen (2003) investigaram a qualidade de vida de 25 pessoas com ileostomias e 25 com colostomias provisórias, entrevistadas, cerca de 8 e 9 semanas após a construção do estoma, por meio de questionário estruturado, cujas questões eram avaliadas em escala visual analógica (0 a $100 \mathrm{~mm}$ ). Embora os autores tenham concluído que o estoma acarreta impacto negativo na qualidade de vida dos estomizados, houve diferenças somente quanto à tolerância ao efluente $(p=0,0020$ e preservação do apetite $(\mathrm{p}=0,002)$, melhores entre ileostomizados comparativamente aos colostomizados.

Em três outros estudos, os autores avaliam a qualidade de vida de pacientes submetidos à bolsa ileal, visando à discussão de suas vantagens e desvantagens, embora usando desenhos metodológicos diferentes. No primeiro, Camilleri-Brennan, Munro e Steele (2003) compararam a qualidade de vida de 19 pacientes com bolsa ileal pareados com indivíduos ileostomizados após panproctocolectomia, todos com retocolite ulcerativa inespecífica. À aplicação da versão 2 do SF-36 e do Inflammatory Bowel Disease Questionnaire, além de questões adicionais sobre a imagem corporal, os autores verificaram que, embora a bolsa ileal tenha se associado significativamente à percepção mais positiva da imagem 
corporal, tanto o número de complicações como o de fases operatórias foram o dobro nesse grupo, enquanto a qualidade de vida foi similar entre ambos grupos.

No segundo estudo, Berndtsson e Oresland (2003) acompanharam 42 pacientes submetidos à confecção da bolsa ileal, antes e um ano após o fechamento da ileostomia temporária. Trinta e um pacientes foram colectomizados e ileostomizados previamente. Para essas avaliações, os autores usaram um instrumento genérico sueco e um específico, além de questões abertas. Os resultados mostraram ausência de diferenças estatisticamente significativas entre as fases pré e pós-operatórias para a qualidade de vida geral, com melhora para a maioria dos fatores específicos investigados para a maioria dos pacientes, apesar da ocorrência de problemas como evacuações noturnas (40\%), lesões perineais intermitentes (51\%) e uso de anti-diarréicos (61\%). No último estudo desta série, Baixauli et al (2004) reforçam o elevado número de complicações decorrentes da cirurgia de bolsa ileal - também confirmado nos estudos anteriores reportando 101 casos em que foram necessárias re-operações por deiscências das anastomoses bolsas ileais - anais, algumas delas crônicas. Ao refazerem as anastomoses, os autores concluíram tratar-se de alternativa válida, mesmo em condições sépticas controladas, uma vez que a satisfação com a cirurgia - 97\% submeter-se-iam novamente, se necessário, e 99\% a recomendariam aos demais - e o nível de qualidade de vida - 8,2 \pm 1,6 para o Cleveland Global Quality of Life Score - reportados pelos pacientes foram elevados. Esses estudos indicam a necessidade de 
discussão com os pacientes para a tomada de decisão acerca da bolsa ileal, como tratamento da retocolite ulcerativa, dentre outras condições.

Tratando ainda das preocupações de pacientes com doenças inflamatórias intestinais - que incluem a realização de uma ileostomia Carlsson, Boseaus e Nordgren (2003) estudaram 21 ileostomizados (14 com Doença de Crohn, 6 com retocolite ulcerativa e 1 com diagnóstico indeterminado), utilizando os instrumentos Inflammatory Bowel Disease Patient Concerns, SF-36 e Jalowiec Coping Scale. Empregando principalmente o estilo confontativo de enfrentamento (similarmente aos resultados por nós obtidos em Santos, Kimura e Chaves 2003a, 2003b e 2006), os pacientes mostraram baixos escores de qualidade de vida e vitalidade reduzida, comparativamente ao grupo controle. As maiores preocupações relacionaram-se a intimidade, atratividade, sentimentos sobre o corpo, perda de orientação e performance sexuais (também apontadas, anteriormente, em nossos estudos: Boccardo et al 1995; Andrade et al 1996; Andrade et al 1999; Santos 2000c); acesso aos serviços de saúde; nivel de energia; odor e constituir sobrecarga aos demais.

No que se refere especificamente aos pacientes com câncer colorretal - embora inseridos em nossos estudos anteriores - em 2000, publicamos um artigo no qual estabelecemos algumas relações entre a reabilitação e a qualidade de vida dessas pessoas. Explorando os significados negativos do câncer na sociedade moderna, descrevemos os sentimentos positivos direcionados à re-construção e re-definição da vida para o, assim denominado, "sobrevivente", em busca do melhor nível de 
qualidade de vida possivel. Apontamos o papel do enfermeiro na potencialização das capacidades remanescentes e das estratégias de enfrentamento para o alcance desses objetivos, exemplificando-o nas atividades específicas do estomaterapeuta frente ao estomizado (Santos 2000d).

Além desse, orientamos uma dissertação de mestrado acerca da qualidade de vida de 48 pacientes sobreviventes de câncer colorretal na região de Marília, com $(n=17)$ e sem estomia $(n=31)$. Os grupos mostraramse homogêneos para a maioria das variáveis sócio-demográficas e clínicas, diferindo apenas quanto à religião e retorno ao trabalho (esta última menos freqüente entre os pacientes com estoma). Empregando o instrumento World Health Organization Quality of Life - Bref (WHOQOL-bref), obtivemos escores que também foram indicativos de boa e muito boa qualidade de vida, sem diferenças estatisticamente significativas entre aqueles com e sem estoma, apesar de levemente menores entre os estomizados. Diferenças estatisticamente significativas indicaram que católicos estomizados apresentaram melhor qualidade de vida, no domínio físico $(p=0,02)$; e pessoas sem estoma que voltaram ao trabalho, no domínio relações sociais $(p=0,04)$ (Michelone e Santos 2002, 2004).

Revisão Cochrane sobre a qualidade de vida de pacientes com e sem colostomia permanente após ressecção retal, efetuada por Pachler e Wille-Jorgensen (2006), incluiu 11 estudos não randomizados - totalizando 1412 pacientes. Em seis ensaios clínicos, verificou-se que os estomizados não possuíam qualidade de vida pior que os demais; em um outro, o estoma 
afetava levemente a qualidade de vida e nos quatro estudos restantes, os indivíduos com amputação de reto apresentavam pior nivel de qualidade de vida. Os autores concluíram que não há evidências suficientes de que a ressecção anterior é superior à amputação de reto, exigindo-se estudos mais amplos, prospectivos e com melhor desenho metodológico.

Essa revisão mostra que a necessidade do estoma, principalmente de caráter definitivo, no tratamento do câncer, particularmente retal, é presente em inúmeros trabalhos, inclusive aqueles por nós levantados no período dos últimos cinco anos. Desse modo, Szczepkowski (2002) verificou significativa deterioração da qualidade de vida, tanto em pacientes com como naqueles sem estoma permanente, apesar das boas condições gerais de saúde (60\% dos casos), quando as evacuações são freqüentes e irregulares além da presença de diarréia. Disfunção social relacionada à relutância em reassumir as atividades profissionais prévias, às limitações nos relacionamentos também sexuais e às alterações nos padrões de sono e lazer, adotando estilos mais passivos e que exijam menor número de pessoas, ocorre em ambos grupos, principalmente entre os estomizados. Similarmente às conclusões estabelecidas na revisão Cochrane, o autor também indica a necessidade de novos estudos que permitam estabelecer critérios mais claros para o tratamento mais adequado de pacientes com câncer colorretal.

Para os tumores de reto médio e inferior, em que a ressecção anterior é mais baixa e geralmente demanda a confecção de estoma temporário - tópico bastante discutido no Capítulo 2 - em estudo 
prospectivo longitudinal utilizando o SF-36, O`Leary et al (2001) concluíram que a presença do estoma piorou alguns aspectos da qualidade de vida e aumentou o tempo de hospitalização, recomendando o seu fechamento precoce como prioridade.

$\mathrm{Na}$ linha da investigação acerca da preservação esfincteriana em tumores do reto inferior - também já comentada no Capítulo 2 - Bretagnol et al (2004) avaliaram os resultados funcionais e oncológicos e seu impacto na qualidade de vida de 77 pacientes não estomizados, 37 dos quais com anastomose colo-anal convencional e 40 com ressecção inter-esfincteriana. Embora sem diferenças quanto à qualidade de vida - avaliada por meio do SF 36 - os pacientes submetidos à técnica experimental apresentaram pior indice de incontinência anal $(\mathrm{p}<0,001)$, necessitando maior quantidade de anti-diarréicos $(\mathrm{p}=0,04)$.

Interessante estudo farmacoeconômico foi desenvolvido por Solomon et al (2003), que avaliaram e compararam as opiniões de 100 pacientes operados, 43 cirurgiões colorretais e 103 oncologistas frente a quatro cenários hipotéticos de tratamento para o câncer colorretal. Os resultados mostraram que os pacientes negociavam a sobrevivência como medida de qualidade de vida, em todos os cenários apresentados, nem sempre equivalentes às opiniões dos médicos. Diferentemente desses, os pacientes preferiam o estoma permanente à quimioterapia. O estudo mostra o quanto é fundamental a participação dos pacientes na tomada de decisões acerca de seu tratamento - panorama nem sempre real em nosso meio. 
Algumas outras publicações encontradas sobre a qualidade de vida em pessoas com estomias referem-se a condições clínicas diversas como estoma continente, Síndrome do Intestino Curto, Exenteração Pélvica, Trauma Raquimedular e trauma colônico; ou ainda em situação religiosa como a muçulmana.

Em seguimento tardio (média de 31 anos) de 68 pacientes com ileostomia continente, Berndtsson et al (2004) constataram que, apesar da necessidade de revisões cirúrgicas para restaurar a continência, os estomizados apresentaram-se satisfeitos e com nível de qualidade de vida (SF - 36) similar à população geral. Além disso, os estomas mostraram boa durabilidade e com função satisfatória.

Ao analisarem os depoimentos de seis pacientes estomizados com Síndrome do Intestino Curto, acarretada por Doença de Crohn há cerca de 25 anos, Carlsson, Berglund e Nordgren (2001) verificaram que a capacidade limitada para agir espontaneamente, decorrente da necessidade de planejar todas as atividades de vida diária, constituiu o aspecto mais importante. Metade dos pacientes não aceitava a estomia e a fadiga influenciava negativamente as atividades sociais inclusive o lazer. Mesmo assim, metade retomou o estilo de vida prévio e metade trabalhava meio período, o que se mostrou favorável para a melhoria da qualidade de vida. As autoras recomendam o uso de instrumentos objetivos de medida da qualidade de vida e investigação das necessidades de coping dessa clientela. 
Revisão de literatura sobre as conseqüências da cirurgia para exenteração pélvica indica que embora esses pacientes sejam acometidos de ansiedade, depressão, alterações de auto-imagem, disfunções sexuais, isolamento e distúrbios sociais, o impacto psicossocial não é tão devastador quanto se esperava. De qualquer maneira, os poucos estudos existentes não permitem conclusões definitivas (Turns 2001).

Em nossa pesquisa bibliográfica, encontramos três publicações que tratam do impacto do estoma em pacientes com Trauma Raquimedular. Todos os autores concluíram que a colostomia eletiva, apesar da morbidade que lhe é inerente - discutida no Capitulo 3 - foi bem aceita, segura, efetiva, reduziu significativamente o tempo de cuidado intestinal e melhorou a qualidade de vida dos pacientes investigados $(n=71)$, devendo ser considerada precocemente para a disfunção intestinal crônica dessa clientela (Randell et al 2001; Rosito et al 2002; Branagan, Tromans e Finnis 2003).

Bondarevs`kyi (2001), por sua vez, em relato do seguimento de 98 pacientes com colostomia, após trauma colônico, menciona que a localização do estoma, a falha técnica em sua construção, o equipamento inadequado e o seguimento inadequado influenciaram negativamente a qualidade de vida. Reforça que o aconselhamento especializado resultou em estabilização dos níveis de qualidade de vida, em torno do $3^{\circ}$ e $4^{\circ}$ meses de pós-operatório. Embora esse fato pareça estar consumado nos países desenvolvidos e nos quais existem políticas de atenção especializada, essa ainda não constitui realidade em países como a Ucrânia - onde o estudo foi 
realizado - e o nosso - principalmente nos estados do nordeste, norte e centro-oeste - dentre outros da América Latina.

Finalizando esta seqüência, no único estudo que discute a questão religiosa e a presença do estoma definitivo, Kuzu et al (2002) compararam a qualidade de vida de 178 pacientes muçulmanos, distribuídos em três grupos conforme o procedimento cirúrgico empregado para o tratamento do câncer retal: amputação de reto $(n=75)$, ressecção com preservação esfincteriana $(n=51)$ e ressecção anterior $(n=52)$. Usando o SF36, os autores constataram que todos os escores foram significativamente menores para os pacientes estomizados $(p<0,001)$, sendo os itens vida social e trabalho significativamente piores $(p<0,001)$, quando comparados aos pacientes dos demais grupos. Além desses, dois importantes aspectos religiosos apresentaram-se comprometidos nesse grupo: orações diárias (individuais ou na mesquita) e jejum durante o Ramadan. Frente a esses achados, os autores recomendam que esses aspectos sejam discutidos previamente com os pacientes, além do necessário aconselhamento religioso com autoridades locais.

Dois trabalhos por nós desenvolvidos resultaram de incursões na Pediatria, que não constitui nossa área de atuação, motivadas pela escassez absoluta de trabalhos sobre a qualidade de vida de crianças com estomas. No único estudo publicado, avaliamos e comparamos a qualidade de vida de 20 crianças estomizadas, de acordo com a sua percepção e a de suas mães. Aplicando o Autoquestionnaire Qualité de Vie Enfant Imagé (AUQEI), adaptado e validado para o Brasil, obtivemos escores totais de 51,95 \pm 7,9 e 
$49,6 \pm 5,6$, atribuídos respectivamente pelas crianças e por suas mães, sem diferenças significativas entre si e superiores à nota de corte em crianças saudáveis (48). Analisando-se os fatores componentes da escala, o lazer e a família foram os fatores mais importantes para a melhor qualidade de vida e a autonomia o mais comprometido, na avaliação das crianças. Família, autonomia e funções foram percebidas pelas mães como fatores para a melhor qualidade de vida de seus filhos. Crianças com menor escolaridade apresentaram pior qualidade de vida $(\mathrm{r}=-0,63 ; \mathrm{p}<0,05)$.

O segundo estudo, que não consta do Quadro 6, refere-se à avaliação da qualidade de vida de 33 crianças com urostomias continentes, por intermédio do AUQEI. Os resultados também mostraram escores totais positivos para as crianças estomizadas $(53,1 \pm 6,6)$ e sem diferença significativa quando comparados com aqueles obtidos por crianças saudáveis $(n=27)$ da população geral $(53,5 \pm 7,3)$. Similarmente ao estudo anterior, tendências de felicidade com a vida também foram obtidas nos fatores da escala, para ambos grupos. (Souza e Santos 2004). Na pesquisa bibliográfica, não foram encontradas publicações indexadas sobre a qualidade de vida de crianças estomizadas.

Ao encerrarmos este Capítulo, apresentamos alguns estudos que tratam de aspectos especiais do cuidar - voltados para a melhoria da qualidade de vida - não mencionados até então.

Black e Hyde (2002) reportam dois casos em que discutem como os pais podem abordar as crianças acerca do diagnóstico de câncer retal 
nos pais e a possibilidade de aquisição de uma colostomia permanente. Uma das mesmas autoras (Black 2004), em outro artigo, descreve a influência positiva do suporte social promovido pelas Associações de Estomizados, em todas as etapas operatórias, bem como do cuidado específico de enfermagem, uma vez fundamentado no conhecimento da problemática dessa clientela em todos os domínios da vida.

E Cheung, Molassiotis e Chang (2001) expõem os resultados do uso de um programa de técnicas de relaxamento muscular progressivo e o seu impacto nos níveis de ansiedade e de qualidade de vida. Utilizando o Chinese State-Trait Anxiety Inventory, o Quality of Life Index for Colostomy e a versão chinesa do $W H O Q O L$, os autores verificaram que o relaxamento reduziu significativamente o nível de ansiedade e melhorou a qualidade de vida geral, com diferenças significativas para a saúde física, independência e percepção geral de qualidade de vida, superiores entre os indivíduos do grupo experimental. Embora não tenham ocorrido diferenças para a qualidade de vida específica, entre os grupos controle e experimental, e a casuística do estudo seja pequena $(n=18)$, o relaxamento pode ser utilizado para reduzir a ansiedade e melhorar a qualidade de vida em estomizados.

Finalmente, dois últimos artigos discutem a importância do cuidar especializado para a melhoria da qualidade de vida de pessoas com estomias. Marquis, Marrel e Jambon (2003) - em estudo já citado aplicaram o Stoma Care Quality of Life Index em 4739 pacientes de 16 países europeus, durante a hospitalização e aos $3^{\circ}, 6^{\circ}, 9^{\circ}$ e $12^{\circ}$ meses depois da cirurgia em que foram estomizados. Apesar dos escores 
melhorarem com o tempo, houve diferença estatisticamente significativa apenas entre o pós-operatório mediato e o $3^{\circ}$ mês $(p<0,001)$. Resultados importantes para a Estomaterapia indicaram que os escores foram significativamente maiores para os pacientes satisfeitos com o cuidado, para aqueles que mantinham bom relacionamento com suas estomaterapeutas e para os que estavam mais confiantes quanto ao equipamento coletor utilizado. Os autores concluíram que o cuidado especializado ministrado por estomaterapeuta é particularmente importante nos primeiros seis meses de pós-operatório.

Também objetivando avaliar a contribuição do estomaterapeuta para a qualidade de vida do estomizado, Karadag et al (2003) conduziram um estudo com 43 pacientes, agrupados conforme o tipo de estoma colostomia $(n=31)$ ou ileostomia $(n=12)$ - e conforme o emprego $(n=16)$ ou não $(n=15)$ da irrigação. Para a avaliação, utilizaram o Digestive Disease Quality of Life 15, antes e três meses após submeterem-se a cuidados especializados. Os autores constataram que todos os escores de qualidade de vida melhoraram significativamente após o programa de cuidados, sendo sempre melhor entre os pacientes que se irrigavam. Esses achados, além de corroborarem os obtidos no estudo anterior, apontam para o papel fundamental do especialista, dentro da equipe de saúde, no estabelecimento e alcance do nível ótimo de qualidade de vida pelo estomizado.

É a educação em estomaterapia, para a formação do estomaterapeuta, que constitui o tema do Capítulo seguinte. 


\section{EDUCAÇÃO EM ESTOMATERAPIA}

"O conhecimento amplia a vida. Conhecer é viver uma realidade que a ignorância impede desfrutar."

(Exegese Logosófica)

Aspectos do cuidar especializado em Estomaterapia foram indicados e discutidos em alguns dos capitulos anteriores, apontando a sua importância desde sob uma abordagem preventiva primária - na prevenção ou diagnóstico precoce dos cânceres, especialmente o colorretal, mas também das causas externas e doenças inflamatórias intestinais secundária e terciária - quando nas fases prévias de pós-operatório às tardias, ambulatoriais e domiciliares. Focalizaram-se também estudos que relacionaram a efetividade do cuidado especializado e o sucesso na reabilitação e alcance de níveis melhores de qualidade de vida pela clientela. Essas considerações levaram ao tema deste Capítulo, qual seja a educação ou formação especializada, particularizada para a Estomaterapia.

A escolha de uma especialidade profissional caracteriza-se como importante momento de transformação pessoal e social, impregnada de simbolismos e significações individuais e coletivas, não constituindo, portanto, uma opção simples. É multidimensional, complexa e plurideterminada por inúmeros fatores pessoais, sociais, filosóficos, políticos e econômicos, dentre outros (Cruz 1998). 
$\mathrm{Na}$ saúde, as profissões também têm caminhado para a especialização do saber e do cuidar, à medida que novos conceitos e tecnologias são desenvolvidos, abrindo-se, como conseqüência, novos campos de atuação e pesquisa.

Visto que a história da Enfermagem está intimamente relacionada à história da Medicina, tem sido muito difícil compreender e conceituar as suas relações, especialmente no que diz respeito à dependência entre ambas profissões (Almeida e Rocha 1986), o que acontece também em relação às especializações.

Em nosso país, após a reforma universitária de 1968, a Medicina passou a preconizar o ensino baseado em sistemas e órgãos isolados do corpo, contribuindo para um modelo de especialidade fragmentado, monopolizado e precocemente gerido na formação acadêmica (Machado 1997). Desse modo, a idéia de expert - aquele que domina uma parte do todo - passou a ser bastante valorizada na sociedade, sustentando o mito da eficácia e racionalidade técnica e tornando-se um sistema de referência, particularmente na área médica.

$\mathrm{Na}$ Enfermagem, embora influenciada pelas especializações médicas, tal escolha não é, no entanto, tão precocemente determinada como na Medicina, o que se justifica pela própria história da profissão.

Essa história mostra que a Enfermagem Moderna decorreu da divisão do trabalho médico. À medida que inúmeras atividades auxiliares - 
como o cuidado - incorporaram-se aos serviços médicos, sobrecarregando o profissional, todo o trabalho direto da assistência ao doente, ou seja, as tarefas ditas manuais, menos nobres e que demandavam menos tempo, passaram a constituir, gradativamente, atribuições da Enfermagem (Almeida e Rocha 1986).

Nessa trajetória profissional da Enfermagem, a década de 70 foi marcada pelas teorias e teoristas que procuravam construir um corpo específico de conhecimentos, caracterizando-se como importante momento de busca do reconhecimento social (Nakamae 1987) e de representação mais positiva da profissão. Esse conhecimento em ascensão e os concomitantes e constantes avanços tecnológicos e científicos, aliados às novas exigências dos usuários e dos serviços de saúde, contribuíram para impulsionar o crescimento e desenvolvimento das especialidades de Enfermagem, as quais encontram, ainda hoje, elementos que as favorecem e as justificam como o custo-efetividade, custo-utilidade e a qualidade dos serviços prestados.

\section{Atualmente existem 29 Sociedades ou Associações de} Especialistas vinculadas à Associação Brasileira de Enfermagem (ABEn) * e/ou à Academia Brasileira de Especialistas em Enfermagem (ABESE) ${ }^{* *}$,

*Disponivel em www.abennacional.org.br, em 10 de março de 2006.

** Disponivel em www.abesenacional.com.br, em 10 de março de 2006. 
dentre as quais encontra-se a SOBEST, representando os interesses da estomaterapia.

Quanto à Estomaterapia, conforme já mencionado (ver Capítulo 1), imputa-se a Norma Gill e Rupert Turnbull o seu estabelecimento, inicialmente por meio da formação de técnicos em estomias - os próprios pacientes - evoluindo para a atualização e reciclagem de profissionais médicos e enfermeiros, principalmente, mas também assistentes sociais e nutricionistas. No Brasil, por exemplo, nossos primeiros "estomaterapeutas" foram o médico Flávio Abby - que participou do curso ministrado por Norma Gill, nos EUA - e a assistente social Maria Célia Borchet - que realizou curso, também com Norma Gill, durante Congresso Brasileiro de Coloproctologia, no Rio Grande do Sul - todos "formados" ainda na década de $70^{* * *}$ (Gill-Thompson 1986).

Somente a partir de 1980, a especialidade tornou-se exclusivamente para enfermeiros o que impulsionou o desenvolvimento de programas cada vez mais complexos, dirigidos a esses profissionais, em nível de pós-graduação sensu latu e, em alguns países como o Japão, até sensu stritu. Em nosso país, a primeira enfermeira estomaterapeuta foi Gelse Mary Zerbetto, titulada em 1980, também nos EUA, em Houston.

*** Gill-Thompson N. Memoirs of Norma Gill-Thompson: South America; 1986 (compilação pessoal) 
Nos anos 90, objetivando a sistematização e padronização desse tipo de educação continuada ao redor do mundo, o Comitê de Educação do WCET estabeleceu critérios que normatizam e direcionam desde a organização e implementação de novos cursos ao seu credenciamento e ao re-credenciamento daqueles pré-existentes, em períodos que variam de dois a quatro anos. Esses vêm sendo revistos e atualizados, sempre em conformidade com as políticas educacionais e legislações nacionais vigentes.

O envolvimento com esse tema, a partir de nosso pioneirismo na implementação do I Curso de Especialização em Enfermagem em Estomaterapia no país, em 1990, fundamentou as publicações apresentadas no Quadro 7.

\section{Quadro 7 - Publicações acerca da qualidade de vida dos estomizados, no periodo 1990 a 2004.}

1. Sousa Jr AHS, Santos VLCG, Habr-Gama A. Curso de Especialização de Enfermagem em Estomaterapia: primeira experiência. [Resumo] Rev. Bras ColoProct 1990; 10 supl1:56-56.

2. Santos VLCG, Sousa Jr AHS. Estomaterapia: uma especialidade que emerge para a enfermagem brasileira. Rev Esc Enf USP 1993; 27(1):9-14.

3. Santos VLCG, Sousa Jr AHS. Trends in the teaching and research of stomal therapy in Brazil. World Conc Enterostom Ther J 1994; 14(4):29-35.

4. Santos VLCG, Sousa Jr AHS. Ensino especializado de estomaterapia no Brasil:1990-1995. [Resumo] Rev. Bras Colo-Proct 1996; 16 supl1:75-75.

5. Santos VLCG, Sawaia BB. A bolsa na mediação "estar ostomizado" - "estar profissional": análise de uma estratégia pedagógica. Rev Latino-am Enf 2000; $8(3): 40-50$. 
6. Santos VLCG, Sawaia BB. The pouch acting as a mediator between "being a person with an ostomy" and "being a professional": analysis of a pedagogical strategy. J WOCN 2001; 28(4): 206-214.

7. Paula MAB, Santos VLCG. The significance of specialization for the enterostomal therapist nurse in Brazil. World Conc Enterostom Ther J 2002; $22(4): 38-41$

8. Paula MAB, Santos VLCG. O significado de ser especialista para o enfermeiro estomaterapeuta. Rev Latino-am Enf 2003; 11(4):474-482.

Dessas publicações, três relacionam-se às experiências preliminares da realização dos cursos de especialização da Escola de Enfermagem da USP-Sousa Jr e Santos (1990) e Santos e Sousa Jr (1993) acerca do primeiro curso, em 1990; e Santos e Sousa Jr (1996) acerca dos cursos no período 1990 a 1995 - e a quarta (Santos e Sousa Jr 1994) trata dos desafios do ensino e pesquisa em estomaterapia no país, para a década.

Nos primeiros artigos (Sousa Jr e Santos 1990; Santos e Sousa Jr 1993; Santos e Sousa Jr 1996), destacam-se o perfil demográfico dos alunos - quanto à diversidade de regiões de origem - e o processo avaliativo - como uma das fontes de inúmeras transformações às quais o programa foi submetido, ainda nos primeiros anos. Ambos aspectos favoreceram, já de início, a despolarização da especialidade através do país - que prossegue até os dias atuais - e a sistematização dos conteúdos teórico-práticos das três áreas da Estomaterapia (estomias, feridas e incontinências) na forma de módulos, a partir de 1996. 
Ao discutirmos as perspectivas do ensino e pesquisa para a especialidade (Santos, Sousa Jr 1994), apresentamos uma revisão das publicações nacionais no período 1979 a 1991, dos resumos de trabalhos apresentados nos congressos de coloproctologia e de enfermagem, no período 1989 a 1992 - ainda não havia os congressos nacionais da SOBEST - e dos projetos de pesquisa desenvolvidos durante os cursos de especialização da EEUSP, no período 1990 a 1993 - não havia ainda outros cursos no país. Dos 105 itens obtidos, constatamos nove trabalhos de pósgraduação sensu stritu, a maioria de mestrado, sendo a primeira datada de 1980. Somente dezoito artigos foram publicados em revistas nacionais indexadas, no período avaliado, gerando média de um artigo ao ano. Desses, apenas três não foram desenvolvidos por enfermeiros e sete deles já o foram por estomaterapeutas, apesar do restrito número de edições dos cursos no Brasil - apenas quatro. Além desses, encontraram-se 29 resumos de trabalhos e 49 projetos de pesquisa - poucos dos quais geraram publicações na íntegra. Esse resultado levou-nos a modificar a exigência, durante os cursos de especialização, para o desenvolvimento de trabalhos completos a partir de 1996. Ressalta-se que grande parte dos estudos versavam sobre a avaliação da clientela e os cuidados especializados.

Em trabalho mais recente (Souza et al 2004), ainda não publicado e já mencionado no Capítulo 1 desta tese, realizamos pesquisa bibliográfica acerca das dissertações e teses em estomaterapia, desenvolvidas no país, no período de 1970 a 2004. Dos 121 estudos encontrados - 106 dissertações de Mestrado, 12 Teses de Doutorado e 3 teses de Livre-Docência - 23,1\% relacionaram-se às estomias. Embora o 
levantamento atual possa ser considerado mais fidedigno, comparativamente ao anterior - principalmente pela melhoria dos bancos de dados existentes e a maior facilidade do acesso por via eletrônica - esses resultados mostram um aumento significativo da produção do conhecimento nessa área. Este fato certamente pode ser atribuído, dentre outros fatores, ao maior número de especialistas, ao maior número de cursos de especialização, à maior motivação para o ingresso de estomaterapeutas nos cursos de pós-graduação em nível de mestrado e doutorado e, enfim, à maior identificação da Estomaterapia, enquanto especialidade que busca as evidências para a sua prática e que se ratifica, paulatinamente, na Enfermagem e Saúde brasileiras, em consonância com a sua presença já internacional.

Dentre as nossas publicações sobre a educação em estomaterapia, destacam-se as duas últimas, ambas publicadas em português e inglês, que se referem à nossa tese de doutorado (Santos e Sawaia 2000 e 2001) e a uma de nossas primeiras orientações de mestrado (Paula e Santos 2002 e 2003).

Utilizando abordagem qualitativa, decidimos estudar os significados do emprego de uma bolsa coletora pelos alunos dos cursos de especialização - estratégia sistematicamente adotada, desde o primeiro curso, em 1990. A análise dos depoimentos de 30 enfermeiros revelou dois grandes eixos discursivos: estar estomizado e estar profissional. Tendo por mediação a bolsa coletora, o aluno do Curso de Especialização em Enfermagem em Estomaterapia vivencia o estar estomizado que se 
manifesta por meio de violações da identidade (auto-estima e imagem corporal) e da qualidade de vida, perpassadas por transformações desde seus papéis às suas relações com o outro (fonte de estigma ou de suporte social). A mobilização de conteúdos simbólicos e afetivos acerca do estar estomizado gera uma crise de significação do estar profissional, até então caracterizado por um cuidar fragmentado. Re-conhecendo o cuidado praticado no passado como um fazer técnico, voltado principalmente para o estoma e bolsa, em um processo transformador, o aluno passa a projetar um cuidar holístico do ser humano que tem uma estomia, incorporando as dimensões afetivas, simbólicas e relacionais (Santos e Sawaia 2000 e 2001).

Os resultados desse estudo mostraram que a estratégia de utilização pontual da bolsa coletora revelou-se pedagógica ao suscitar o sentido e valor individuais, de cada aluno, quanto ao corpo sadio - norma e ao corpo deficiente - desviante - e ao provocar a emergência de conflitos sobre o estar profissional e o estar estomizado. Certamente, as representações sociais - que ancoram não só esses significados mas também os papéis sociais no processo de cuidar em enfermagem e, mais especificamente, em estomaterapia - possibilitaram ao enfermeiro resignificar o seu papel profissional, propondo transformações no cuidar futuro, onde o simbólico e o afetivo são reconhecidos e valorizados, fundamentando a visão de um indivíduo que particulariza, na sua experiência singular, o universal humano (Santos e Sawaia 200 e 2001). Atualmente, esse procedimento é empregado não apenas em alguns dos outros programas de especialização em estomaterapia, ora vigentes no país (Fortaleza, Juiz de Fora, Taubaté, Curitiba), mas também em alguns cursos 
ou serviços, como atividade "sensibilizadora" para alunos de graduação ou membros da equipe de saúde.

Se o estudo anterior trata especificamente da formação do estomaterapeuta, nossa última publicação (Paula e Santos 2002 e 2003) refere-se aos significados de ser especialista, ou seja, de ser estomaterapeuta após a educação formal e atuação no mercado de trabalho específico. Também sob abordagem qualitativa e usando o mesmo referencial teórico das Representações Sociais, identificamos três unidades temáticas, a partir da análise dos discursos de 12 enfermeiros estomaterapeutas: o estomaterapeuta como profissional, como pessoa e junto ao cliente. Verificamos representações principalmente positivas como: valorização e reconhecimento profissionais - oriundas da posição de destaque assumida, da capacidade técnica e do conhecimento e geradoras de realização, satisfação e prazer pessoais; a remuneração - como profissional autônomo; e ascensão profissional, melhoria da qualidade da assistência e segurança do cliente - acarretadas pelas mudanças de comportamento, busca e repasse contínuo do conhecimento. Certamente, houve significações negativas, como a cobrança e a falta de reconhecimento institucional; ou conflituosas como a dualidade enfermeiro generalista $\& / X$ enfermeiro especialista, na prática clínica diária. O estudo revelou, portanto, que existem importantes interfaces entre o ser profissional e o ser pessoal que refletem nas relações e desempenho junto ao cliente e, para o qual, o saber e o cuidado especializado e humanizado representam elementos fundamentais em busca de novos espaços, credibilidade e autonomia. Como importante caminho para a "identificação" do enfermeiro na sociedade, a 
especialização constitui, atualmente, dimensão fundamental do percurso profissional, fato que tem influenciado positivamente a trajetória, particularmente do estomaterapeuta.

Concluindo, verifica-se que embora as especialidades profissionais constituam um fato, trazem, em seu bojo, inúmeros desafios relacionados à maior demanda de consumidores mais conscientes de seus direitos e, portanto, à maior responsabilidade profissional. Paralelamente, as políticas públicas, ao implicarem em seleção de elementos, qualidade do cuidado e custos, colocam os profissionais no centro de um labirinto de dificil saída. Quanto ao desenvolvimento tecnológico constante, se por um lado amplia o campo de atuação do profissional, por outro, pode repercutir negativamente na prática diária, ao passar a ser visto como produto final da assistência, desumanizando-a (Campos 1999). Pode-se afirmar, então, que a verticalização e fragmentação do saber e a visão não holística do ser humano constituem os aspectos primordiais dos conflitos que atingem o especialista, impondo-se a necessidade do estabelecimento de um ponto de equilíbrio entre ambos, que possa garantir uma assistência humanitária e cientificamente adequada.

Nesse panorama, pode-se afirmar que o estomaterapeuta vem construindo a sua existência no tempo, vivendo a tensão entre a utopia que o anima sempre a olhar para cima e para a frente - e a história real que o obriga a buscar mediações, dar passos concretos e olhar atentamente o caminho e sua direção, suas bifurcações, ciladas e oportunidades. Desse modo, está efetivamente escrevendo a sua história, por meio da concretude 
do cuidado cada vez mais especializado pois, afinal "tudo o que existe e vive precisa ser cuidado para continuar a existir e a viver" (Boff 2000). 


\section{POLÍticas PÚBLICAS DE ATENÇÃo AO ESTOMIZAdo}

"Procuremos acender uma vela em vez de amaldiçoar a escuridão!"

(Provérbio chinês)

No Brasil, o Sistema Único de Saúde (SUS) envolve, como principios fundamentais, a garantia de acesso universal à assistência à saúde, a prevenção de doenças, a identificação e redução de riscos e determinantes de agravos, a integralidade e resolutividade (Brasil 1990). Embora vigente há mais de dez anos, inúmeros problemas impedem ou dificultam sua operacionalização, acarretando um perfil de saúde marcado pela presença de doenças e uma clientela cada vez mais dependente de recursos tecnológicos de diagnóstico e tratamento sofisticados e caros, nem sempre acessiveis e disponiveis no sistema que, por sua vez, deve atender a uma demanda cada vez maior (Murai et al 2005).

Quanto às pessoas com necessidades especiais ou deficientes como população também usuária do SUS - alguns movimentos isolados particulares, voltados para sua inserção no panorama nacional, iniciaramse na área educacional a partir do século XIX, refletindo o interesse de alguns educadores inspirados em experiências internacionais. Porém, foi somente em meados do século XX que alguns direitos foram conquistados e 
reconhecidos, como elementos integrantes de algumas políticas sociais, começando a caracterizar a sua inserção nos sistemas gerais de atenção .

Especificamente na saúde, atendimento elementar era desenvolvido em instituições filantrópicas, evoluindo depois para o atendimento de reabilitação, sem assumir, contudo, uma abordagem integradora desse processo e preservando, na maioria dos casos, uma postura assistencialista*.

Efetivamente, foi a Constituição Federal de 1988 que assegurou os direitos das pessoas com deficiências em diferentes campos e aspectos. Em seu artigo 23, Capítulo II, determina que "é competência comum da União, dos Estados, do Distrito Federal e dos Municípios cuidar da saúde e assistência públicas, da proteção e garantia das pessoas portadoras de deficiências". Esses direitos foram posteriormente regulamentados por meio de outros instrumentos legais, entre os quais destacam-se as Leis nos 7.853/89 e 8.080/90 (Lei Orgânica da Saúde), e o Decreto no 3.289/99*.

A Lei $\mathrm{n}^{\circ} 7.853 / 89$ - que dispõe sobre o apoio às pessoas portadoras de deficiências e a sua integração social - no que se refere à saúde, atribui ao setor a promoção de ações preventivas; a criação de uma

Disponivel em http://portal.saude.gov.br/portal/sas/sapd, em 11 de março de 2006.

* Disponível em http:// portal.saude.gov.br, em 11 de março de 2006. 
rede de serviços especializados em reabilitação e habilitação; a garantia de acesso aos estabelecimentos de saúde e do adequado tratamento no seu interior, segundo normas técnicas e padrões apropriados; a garantia de atendimento domiciliar de saúde ao deficiente grave não internado; e o desenvolvimento de programas de saúde voltados para as pessoas portadoras de deficiências, desenvolvidos com a participação da sociedade (art. 2..$^{\circ}$, Inciso II) ${ }^{*}$.

Na Lei Orgânica da Saúde, destacam-se os princípios relativos “à preservação da autonomia das pessoas na defesa de sua integridade fisica e moral", à garantia da universalidade de acesso e à integralidade da assistência (art. $7 .^{\circ}$ Incisos I, II, III e IV) ${ }^{*}$.

Falando especificamente dos conceitos modernos relacionados à deficiência, a Política Nacional de Saúde da Pessoa Portadora de Deficiência (Brasil 2006), adota a Classificação Internacional das Deficiências, Atividades e Participação (CIDDM-2) - versão atualizada da Classificação Internacional de Deficiências, Incapacidades e Desvantagens (CIDID) publicada pela OMS em 1997, que concebe: deficiência como uma perda ou anormalidade de uma parte do corpo (estrutura) ou função corporal (fisiológica), incluindo as funções mentais; atividade, relacionada com o que

\footnotetext{
* Disponível em http://portal.saude.gov.br, em 11 de março de 2006.
} 
as pessoas fazem ou executam em qualquer nivel de complexidade, desde aquelas simples até as habilidades e condutas complexas; e limitação da atividade, antes conceituada como incapacidade, agora entendida como uma dificuldade no desempenho pessoal. Nessa nova abordagem, o termo incapacidade não é mais utilizado porque pode ser entendido e valorizado como desqualificação social.

Esses conceitos marcam evoluções conceitual e filosófica significativas, nos últimos 40 anos. Na década de 60, estabeleceram-se as estreitas relações entre as limitações vivenciadas pelas pessoas deficientes, a concepção e estrutura do meio ambiente e as atitudes da sociedade frente à questão da deficiência (Coordenadoria para Integração da Pessoa Portadora de deficiência - CORDE, 1996). Posteriormente, a Organização Mundial da Saúde publicou o Programa de Ação Mundial para Pessoas com Deficiência, em 1982 - resultante das ações internacionais do Ano Internacional da Pessoa deficiente - e as classificações internacionais CIDID, em 1989 e a CIDDM-2, em 1997. Muito além da integração social, a recente CIDDM-2 pauta-se na perspectiva da inclusão social, entendida "como o processo pelo qual a sociedade se adapta para incluir, em seus sistemas sociais gerais, pessoas com necessidades especiais e, simultaneamente, estas se preparam para assumir seus papéis na sociedade. A inclusão social constitui, então, um processo bilateral no qual as pessoas, ainda excluídas, e a sociedade buscam, em parceria, equacionar problemas, decidir sobre soluções e efetivar a equiparação de oportunidades para todos" (Brasil 2006). Esses eventos contribuíram sobremaneira para o surgimento de politicas internacionais inclusivas das pessoas com 
deficiência ou incapacidade e que também subsidiou a Política Nacional, recém publicada no país.

Do ponto de vista epidemiológico, a OMS estima que cerca de $10 \%$ da população, de qualquer país em tempo de paz, é portadora de algum tipo de deficiência, das quais: $5 \%$ com deficiência mental; $2 \%$ com deficiência física; $1,5 \%$ com deficiência auditiva; $0,5 \%$ com deficiência visual; e $1 \%$ com deficiência múltipla.

No Brasil, segundo o Instituto Brasileiro de Geografia e Estatística (IBGE) ${ }^{*}$, os dados do Censo 2000 mostraram que 24,5 milhões de pessoas apresentavam algum tipo de deficiência física ou mental, equivalendo a $14,5 \%$ da população brasileira. Desses, 5,8\% possuem deficiência física - no levantamento, definida como de locomoção).

Nas últimas décadas, o aumento da expectativa de vida da população brasileira tem feito com que as causas da deficiência sejam cada vez mais relacionadas às doenças crônico-degenerativas, como a hipertensão arterial, o diabetes mellitus, o infarto, os acidentes vásculoencelálicos, a doença de Alzheimer, o câncer, a osteoporose e outros. Urbanização e industrialização crescentes, dissociados dos cuidados de

Disponivel em http://www.ibge.gov.br/home/estatistica/populacao/censo2000, em 11 de março de 2006. 
preservação da vida e do meio ambiente, geram o aumento das incapacidades. Em nosso meio, as principais causas das deficiências são os transtornos congênitos e perinatais (decorrentes da falta de assistência ou assistência inadequada às mulheres na fase reprodutiva); as doenças transmissiveis e crônicas não-transmissiveis; perturbações psiquiátricas; abuso de álcool e de drogas; desnutrição; e os traumas e lesões (principalmente nos centros urbanos mais desenvolvidos, onde são crescentes os índices de violências e de acidentes de trânsito) (Brasil 2006).

A Politica Nacional de Saúde da Pessoa Portadora de Deficiência (Brasil 2006) visa a reabilitar a pessoa portadora de deficiência, na sua capacidade funcional e desempenho humano - de modo a contribuir para a sua inclusão plena, em todas as esferas da vida social - a proteger a saúde dessas pessoas e a prevenir agravos que determinem o aparecimento de deficiências. Para tanto, a Política inclui como diretrizes: a promoção da qualidade de vida das pessoas portadoras de deficiência; a assistência integral à saúde dessas pessoas; a prevenção de deficiências; a ampliação e o fortalecimento dos mecanismos de informação; a organização e o funcionamento dos serviços de atenção e a capacitação de recursos humanos.

A Politica inclui ainda inúmeros direitos, estabelecidos por meio da própria Constituição, em artigos específicos, por novas leis ou por atividades inter-ministeriais, como do Trabalho e da Educação. São eles:

$\checkmark$ acessibilidade (Leis nos $10.048 / 00$ e 10.098/00); 
$\checkmark$ assistência social (Lei Orgânica da Assistência Social no 8742/93);

$\checkmark$ cultura (Programa Arte sem Barreiras);

$\checkmark$ educação ( artigo 208 da Constituição e Lei Diretrizes e Bases da Educação no 9394/96);

$\checkmark$ esporte (Projeto Esporte Especial do Ministério dos Esportes);

$\checkmark$ financiamento e isenções fiscais (Programas Empresariais de Inclusão; Programa de Apoio a Incentivos Sociais de Empresas - PAIS);

$\checkmark$ passe livre (Lei do Passe Livre no 8899/94);

$\checkmark$ saúde e reabilitação (Portaria no 818 de 2001; Política Nacional para a Integração da Pessoa Portadora de Deficiência, decreto no 3298; e Leis 8.686/93 e 9.656/98, acerca de planos privados de saúde);

$\checkmark$ trabalho (Convenção 159 da Organização Internacional do Trabalho - OIT; Lei 9.867/1999 de cooperativas sociais; Constituição Federal, Lei no 8112/90 e artigo 36 do Decreto 3.298/9 acerca da reserva de mercado de trabalho);

$\checkmark$ crimes contra a pessoa com deficiência (Lei 7.853/89). 
Além desse, a Lei 11.133 de 14 de julho de 2005 instituiu o Dia Nacional de Luta da Pessoa Portadora de Deficiência, a ser celebrado em 21 de setembro.

Quanto às Redes Estaduais de Reabilitação Física, disponiveis para o atendimento das pessoas com esse tipo de deficiência, atualmente existem 132 serviços credenciados pelo Ministério da Saúde, em vários níveis de complexidade, adequados aos critérios populacionais e epidemiológicos de cada região (Tabela 1). Esses são classificados em: Ações de Saúde e Reabilitação na Atenção Básica; e Serviços de Saúde e Reabilitação na Média e Alta Complexidade (responsáveis pela reabilitação e fornecimento de órteses, próteses e equipamentos de locomoção).

Tabela 1 - Instituições habilitadas por nivel de complexidade; 2006.

\begin{tabular}{lcccc}
\hline & \multicolumn{3}{c}{ Nivel de Complexidade } & \multirow{2}{*}{ Instituições } \\
Região & Intermunicipa & Intermediário & Referência & \\
\hline Sudeste & 0 & 39 & 31 & 70 \\
Norte & 5 & 8 & 1 & 14 \\
Nordeste & 0 & 14 & 6 & 20 \\
Sul & 0 & 17 & 5 & 22 \\
Centro-Oeste & 0 & 4 & 3 & 7 \\
Total & 5 & 82 & 46 & 133 \\
\hline
\end{tabular}

(Fonte: http://portal.saude.gov.br)

Apesar da elevada prevalência de incapacidades decorrentes das doenças crônico-degenerativas - como as doenças cardiovasculares, a hipertensão arterial, a insuficiência coronária, as doenças do aparelho 
respiratório (enfisema), as doenças metabólicas (diabetes mellitus e nefropatias), as doenças hematológicas (anemia falciforme, hemoglobinopatias, hemofilias), o reumatismo e a hanseníase - elas não são objetos específicos dessa Política Nacional, exigindo portarias específicas.

Embora as pessoas com estomias representem um segmento recentemente classificado como portador de deficiência - "na medida em que a doença prévia resulta em deficiência do sistema excretor, que produz limitações, em várias esferas da vida, tanto social quanto pessoal” (Brasil 2006) - e, portanto, possa enquadrar-se no escopo da clientela abrangida por essa Política Nacional, as suas características exigem legislação específica.

É sobre esse tema que passamos a discorrer, a partir das publicações efetuadas, seja como participante da organização de Serviço de Assistência seja como membro dos comitês que elaboraram as Politicas de Atenção às Pessoas Portadoras de Estomas, tanto ao nível da Secretaria de Saúde do Estado de São Paulo como ao nivel federal, junto ao Ministério da Saúde. 


\section{Quadro 8 - Publicações referentes à organização de Serviços e Políticas Públicas de Atenção ao Estomizado, no periodo 1989 a 2005.}

1. Sousa Jr AHS, Santos VLCG,Mileo LF, Delatorre GA,Nahas P, Pinotti HW, Habr-Gama A. Equipe multiprofissional nocuidado de ostomizados: 164 casos seguidos no Núcleo de Assistência a Ostomizados. [Resumo] Rev Bras Coloproct 1989; 9 supl 1:56-56.

2. Santos VLCG, Sousa Jr AHS, Ribeiro AM, Schnitter MA, Baxter YC, Ferreira SHC, Oliveira DV. Núcleo de Assistência a Ostomizados: um relato de experiência. [Resumo] Rev Med Reab 1991; 1 (29/30):16-16.

3. Secretaria de Estado da Saúde de São Paulo. Proposta Básica para Assistência aos Ostomizados do SUS-SP. São Paulo: Secretaria da Saúde; 1993.

4. Brasil. Ministério da Saúde. Política Nacional de Saúde das Pessoas com Estomas. Brasília: Ministério da Saúde; 2005. (em julgamento)

Iniciando uma experiência, quase pioneira, na organização do Núcleo de Assistência a Ostomizados do Hospital das Clínicas da Faculdade de Medicina da USP - NAO - implantado oficialmente em 1985 (Sousa Jr et al 1989; Santos et al 1991), esse pautava-se na atenção especializada e integral à pessoa estomizada, sob um referencial de trabalho multidisciplinar, nas fases pré e pós-operatórias, imediata, mediata e tardia, incluindo ainda objetivos de ensino e pesquisa. Em 1989, com seguimento de apenas 164 pacientes (Sousa Jr et al 1989), concluíamos que a "observação sistematizada e prospectiva de pacientes com estoma intestinal, em equipe multiprofissional, permite o estabelecimento de medidas reabilitatórias e também propicia a detecção e eventual profilaxia de complicações então passiveis de tratamento precoce”. Dois anos após, com 370 pacientes cadastrados e oriundos principalmente do próprio 
hospital, já contávamos com três estomaterapeutas e publicávamos os resultados das atividades de ensino, relacionadas particularmente ao suporte técnico e estrutural aos Cursos de Especialização da EEUSP. Além disso, cursos de atualização teórica bem como campo para a prática de alunos dos Cursos de Aprimoramento das áreas médica, de enfermagem, serviço social, nutrição e psicologia ampliavam as funções acadêmicas do serviço e o cumprimento adequado da responsabilidade da integração docente-assistencial - política vigente à época (Santos et al 1991).

Visando a uma articulação mais ampla do serviço com a Secretaria de Estado da Saúde de São Paulo e diante de nossa atuação em um modelo adequado de atenção, vários profissionais do NAO passaram a compor a Comissão de Normatização de Assistência aos Ostomizados do SUS-SP, desde 1990 (Resolução SS no 194 de 10 de agosto de 1990, alterada pela Resolução SS no 359 de 16 de setembro de 1991), responsável pelo desenvolvimento da Proposta Básica para Assistência aos Ostomizados do SUS-SP, publicada em 1993 (Secretaria de Estado da Saúde de São Paulo 1993).

Certamente, foram inúmeras as justificativas para o desenvolvimento dessa proposta. Em ambiente propício da implantação do Sistema Único e Descentralizado de Saúde (SUDS), hoje SUS, reconhecia-se haver: assistência centralizada e insuficiente, face ao aumento significativo da demanda de usuários estomizados, além de pouco acessivel, deficiente, não sistematizada e proporcionada por profissionais não qualificados, em ambientes também não adequados; ações isoladas e falta de articulação 
entre os serviços de atenção, públicos e privados, e as associações de estomizados, decorrentes da falta de projetos institucionais mais amplos e da falta de dados epidemiológicos sobre esse tipo de usuário; desmotivação dos profissionais frente às dificuldades e aos recursos humanos e materiais deficitários para o desenvolvimento das atividades assistenciais e educativas, gerando baixa resolutividade e alcance restrito; e elevada incidência de complicações acarretada pela ausência de atenção preventiva, desde a fase pré-operatória, falta de seguimento tardio precoce e acesso insatisfatório a equipamentos coletores também não padronizados (Secretaria de Estado da Saúde de São Paulo 1993).

Tendo-se como premissas básicas: a capacitação de recursos humanos, a padronização dos equipamentos coletores e acessórios (assim denominados nesse momento), a descentralização e regionalização da assistência - sistematizada em todas as fases de tratamento - a racionalização e otimização dos recursos materiais e humanos, a educação da clientela, a garantia de liberação de recursos orçamentários específicos para a aquisição e distribuição de equipamentos coletores - devidamente planejados e gradativamente descentralizados - a proposta incluiu a descrição da atenção aos estomizados, de acordo com os níveis primário, secundário e terciário, vigentes na época (Secretaria de Estado da Saúde de São Paulo 1993).

Ao final, a proposta trouxe em seu bojo três grandes contribuições: a definição de cuidados específicos aos estomizados, em todas as fases operatórias; a padronização descritiva dos equipamentos 
coletores e acessórios disponíveis no mercado nacional e a inclusão do enfermeiro especialista na equipe de saúde mínima para atendimento nos denominados Centros e Pólos de Referência, responsáveis por ministrar os cuidados e técnicas especializados (Secretaria de Estado da Saúde de São Paulo 1993).

Sendo praticamente o primeiro Estado da federação a instituir política pública específica de atenção para o estomizado, tornou-se modelo para alguns outros estados e, mais tarde, para a própria política nacional, principalmente no que se refere ao nível de complexidade do cuidado especializado, em função da presença ou não do estomaterapeuta, bem como à sistematização descritiva dos equipamentos coletores e acessórios (Secretaria de Estado da Saúde de São Paulo 1993).

Implantada desde 1993, a política de assistência aos estomizados no estado de São Paulo sofreu várias modificações, principalmente decorrentes do processo de municipalização - como uma das estratégias de descentralização do SUS - instaurado de maneira distinta nas várias regiões, por razões especialmente de natureza politica. Estabeleceram-se vários Centros e Pólos de Referência, em todo o estado que, no entanto, gradativamente se distanciaram das normas originalmente previstas, dentre as quais a existência de um enfermeiro estomaterapeuta na equipe. Processos de planejamento, compra e distribuição de equipamentos também modificaram-se, tornando-se menos centralizados à medida da gestão plena dos municípios. A cidade de São Paulo, última do estado a municipalizar-se, sofreu as conseqüências desse atraso, persistindo até hoje 
a centralização de tais processos de aquisição para muitos dos serviços que atendem estomizados.

Depois de cerca de 13 anos de lançamento da Proposta Básica de Assistência ao Estomizado no estado de São Paulo, embora ainda ativa em várias regiões, necessita de reavaliação, à luz da reorganização em que se encontra a Secretaria de Estado da Saúde de São Paulo, que visa a resgatar o seu papel de gestora muito mais do que executora dos serviços de saúde. Aspectos como a adequação dos recursos humanos e materiais qualificados; a sistematização de informações epidemiológicas sobre essa clientela; a divulgação para encaminhamento dos usuários junto aos profissionais dos serviços terciários; novas e mais eficazes formas de aquisição dos equipamentos coletores bem como as fontes dos recursos financeiros; fixação dos especialistas nos serviços; educação continuada dos profissionais envolvidos e a ampliação da rede de atenção devem ser discutidos.

Nesse período, desde a implantação do programa no estado de São Paulo - praticamente coincidente com o estabelecimento da Estomaterapia no país - vários estados organizaram-se com programas, estaduais ou municipais, e incrementaram-se o número de cursos de especialização em estomaterapia, o número de especialistas bem como o número de associações de estomizados no país, acarretando o aumento da informação e do conhecimento entre profissionais e clientela e, conseqüentemente, da demanda de usuários e dos serviços. Além disso, houve algum avanço na legislação voltada para as pessoas com deficiências, 
conforme já mencionada antes, com inclusão de aspectos de interesse para as pessoas com estomas. Ressaltam-se a Portaria no 146 , de 14 de outubro de 1993 - que trata das diretrizes gerais para a concessão de órteses e próteses, através da Assistência Ambulatorial, e que incluiu seis itens específicos para estomizados; a Portaria no 116 de 9 de setembro de 1993 que incluiu a concessão de órteses e próteses no Sistema de Informações Ambulatoriais do SUS (SIA-SUS) e incorporou outros cinco itens específicos para estomizados; e a Resolução no 18 de 13 de dezembro de 1994 - que determinou que as secretarias estaduais e municipais elaborassem plano para o financiamento das órteses e próteses (Carvalheira 2000; Cesaretti, Tanaka e Filippin 2000). Certamente, a inclusão dos equipamentos para estomizados nessas portarias e resolução - principalmente por intermédio das ações da Associação Brasileira dos Ostomizados - facilitou a organização e implementação de programas específicos em outras regiões do país bem como favoreceu aqueles já existentes, pelo menos no que tange ao financiamento dos equipamentos coletores e acessórios, já que muito pouco incluíam sobre o cuidar.

De qualquer maneira, tais movimentos sociais e politicos contribuíram para que o Ministério da Saúde, em 2002 e, posteriormente, em 2004 compusesse, respectivamente, duas comissões para a elaboração de uma Política Nacional de Saúde das Pessoas com Estomas, finalizada em 2005 (Brasil 2005) e com perspectivas de publicação ainda no primeiro semestre de 2006. 
Participante de ambas comissões ${ }^{*}$, inicialmente produzimos um documento que acabou não sendo publicado, embora entregue ao governo de transição democrática, no final de 2002. Este foi utilizado como base para os trabalhos da nova comissão ${ }^{* *}$, instituída formalmente pelo Ministério da Saúde, em 2004, congregando membros da Sociedade Brasileira de Estomaterapia (SOBEST) e da Associação Brasileira de Ostomizados (ABRASO), além das componentes da comissão original, para elaboração da Política Nacional.

Envolvendo duas portarias - de Atenção e de Aquisição de equipamentos coletores, adjuvantes e protetores de pele - a Política Nacional de Saúde das Pessoas com Estomas normatiza a estrutura e os recursos humanos, materiais e físicos dos serviços de atenção, em níveis primário, intermediário e de referência, aos estomizados bem como os procedimentos inseridos na assistência a ser prestada nesses serviços, incluindo os equipamentos coletores, adjuvantes e protetores de pele. Apresenta ainda os formulários a serem padronizados, os serviços de saúde

\footnotetext{
Em 2002, a Comissão foi composta pela pesquisadora além da Profa Margarete Knoch Mendonça, da Universidade Federal de Mato Grosso do Sul, e de Sheila Miranda, psicóloga da Coordenadoria de Saúde da Pessoa com Deficiência - CADAIS, do Ministério da Saúde. Contou com financiamento da OPAS.

${ }^{*}$ Membros da Comissão no sítio da SOBEST: www.sobest.org.br
} 
incluídos no atendimento e o programa para capacitação dos profissionais das unidades de atenção primária ${ }^{* * *}$.

Neste momento, a Política encontra-se sob avaliação no Ministério da Saúde, para estudo do conseqüente impacto econômico bem como para os devidos ajustes à formatação de documentos públicos. Espera-se que possa ser publicada ainda no primeiro semestre de 2006.

Ao considerar-se que a situação da assistência à pessoa deficiente, no Brasil, é ainda bastante frágil, desarticulada e descontínua em suas ações, nas esferas pública e privada, e que, no âmbito assistencial, a maioria dos programas é bastante centralizada, atende a um reduzido número de pessoas, não contempla experiências comunitárias e não dispõe de resultados de avaliação - segundo a própria Política Nacional de Saúde da Pessoa Portadora de Deficiência (Brasil 2006) - a elaboração de uma política específica ao estomizado, de caráter nacional, parece constituir um avanço importante nessa área, não somente para o país mas já projetandose para a América Latina em geral, onde esses modelos não existem.

*** Disponivel em www.sobest.org.br, em 11 de março de 2006. 


\title{
PERSPECTIVAS DO ENSINO, PESQUISA E ASSISTÊNCIA EM ESTOMATERAPIA
}

\begin{abstract}
"Não existe arte maior nem mais benéfica para a alma humana que a de esculpir a própria escultura."
\end{abstract}

(Logosofia)

As recentes histórias da Enfermagem e da Enfermagem em Estomaterapia - em parte apresentadas nesta tese - permitem que se projetem profundas mudanças, com importantes perspectivas para o seu desenvolvimento futuro.

Nos últimos anos, temos feito algumas conferências acerca desse tema, destacando-se as realizadas para as aberturas do III Congresso Brasileiro de Estomaterapia, em 1999, e do 15th Biennial Congress of the World Council of Enterostomal Therapists, em 2004, além das proferidas durante o I Encontro Nacional de Tratamento de Feridas, em 2000, e durante o V Congreso Nacional de Enfermería en Ostomías, em 2004 (Quadro 9). Embora norteadas pelos temas centrais dos respectivos eventos e somente duas delas encontrarem-se publicadas, essas conferências fundamentaram o desenvolvimento deste Capítulo. 


\section{Quadro 9 - Conferências cujos temas versaram sobre as perspectivas da Estomaterapia (1999 a 2004).}

1. Santos VLCG. Cuidados avançados em estomaterapia: vislumbrando o $3^{\circ}$ milênio. Rev Esc Enf USP 1999; 33 n esp: 1-3.

2. Santos VLCG. Avanços no tratamento de feridas. Cuidado Integral e Personalizado. In: $1^{\circ}$ Encontro Nacional de Tratamento de Feridas; 2000e. Nov. 16-17; Campinas, SP. Campinas: Unicamp; 2000e.

3. Santos VLCG. Humanization of specialized care and the evolution of technology. In: Proceedings of the $15^{\text {th }}$ Biennial Congress of the World Council of Enterostomal Therapists and $5^{\circ}$ Brazilian Congress of Enterostomal Therapy; 2004 May 16-19; Florianópolis; Santa Catarina; 2004a.

4. Santos VLCG. Estomaterapia y formación: estomaterapia en el mundo. Estomaterapia.com: un paso al futuro. In: $5^{\circ}$ Congreso Nacional de Enfermería en Ostomías; 2004. Nov. 25-27; Pamplona, España. Pamplona: Sociedad Española de Enfermería Experta en Estomaterapia; 2004b.

\section{Na Enfermagem, como profissão}

O cuidar em saúde e, especialmente em Enfermagem, tem vivido, nas últimas duas décadas, um processo de profundas e diversas transformações e reformulações, à luz da própria "idade da transformação social" em que nos encontramos (Drucker apud Oulton, 1999).

A Enfermagem, oriunda de Florence Nightingale, em meados do século passado, tem evoluido de um "conhecimento silencioso", acobertado pela obediência à autoridade médica e pela crença no modelo biomédico (Cianciarullo 1999; Guthrie 1999), para o seu estabelecimento como 
Disciplina, assim fundamentada em um novo paradigma, a começar pela saúde.

Tennant (1999) menciona Smith e Newman para a construção desses novos paradigmas de saúde. Smith descreve a saúde como desempenho adequado de papéis e tarefas sociais, como adaptação a acontecimentos e ambientes e como eudaimonia, que enfatiza o bem-estar, energia e auto-realização. É a “consciência em expansão", conforme definida por Newman, e parte das manifestações do padrão individual, assim como a doença. Um verdadeiro processo de sintese.

Esses modelos conceituais para a saúde/ doença possibilitam contextualizar a Enfermagem como uma disciplina ainda prática, embasada na escolha moral e no conhecimento pessoal e estético, e voltada para o cuidar, educar e restaurar - como instrumental para o alcance da saúde (Cianciarullo 1999; Tennant 1999), porém, adquirindo outros componentes do conhecimento, o cognitivo de competência empírica (resolução de problemas e raciocínio lógico) e o sócio-político (prática, programas e políticas de saúde), os quais atuam como pano de fundo para o posicionamento profissional frente aos cenários acadêmicos e assistenciais (Cianciarullo 1999).

A Enfermagem atual é, assim, marcada pela mistura sofisticada do velho e do novo, persistindo o forte caráter da benevolência associado às crescentes autonomia, independência e competência em seus novos papéis, caracterizados pela tomada de decisão e liderança, especialmente, nas 
politicas públicas voltadas para a promoção e restauração da saúde junto à clientela ambulatorial, domiciliar ou comunitária (Guthrie 1999; Oulton 1999).

Mas, se a saúde é a meta, como ela será neste novo milênio?

Segundo a Organização Mundial de Saúde e o International Council of Nurses, em 2020 teremos um aumento da população idosa e declínio da taxa de nascimentos; persistência da pobreza, decréscimo da filantropia e preocupação com os direitos humanos; crescimento das doenças crônicas e da AIDS; controle de muitas doenças contagiosas; preocupação com a saúde mental; disseminação da tecnologia e maior e mais rápido acesso à informação, valorização do dinheiro; aumento dos dilemas éticos; aumento do número de consumidores educados, politizados e exigentes; desenvolvimento do senso de empresa e autonomia; gerenciamento direcionado pelo mercado dentre outros (Oulton 1999; Saver 1999; Turnbull 1999a).

Os panoramas da sociedade e da saúde - como apresentados prospectivamente - são, portanto, altamente favoráveis para a Enfermagem como disciplina. Ducker apud Oulton (1999) prevê que o recurso primário na sociedade pós-capitalista será o conhecimento, sendo fundamentais o que ele denomina como knowledge work e knowledge worker. O autor menciona o enfermeiro como um desses trabalhadores do conhecimento, ou seja, como um profissional que requer uma educação formal além da habilidade de aplicar o conhecimento teórico e analítico. E acrescenta que o 
knowledge worker é alguém que aprendeu como aprender e continua aprendendo, de maneira formal, ao longo de sua vida profissional.

Desse modo, Guthrie (1999), Oulton (1999) e Saver (1999) apontam como perspectivas da atuação do enfermeiro, desde o planejamento e gerenciamento de políticas e programas de saúde, de tecnologias de informação e de recursos humanos ao desenvolvimento de programas clínicos, de modelos, de cuidado baseado em evidência e de programas educativos; liderança da equipe interdisciplinar e gerenciamento do cuidado em atuação independente e empresarial. Essas serão as características do cuidado avançado em Enfermagem neste milênio que ora se inicia.

A questão presente é se estaremos prontos ou não?

Estarmos prontos e preparados implica em inúmeras mudanças e desafios referentes à qualidade, à prática diferenciada, à liderança, ao trabalho como carreira, à atualização, à diversidade e à ética.

A qualidade do serviço prestado, do cuidado ministrado, será um desafio prioritário, uma vez relacionada à satisfação da clientela, sejam consumidores, sejam administradores (Guthrie 1999; Saver 1999).

Uma prática diferenciada, que certifica o cuidado avançado, deverá prevalecer, mesmo que compartilhada por uma equipe de enfermagem com menor qualificação profissional, como já ocorre no 
momento, principalmente nos países em desenvolvimento ou mesmo naqueles já desenvolvidos em que a Enfermagem adquiriu um status universitário somente há poucos anos. Aspectos como a reciclagem e atualização constantes, o pensamento crítico e a liderança farão a diferença (Saver 1999).

A liderança das equipes multidisciplinares, nos diversos contextos institucionais, caracterizar-se-á pela diferenciação com o gerente atual e exigirá competências específicas em resolução de conflitos, técnicas motivacionais e planejamento estratégico (Guthrie 1999; Saver 1999).

O trabalho será visto como carreira e não mais como emprego, o que implicará na terceirização e especialização crescente de serviços, na educação continuada do profissional e, particularmente, no desenvolvimento de competências empresariais (Saver 1999).

A atualização constante, através da educação formal, o conhecimento e o cuidado baseado em evidências constituirão os fundamentos de todos os desafios que marcarão as transformações necessárias para a atuação avançada do enfermeiro. Impõe-se o domínio da tecnologia, desde a bio à cybertecnologia. $\mathrm{O}$ acesso eletrônico ao conhecimento ocorrerá cada vez mais, tanto para leigos como para profissionais. Estes terão um papel adicional e específico de decodificação das mensagens para o consumidor, cliente ou cuidador (Saver 1999; Turnbull 1999a; Van Rijswijk 1999a). 
A diversidade cultural, gerada pela mobilização dos povos e pela globalização, já hoje uma tendência, constituirá importante foco de preocupação para a Enfermagem neste novo milênio, seja do ponto de vista da clientela ou da própria equipe de trabalho. Isso significará, de um lado, o cuidar voltado para as minorias étnicas e do outro, um cuidar compartilhado com profissionais de outras etnias e culturas (Krasner 1999; Saver 1999).

Alguns dilemas éticos persistirão e novos surgirão, especialmente relacionados à genética humana (Saver 1999) e à visão do cuidado em saúde como um negócio (Gallagher 1999; Turnbull 1999b). O conhecimento ético, os valores pessoais e a postura profissional serão fundamentais frente a esse desafio (Guthrie 1999; Saver 1999).

Embora esse cenário seja favorável à ampliação do papel do enfermeiro, os autores ressaltam o desenvolvimento tecnológico e os dilemas éticos como dois fatores que, já no início deste milênio, encontramse no centro das discussões sobre a humanização ou re-humanização da assistência, permeada pelo relacionamento profissional de saúde e paciente/família, que também merecem ser discutidos (Santos 2004a).

Analisando-se a palavra técnica/tecnologia, segundo Heidegger (1997), ela origina-se do grego e assemelha-se à palavra episteme: velar sobre uma coisa, compreendê-la, conhecer-se em qualquer coisa. Ambas revestem-se do significado de eficácia trans-formadora e pro-dutora. 
Nas ciências Aristotélicas, a manifestação ou produção tecnológica envolvia quatro modos de comprometimento: causa materialis matéria prima; causa formalis - forma/figura em que se instala o material; causa finalis - objeto, e causa efficiens - efeito final do objeto produzido (Cahuí 1994). Paralelamente, a medicina ocidental, segundo o modelo hipocrático, era essencialmente humanística e pautada na visão holística do ser humano e na relação humano-científica entre médico e paciente (Nascimento, Guimarães 2003).

No Renascimento, a tecnologia era encarada como fruto da associação entre técnica e ciência, ou seja, constituía a conquista prática da natureza penetrada pela teoria. Já, na Modernidade, encontrava-se profundamente integrada ao modelo de organização da produção. Nessa época, a revolução na prática médica ocorria na medida em que aumentavam as probabilidades de cura e as possibilidades de melhor controle das doenças. O modelo cientificista da Medicina, baseado nas evidências clínicas e tecnológicas, ao supervalorizar a técnica em detrimento dos valores humanísticos, passava a visualizar o indivíduo de maneira segmentada, como se fora uma máquina com defeitos que necessitam ser adequadamente consertados. Caracterizava-se o rompimento do vínculo médico - paciente, perfeitamente cabivel a qualquer profissional da área de saúde (Nascimento, Guimarães 2003).

Tais relatos permitem considerar que é a tecnologia que se integra à natureza histórica do homem à medida que tem permitido a superação dos limites humanos aumentando o controle e, 
consequentemente, o poder e o status (Nunes 1999). A busca pelo desempenho pautado no conhecimento relaciona-se intrinsecamente aos conceitos de performance ou resultados e de competência ou capacidade, vigentes na pós-modernidade (Nunes 1999).

Em saúde, ainda nos dias de hoje, as intervenções são marcadas pelo paradigma de cura direcionado por uma medicina de alta tecnologia que, embora necessária - e cuja crescente evolução é prevista para este novo milênio - ao adquirir um caráter predominante, compromete a sua humanização (Pessini 2003). O deslumbramento pela tecnologia, o fascínio por produtos extraordinários e generosos oferecidos pela alta tecnologia, podem afetar a essência da atividade profissional, particularmente do enfermeiro (Hawthorne e Yurkovich 1995), camuflando as relações, transformando a prática e os valores morais e políticos sem que se reconheça a importância - e a direção - dessa transformação (Barnard 1997). Segundo esses conceitos, a tecnologia, que deve orientar a tomada de decisões também em saúde, torna-se perigosa quando ameaça a natureza do Homem. Para Ladrière (1979), “a tecnologia de base científica povoa o meio ambiente humano com uma multidão de objetos e de produtos artificiais que constituem, cada vez mais, um anteparo entre o homem e a natureza e mesmo, em certo sentido, entre o homem e sua própria natureza".

Dessa maneira, o que se vê na atualidade, nesta era pósmoderna -que se caracteriza pela ruptura com os antigos paradigmas e 
modelos - é uma insatisfação crescente da clientela e dos profissionais, o que tem demandado a re-humanização da assistência em saúde.

A percepção também crescente de que o paciente é autônomo e, portanto, co-responsável por sua saúde e que a tecnologia é complementar no processo de tomada de decisão envolvido no tratamento, passam a indicar o paradigma do cuidar - caring - como a resposta para o re-novado compromisso do respeito e valorização da dignidade humana, sobre cujos valores deverá ser construído em direção à sua re-humanização.

A palavra cuidado deriva do latim cura/coera e também cogitare/cogitatus, e abrange duas significações básicas, intimamente conectadas: atitude de desvelo, solicitude e atenção para com o outro e preocupação e inquietação advindas do envolvimento e da ligação afetiva com o outro por parte da pessoa que cuida, respectivamente (Davis 1999; Reich 1995; Boff 2000). Ao cuidar aplica-se o ethos da atenção que tem como valor central a dignidade humana e enfatiza a solidariedade entre o indivíduo e os profissionais da saúde. O paciente é o soberano (Pessini 2003)

Para Callahan (1998), "cuidar de alguém é dar a ele nosso tempo, nossa atenção, nossa empatia e qualquer ajuda social... para tornar a situação suportável e, se não suportável, pelo menos que nunca leve ao abandono...É ser ministro de seus medos...frente à ansiedade da separação dos outros...É assegurar que ele continua sendo importante para os outros, 
que sua doença não o isolou da comunidade...”. Sem o cuidado, a ação não seria possivel (Reich 1995).

Historicamente, para os profissionais de saúde, cuidar tem significado prestar tratamento adequado e especializado ou preocupar-se com o indivíduo doente como uma pessoa única, caracterizando respectivamente, desde um enfoque mais limitado ao corpo a um enfoque mais holístico. Davis (1999) afirma que, para algumas pessoas, o cuidado é o fator mais importante da totalidade da vida moral!

Cuidar é, então, basicamente um processo onde o cuidado deveria ser a raiz da ética visto que a boa vida - o bem-estar, a qualidade de vida - vem do que tem importância e merece ser cuidado, conforme Reich (1995). Nesta ótica, os valores morais são encarados como inerentes ao processo de cuidar. Do cuidar ético. A ética no cuidar.

Existem inúmeras abordagens teóricas acerca da ética do cuidar.

Para Gilligan (1993), a ética do cuidado, prevalente na perspectiva feminina, fundamenta-se no reconhecimento da responsabilidade de uns pelos outros, no entendimento de moralidade como conseqüência da consideração desse relacionamento e na convicção de que a comunicação cooperativa é o modo de solucionar conflitos, visando ao fortalecimento em vez do rompimento. 
Sob a ótica de Noddings (1984), a capacidade de agir eticamente é entendida como uma "virtude ativa" que exige dois sentimentos: natural do cuidado ou querer e o dever. Cuidar requer ato de compromisso e avaliação do relacionamento de cuidado como algo bom, melhor do que qualquer outra forma de relação.

Especificamente para a Enfermagem, nos últimos 40 anos, as decisões e intervenções passaram da fundamentação na ética da virtude, ou seja, no caráter da enfermeira, à ética dos principios, que se refere aos conceitos de direitos, obrigações e deveres assim como à conseqüência das ações. Os seguintes princípios compõem a ética do cuidado:

- o respeito às pessoas, segundo o qual cada indivíduo deve ser tratado como ser único embora mantendo a igualdade a todos os demais;

- a não maleficência, ou seja, não causar dano, preveni-lo e erradicálo. Este pode ser encontrado tanto no juramento hipocrático como nos escritos de Florence Nightingale;

- a beneficência, isto é, fazer o bem. Este princípio exige provisão de beneficios e equilíbrio entre estes e os danos em determinada situação;

- e justiça, como fundamental tanto para a sociedade como para os cuidados em saúde, referindo-se tanto às decisões políticas em 
âmbito nacional como às decisões ética, clínica e administrativa (Davis 1999).

Souza e Lemonica (2003), em artigo sobre cuidados paliativos, acrescentam um quarto princípio, o da prudência, "virtude que facilita a escolha dos meios certos para um bom resultado, buscando o que é bom pela recusa do que é mal". Segundo os autores, trata-se de uma postura de pensar adotada previamente ao agir.

Além desses principios éticos, têm-se duas normas deles oriundas: a fidelidade - essencial para a confiança na relação enfermeiro/ paciente - e a veracidade, segundo a qual não somente as ações são importantes mas também as conseqüências (Davis 1999).

Em estudo publicado em 1997, por McCance, McKenna e Boore (1997), o significado de cuidado em Enfermagem possui seis características: estar autenticamente presente, preocupar-se com, administrar, respeitar a, quantidade de tempo necessário e conhecer o paciente. No sentido prático e moral, estas características remetem ao importante conceito da presença cuidadora do enfermeiro.

De dificil definição, a presença cuidadora envolve atributos de relações como a atenção, eficiência, confiança, concretude, controle e respeito. Ela evidencia conhecimentos, habilidades e cuidados inseridos muito mais em uma Enfermagem Básica do que em uma Enfermagem de alta tecnologia. A presença cuidadora, como forma de interação, favorece a 
confiança e as atitudes positivas que promovem a boa saúde. A presença cuidadora estimula um ambiente que proporciona, por sua vez, a atuação terapêutica através da qual os pacientes demonstram satisfação com o cuidado prestado e orgulham-se de participar dele ativamente (Davis 1999). A presença cuidadora reconhece que a responsabilidade do paciente é não negociável, indivisivel e inescapável, à luz de uma abordagem baseada em empowerment (Anderson e Funnell 2000). A presença cuidadora é construto fundamental quando se busca a re-humanização do cuidar.

A ética do cuidado formula, então, o seguinte questionamento básico: qual deve ser a natureza da relação profissional e quais os compromissos éticos nela implícitos ou implicados? (Davis 1999).

Moore (2004), em editorial recente para o WOCN Journal, questiona se temos individualizado realmente os cuidados aos pacientes quando se discute o patient-centered care sob os fundamentos de um modelo econômico de assistência, no qual as diferenças individuais não são econômicas! No momento atual, em que se estabelecem algoritmos e diretrizes para o cuidar, em que se fundamenta o cuidar em evidências, o quanto temos, de fato, considerado a subjetividade no cuidar? O quanto temos de fato favorecido e considerado um cuidar negociado onde as necessidades e autonomia do indivíduo são valorizadas? O quanto temos favorecido um cuidar ético?

Ao reconhecermos os processos psicodinâmicos, mentais e emocionais, subjacentes à relação profissional - paciente/família e frente 
aos conceitos referentes ao cuidar ético e à presença cuidadora, esses podem constituir bases importantes para o cuidar neste novo milênio e frente aos desafios e cenários que se projetam. Ao assumirmos que o que nos diferencia realmente dos demais seres vivos é a capacidade que dispomos de desenvolver uma percepção complexa sobre o que é bom ou mal e de desenvolver códigos e comportamentos morais e que, portanto, sem a ética não há civilização (Davis 1999), pode-se afirmar que a ética do cuidar constituirá um dos fundamentos inegociáveis para atuarmos como enfermeiros e especialistas, tecnologicamete competentes, em direção à rehumanização em saúde.

O cuidado avançado de Enfermagem no $3^{\circ}$ milênio está posto!

Como, então, prever a situação das especialidades, como a Estomaterapia, no seu âmbito de ação, estomias, feridas e incontinências?

\section{Na Estomaterapia, como especialidade}

Discorrer sobre as perspectivas da Estomaterapia, reporta-nos à situação da especialidade no mundo, particularmente aquela ditada por diversos autores, na virada do século e milênio, ao preconizarem a necessidade de se estar bem preparado como profissional e especialista, para as inúmeras mudanças e desafios da nova era, referentes à qualidade do serviço prestado, à prática diferenciada, aos dilemas éticos, à liderança, 
ao trabalho como carreira, à atualização e à diversidade cultural da clientela (Santos 1999; Santos 2004b).

Cianciarullo (1999), citando Benner, descreve o enfermeiro especialista como aquele que domina as múltiplas dimensões estabelecidas pelas teorias, garantindo os limites da flexibilização do seu uso frente às reais necessidades do paciente, por meio da intuição, raciocinio e experiências advindas da própria clientela. Saver (1999) corrobora esta definição ao afirmar que a especialidade não significa inflexibilidade. Além disso, a autora vislumbra para a nova época, um enfermeiro com formação especializada diversa, o que possibilitará maiores abrangência e consistência de uma atuação voltada, principalmente, para as áreas emergentes - como a Estomaterapia.

A Estomaterapia, ou especialidade que se iniciou com a assistência ao estomizado, através dos esforços de Norma Gill e Rupert Turnbull, no final da década de 50, estabeleceu-se, inicialmente, como prática baseada em um conhecimento apenas vivencial e tradicional, tendo como pano de fundo a própria clientela e todas as dificuldades caracterizadas pela precariedade de dispositivos e falta de sistemas de suporte social (ver Capítulo 1). Esta, certamente, constituiu a época da "Enfermagem como arte", na qual, nós enfermeiras, éramos as artesãs. Foram os idealizadores da especialidade que, com sua compaixão e sensibilidade, mas também motivação e inspiração contribuíram para a definição de um modelo baseado em princípios e cuja essência permanece até hoje, quando o orgulho de nossa herança tem-nos levado a lutar pelos 
pacientes, estabelecer normas de cuidar, educar a equipe, administrar e questionar, persuadir os outros e manter nossas posições, desenvolver ou melhorar o acesso à qualidade de cuidado para a clientela, buscar nosso desenvolvimento pessoal e coletivo, reconhecer a necessidade de expandir nossa prática, conhecimentos e habilidades e, finalmente, compartilhar o compromisso com a colaboração profissional como uma das mais importantes habilidades do "kit de sobrevivência", num mundo cada vez mais complexo, exigente e competitivo que nos leva a fundamentar nossas decisões no conhecimento coletivo, ético, no insight e na sabedoria (Doughty 2000a, 2000b; Bonham 1999).

$\mathrm{Na}$ realidade, essas condições podem ser consideradas como etapas e características do estabelecimento de uma prática baseada em evidências, cuja demanda tem, gradativamente, se imposto na última década.

Basear a tomada de decisões em evidências e, assim, justificar o impacto do cuidado na sociedade frente à clientela, ao governo, às agências financiadoras e aos órgãos de acreditação e fiscalização, implica em que nos tornemos consumidores sofisticados e discriminadores do conhecimento advindo da pesquisa na literatura especializada e geral, com o olhar ávido de estudantes e crítico de pesquisadores que argumentam e convencem mais do que confrontam (Gray 1999b). São os próprios knowledge workers, isto é, pessoas que têm no conhecimento um dos recursos primários para a atuação. Basear a prática em evidências significa ainda, antecipar, monitorar e aproveitar as mudanças e estar prontos para mudar, e mudar e 
mudar... (Krasner 2000); e significa, finalmente, transformarmo-nos de consumidores em produtores e divulgadores da pesquisa, com a certeza de uma prática mais consistente e segura, de menor custo e maior efetividade.

A prática baseada em evidência traduz-se, também, na perspectiva da prática avançada do especialista e, tendo evoluído como uma busca natural e madura das especialidades, passou da certificação concedida em programas de treinamento e de especialização para níveis mais elevados da formação educacional, como a pós-graduação sensu strictu, particularmente o mestrado (Hamric 2000).

O especialista, preparado em nível avançado é um profissional mais atraente para o mercado à medida de sua maior autonomia, visibilidade e reconhecimento como elemento regulador para expandir atividades com autoridade prescritiva, fundamental para as novas formas de organização dos sistemas de saúde. Além disso, ratifica seu valor inquestionável ao ampliar suas competências, principalmente as investigativas, através das quais valida protocolos de avaliação e tratamento, compara a eficácia de medidas e produtos e demonstra custoefetividade de suas intervenções (Hamric 2000; Doughty 2000c).

Acerca do tema, Beitz (2000) afirma que a Enfermagem respondeu à necessidade da prática especializada criando as organizações de especialistas e, posteriormente, a própria prática avançada. Nesse sentido, estabelece suas diferenças a partir das características apresentadas no Quadro 10. 


\section{Quadro 10 - Caracteristicas das práticas especializadas e avançadas.}

\begin{tabular}{|c|c|c|}
\hline Preparo/ Técnicas & Prática especializada & Prática avançada \\
\hline Nivel educacional & bacharelado & mestrado \\
\hline Locais de atuação & variável & primário aguda/crônico \\
\hline Avaliação física & focalizada & ampla \\
\hline Diagnóstico & limitado & avançado \\
\hline $\begin{array}{l}\text { Manuseio de } \\
\text { problemas }\end{array}$ & intervenção médica & privilégio prescritivo \\
\hline $\begin{array}{l}\text { Foco nos sistemas de } \\
\text { saúde }\end{array}$ & $\begin{array}{c}<\text { ênfase no contexto } \\
\text { social }\end{array}$ & $\begin{array}{c}\text { > ênfase no contexto } \\
\text { social }\end{array}$ \\
\hline Liderança & focos variáveis & forte ênfase \\
\hline $\begin{array}{l}\text { Abordagem } \\
\text { interdisciplinar }\end{array}$ & intra-grupal & Inter-profissional \\
\hline Autonomia & limitada & expandida/essencial \\
\hline
\end{tabular}

As características apontadas por Beitz (2000) permitem confirmar que, embora a Estomaterapia mundial trilhe o caminho certo em direção à prática avançada, inúmeras questões legais, educacionais e de certificação ainda necessitam de elucidação e definição. De qualquer forma, a integração da prática avançada em estomaterapia deve ser fomentada como uma opção, uma preferência para o futuro e não como conseqüência inevitável do progresso ou sobrevivência no novo milênio (Beitz 2000; Gray, Ratliff e Mawyer 2000). 
No contexto da prática- avançada - baseada em evidências, autorizamo-nos a incluir duas expressões que vêm sendo mencionadas na literatura atual, quais sejam, o management care e o management case, oriundas das transformações do sistema de saúde norte-americano. Apesar de sugeridas por autores diferentes em situações e momentos diferentes, têm significações semelhantes. Turnbull (1999c) fala do management care ou cuidado gerenciado como o trabalho do especialista cuja efetividade resulta da perfeita sintonia entre provedores e consumidores do cuidado, ou seja, a combinação de talentos, recursos, custos e estratégias. E case management, por sua vez, refere-se à coordenação do cuidado em que o profissional, particularmente o especialista, desempenha papel preponderante como responsável pela análise dos processos de prestação de serviços, pela determinação e definição das mudanças exigidas e pela mensuração dos seus efeitos.

Defrontar-se com os desafios da busca e alcance da prática avançada/ baseada em evidências requer um profissional especialista consciente das transformações tecnológicas, sociais e políticas que a influenciam e determinam bem como o mercado e o usuário dos serviços de saúde, com demandas que se modificam rápida e constantemente. Exige-se, portanto, um profissional cujo perfil de competências e atitudes se realinhe e se atualize. Kanaane e Ortigoso (2000), falando do enfermeiro rumo ao século 21, mencionam as contribuições de Goleman $(1995,1998)$ acerca de algumas dimensões da Inteligência Emocional, como auto-percepção, controle das emoções, auto-motivação, empatia e habilidades sociais para definir as principais atitudes e competências desses profissionais de saúde, 
objetivando o alcance da excelência na qualidade dos serviços junto à clientela e, assim, a maior qualidade de vida para ambos.

Nesta tese, que visou a apresentar uma sintese crítica de nossa produção na área de estomias - da qual a Estomaterapia se originou enquanto especialidade - associada à pesquisa bibliográfica realizada, permitiu depreender os principais avanços principalmente nos protocolos médicos de tratamento, especialmente relacionados às técnicas cirúrgicas de conservação esfincteriana associadas a novas formas de terapia adjuvante, bem como o diagnóstico precoce do câncer. Especificamente na área do cuidar especializado, os dispositivos coletores e as barreiras protetoras de pele periestoma, passaram daqueles permanentes e reutilizáveis de borracha e do óxido de zinco, respectivamente, para produtos de alta tecnologia que cumprem adequadamente suas funções de coleta e armazenamento de efluentes com segurança, conforto e maior proteção contra complicações (Turnbull e Erwin-Toth 1999; Van Rijwisjk 2000). E, embora princípios de ação tenham sido estabelecidos, continuamos a utilizar uma prática baseada na tradição desses princípios, dificultando o acesso da clientela a intervenções e recursos mais adequados à complexidade e exigência desse próprio mercado (Turnbull e Erwin-Toth 1999), conforme mencionado no Capítulo 3.

Em revisão da literatura citada no Capítulo 3, Turnbull e ErwinToth (1999) revelavam a escassez de pesquisas acerca do cuidar em estomias, o que se mantém e se repete em nosso meio mesmo após seis anos dessa publicação. As autoras acrescentavam que a efetividade de 
muitos cuidados preconizados como a demarcação pré-operatória do estoma, a seleção dos dispositivos e a prevenção de complicações do estoma e pele periestoma estavam ricos de evidências empíricas porém sem comprovação investigativa que lhes desse suporte, anteriormente confirmado por Gray (1998).

Em nosso meio, certamente transformações positivas e inovadoras podem ser constatadas como o estabelecimento de protocolos e políticas de saúde das pessoas estomizadas, em niveis estadual e federal; o aumento do número de cursos de especialização, que iniciam sua despolarização do eixo sudeste-sul; aumento do número de estomaterapeutas que ingressam e concluem os cursos de pós-graduação sensu stritu (mestrado e doutorado); a existência de revista especializada, em busca de sua indexação; a formação de novas seções e regionais da Sociedade Brasileira de Estomaterapia; estudos ainda pontuais sobre o impacto da estomia sobre a qualidade de vida da clientela; alguns estudos comparativos sobre dispositivos coletores para estomias e alguns outros que, no entanto, ainda são incipientes e restritos à academia, nos grandes centros universitários das grandes cidades e, portanto, ainda pouco consumidos pelos profissionais, principalmente enfermeiros.

Frente às considerações aqui expostas, percebemos que, para sermos enfermeiros especialistas em Estomaterapia, nos deparamos com um outro dilema: faremos parte do problema ou da solução? 
Ao optarmos por constituir parte da solução do vir a ser do Estomaterapeuta, neste novo milênio, é imprescidivel assumir e liderar o cuidar holístico e interdisciplinar - a presença cuidadora - com qualidade diferenciada e custo-utilidade comprovadas, fundamentado nos conhecimentos prático, estético, étnico, empírico e sócio-político constantemente atualizados e baseados em evidências - e voltado para uma clientela, diversa em suas necessidades, porém única na sua humanidade.

Lembremo-nos das palavras de Van Rijswijk (1999b), num justo e fraterno tributo à pioneira da Estomaterapia, Norma Gill: "Pessoas, sistemas ou eventos que desafiam os padrões de nossa prática, raramente são recebidos com braços abertos e geralmente são percebidos como ameaças. Eles invadem nosso conforto e penetram a armadura do conhecimento com a qual muitos profissionais protegem-se contra as incertezas da prática diária. Já, sem desafiar o status quo, a disciplina não se desenvolverá, a ciência não progredirá e o cuidado à saúde não melhorará. É no coração das transformações e do progresso que reside a crença de que as coisas podem, ou deveriam, ser diferentes e a habilidade de olhar o mundo através de lentes diferentes. Novos paradigmas ajudam a abrir os nossos olhos e preparam o caminho para novas soluções e possibilidades". 


\section{REFERÊNCIAS BIBLIOGRÁFICAS}

Achneck HE, Wong IY, Kim PJ, Fernandes MA, Walther Z, Seymour NE, Jain D. Ileostomy adenocarcinomas in the setting of ulcerative colitis. J Clin Gastroenterol. 2005;39(5):396-400.

Adesanya AA, Ekanem EE. A ten-year study of penetrating injuries of the colon. Dis Colon Rectum. 2004;47(12):2169-2177.

Agabiti E, Loganathan A, Rimmer M, Eames RA, Cullen PT. Cancer of ileostomy: a late complication of colectomy for ulcerative colitis. Acta Chir Belg. 2005;105(1):99-101.

Ahmad M, Abbas S, Asghar MI. Is mechanical bowel preparation really necessary in colorectal surgery? J Coll Physicians Surg Pak. 2003;13(11):6379.

Aldridge AJ, Simson JN. Erosion and perforation of colon by synthetic mesh in a recurrent paracolostomy hernia. Hernia. 2001;5(2):110-2.

Almeida MCP, Rocha JSY. O saber de enfermagem e sua dimensão prática. São Paulo: Cortez; 1986.

Almeida MCS, Santos VLCG. Qualidade de vida de clientes com estomas intestinais definitivos e provisórios [resumo]. Rev Esc Enferm USP. 1999; 33(n.esp):88.

Alonso Gracia N, Lorente Garín JA, de León Morales E, Cañis Sánchez D, Cortadellas Angel R, Sánchez de la Blanca MI, Gelabert-Más A. Analysis of medical/surgical complications of cutaneous ileostomy. Actas Urol Esp. 2004;28(6):437-42.

Amin SN, Armitage NC, Abercrombie JF, Scholefield JH. Laterly repair of parastomal hernia. Ann R Coll Surg Engl 2001;83(3):206-208.

Anderson B, Funnell M. The art of empowerment: stories and strategies for diabetes educators. Canada: American Diabetes Association; 2000.

Anderson FJ. History of enterostomal therapy. In: Broadwell DC, Jackson BS. Principles of ostomy care. Saint Louis: Mosby; 1982. p.14-6. 
Andrade V, Ferreira AM, Barco RS, Escorse PR, Santos VLCG. A sexualidade do ostomizado: uma trajetória de transformações. Rev Bras Coloproctol. 1996; 16 Supl 1:74.

Andrade V, Ferreira AM, Barco RS, Santos VLCG. A sexualidade do ostomizado na visão do parceiro. Rev Paul Enferm. 1999;18(1/3):35-49.

Armenta Galán J. Mejora de la calidad de vida de personas colostomizadas con métodos continentes. Rev Rol Enferm. 1999;22(1):17-2.

Aron S, Carrareto R, Prazeres SMJ, Cerqueira APB, Santos VLCG. Selperceptions about having an ostomy: a postoperative analysis. Ostomy Wound Manage. 1999;45(4):46-62.

Asano TK, McLeod RS. Dietary fibre for the prevention of colorectal adenomas and carcinomas. Cochrane Database Syst Rev [database online]. 2006;(1). Available from: http://www.cochrane.org/reviews. [Access at 27 jan 2006].

Associação Brasileira de Ostomizados (ABRASO). Política pública: a saúde da pessoa ostomizada. Rev ABRASO. 2004a;(3):12.

Associação Brasileira de Ostomizados (ABRASO). Política pública: recomendações para a criação da Portaria Nacional específica para o atendimento à pessoa ostomizada. Rev ABRASO. 2004b;(3):13-4.

Associação Brasileira de Ostomizados (ABRASO). Giro pelo mundo: ações pelo mundo. Rev ABRASO. 2005;(5):19-21.

Aukkett KW. Mensagem do Presidente da IOA. Bol Inf SOB. 1995;(1):1.

Awad RW, el-Gohary TM, Skilton JS, Elder JB. Life quality and psychological morbidity with an ileostomy. Brit J Surg. 1993;80(2):252-3.

Bailey CM, Wheeler JM, Birks M, Faraouk R. The incidence and causes of permanent stoma after anterior resection. Colorectal Dis. 2003;5(4):331-4.

Baixauli J, Delaney CP, Wu JS, Remzi FH, Lavery IC, Fazio VW. Functional outcome and quality of life after repeat ileal pouch-anal anastomosis for complications of ileoanal surgery. Dis Colon Rectum. 2004;47(1):2-11. 
Bakx R, Busch OR, van Geldere D, Bemelman WA, Slors JF, van Lanschot JJ. Feasibility of early closure of loop ileostomies: a pilot study. Dis Colon Rectum. 2003;46(12):1680-4.

Bakx R, Busch OR, Bemelman WA, Veldink GJ, Slors JF, van Lanschot JJ. Morbidity of temporary loop ileostomies. Dig Surg. 2004;21(4):277-81.

Bancu S. A simplified method of diverting colostomy. Chirurgia (Bucur). 2003; 98(4):361-3.

Barnard A. A critical review of the belief that technology is a neutral object and nurses are its master. J Adv Nurs. 1997;26(1):26-31.

Barreire SG, Oliveira OA, Kazama W, Kimura M, Santos VLCG. Qualidade de vida de crianças ostomizadas na ótica das crianças e das mães. J Pediatr. 2003;79(1):55-62.

Batista RF, Viana RM, Santos MC, Schiftane SS, Guimaráes RP, Cesaretti IUR, Santos VLCG. Crianças e adultos com ostomias: um perfil da clientela. [resumo]. Rev Bras Coloproctol. 2003a; 23 Supl 1:40.

Batista RF, Schiftane SS, Santos MC, Guimarães RP, Viana RM, Cesaretti IUR, Santos VLCG. Avaliação do equipamento coletor para uso em ostomias na ótica do cliente e enfermeiro [resumo]. Rev Bras Coloproctol. 2003b; 23 Supl 1: 39.

Batista RF, Santos MC, Schiftane SS, Viana RM, Guimarães RP, Cesaretti IUR, Santos VLCG. Avaliação do equipamento coletor para uso em crianças ostomizadas na ótica do cliente e enfermeiro [resumo.] Rev Bras Coloproctol. 2003c; 23 Supl 1:78.

Behrens DT, Paris M, Luttrell JN. Conversion of failed ileal pouch-anal anastomosis to continent ileostomy. Dis Colon Rectum. 1999;42(4):490-5.

Beitz JM. Specialty practice, advanced practice, and WOC nursing: curent professional issues and future opportunities. WOCN J. 2000; 27(1):55-64.

Berg K, Seidler H. Randomized crossover comparison of adhesively coupled colostomy pouching systems. Ostomy Wound Manage. 2005;51(3):30-2. 
Berndtsson I, Oresland T. Quality of life before and after proctocolectomy and IPAA in patients with ulcerative proctocolitis: a prospective study. Colorectal Dis. 2003;5(2):173-9.

Berndtsson I, Oresland T, Hultén L. Sexuality in patients with ulcerative colitis before and after restorative proctolocolectomy: a prospective study. Scand $\mathrm{J}$ Gastroenterol. 2004;39(4):374-9.

Berndtsson IE, Lindholm E, Oresland T, Hultén L. Health-related quality of life and pouch function in continent ileostomy patients. Dis Colon Rectum. 2004;47(12):2131-7.

Black P. Treating peristomal skin problems in the community. Br $\mathrm{J}$ Commun Nurs. 2002;7(4):212-217.

Black P, Hyde C. Caring for people with a learning disability, colorectal cancer and stoma. Br J Nurs. 2004;13(16):970-5.

Black PK, Hyde C. Parents with colorectal cancer: "What do I tell the children?” Br J Nurs. 2002;11(10):679-85.

Black PK. Psychological, sexual and cultural issues for patients with a stoma. Br J Nurs. 2004;13(12):692-7.

Blanco Diez A, Fernández Rosado E, Alvarez Castelo L, Sánchez RodríguezLosada J, Chantada Abal V, Novás Castro S, Barbagelata López A, Serrano Barrientos J, González Martín M. Double-barreled wet colostomy: analysis of a urinary diversion. Actas Urol Esp. 2003;27(8):611-7.

Boccardo LM, Nogueira AS, Santos ER, Miyadahira AMK, Santos VLCG. Aspectos da reinserção social do ostomizado. Rev Esc Enferm USP. 1995; 29(1):59-71.

Boff L. Saber cuidar: ética do humano - compaixão pela terra. Petrópolis: Vozes; 2000.

Bondarevs ${ }^{-k y i}$ AO. Quality of life of patients with colostomy after colonic injury. Klin Khir. 2001;(5):18-21.

Bonham P. Titles and transitions: the challenges of change. WOCN J. 1999; 26(1):5-6. 
Börjesson L, Oresland T, Hultén L. The failed pelvic pouch: conversion to a continent ileostomy. Tech Coloproctol. 2004;8(2):102-5.

Branagan G, Tromans A, Finnis D. Effect of stoma formation on bowel care and quality of life in patients with spinal cord injury. Spinal Cord. 2003;41(12):680-3.

Brasil. Ministério da Saúde. Secretaria Nacional de Assistência à Saúde (SNAS). ABC do SUS: doutrinas e principios. Brasília; 1990.

Brasil. Ministério da Saúde. Política Nacional de Saúde da Pessoa Portadora de Deficiência [online]. Brasília; 2006. Disponivel em: http://portal.saude.gov.br [Acesso em 11 mar 2006].

Braun K. Managing a highly exudative wound adjacent to an ileostomy. WOCN J. 2003;30(3):159-64.

Breckman B. Enfermería del estoma. Madrid: Interamericana; 1987.

Bretagnol F, Rullier E, Laurent C, Zerbib F, Gontier R, Saric J. Comparison of functional results and quality of life between intersphincteric resection and conventional coloanal anastomosis for low rectal cancer. Dis Colon Rectum. 2004;47(6):832-8.

Broadwell DC, Jackson BS. Principles of ostomy care. Saint Louis: Mosby; 1982.

Brown H, Randle J. Living with a stoma: a review of the literature. J Clin Nurs. 2005;14(1):74-81.

Brydolf M, Berndtsson I, Lindholm E, Berglund B. Evaluation of a Swedish version of the Ostomy Adjustment Scale. Scand J Caring Sci. 1994;8(3):17983.

Burch J, Sica J. Colostomy products: an update on recent developments. Br J Community Nurs. 2004;9(9):373-8.

Burch J. The pre- and postoperative nursing care for patients with a stoma. Br J Nurs. 2005;14(6):310-8. 
Burcharth F, Ballan A, Kylberg F, Rasmussen SN. The colostomy plug: a new disposable device for a continent colostomy. Lancet 1986;2:1062-3.

Callahan D. What kind of life: a challenging exploration of the goals of medicine. New York: Simon \& Schuster; 1998.

Camilleri-Brennan J, Steele RJC Objective assessment of quality of life following panproctocolectomy and ileostomy for ulcerative colitis. Ann R Coll Surg Engl. 2001;83(5):321-4.

Camilleri-Brennan J, Munro A, Steele RJ. Does an ileoanal pouch offer a better quality of life than a permanent ileostomy for patients with ulcerative colitis? J Gastrointest Surg. 2003;7(6):814-9.

Campos GWS. O século XX. Glórias e equívocos. Ser Médico 1999;2(6):44-6.

Cantele H, Méndez A, Leyba J. Colostomy closure using local anesthesia. Surg Today. 2001;31(8):678-80.

Carlsson E, Berglund B, Nordgren S. Living with an ostomy and short bowel syndrome: practical aspects and impact on daily life. WOCN J. 2001;28(2):96105.

Carlsson E, Bosaeus I, Nordgren S. Body composition in patients with an ileostomy and inflammatory bowel disease: validation of bio-electric impedance spectroscopy (BIS). Eur J Clin Nutr. 2002;56(7):680-6.

Carlsson E, Boseaus I, Nordgren S. What concerns subjects with inflammatory bowel disease and an ileostomy? Scand J Gastroenterol. 2003;38(9):978-84.

Carne PW, Robertson GM, Frizelle FA. Parastomal hérnia. Br J Surg. 2003;90(7):784-93.

Carvalheira C. Suporte social: da teoria à prática: a realidade das associações de ostomizados no país. In: Santos VLCG, Cesaretti IUR. Assistência em estomaterapia: cuidando do ostomizado. São Paulo: Atheneu; 2000. p. 303-15.

Castillo E, Thomassie LM, Whitlow CB, Margolin DA, Malcolm J, Beck DE. Continent ileostomy: current experience. Dis Colon Rectum. 2005;48(6):12638. 
Centellas Morral M. Evaluación clínica de un nuevo dispositivo para personas colostomizadas. Rev Rol Enferm. 2000;23(4):293-300.

Cesaretti IUR, Leite MG. Bases para o cuidar em estomaterapia. In: Santos VLCG, Cesaretti IUR, coordenadoras. Assistência em estomaterapia: cuidando do ostomizado. São Paulo: Atheneu; 2000. p. 19-37.

Cesaretti IUR, Santos VLCG, Filippin MJ, Lima SRS. O cuidar de enfermagem na trajetória do ostomizado: pré \& trans \& pós-operatórios. In: Santos VLCG, Cesaretti IUR, coordenadoras. Assistência em estomaterapia: cuidando do ostomizado. São Paulo: Atheneu; 2000. p. 113-31.

Cesaretti IUR, Tanaka LH, Filippin MJ. Suporte social: da teoria à prática. Serviços de assistência em estomaterapia: aspectos filosóficos e organizacionais. In: Santos VLCG, Cesaretti IUR, coordenadoras. Assistência em estomaterapia: cuidando do ostomizado. São Paulo: Atheneu; 2000. p. 316-25.

Cezaretti IUR, Santos VLCG, Filippin MJ, Lima SRS, Ribeiro AM. A enfermagem e o processo de cuidar de estomizados. In: Crema E, Silva R, coordenadores. Estomas: uma abordagem interdisciplinar. Uberaba: Ed. Pinti; 1997. p.125-44.

Chambrier C, Normand S, Ecochard R, Pachiaudi C, Laville M, Boulétreau P. Total body-water measurement with (18)O-labeled water in short-bowel patients with an ileostomy. Nutrition. 2001;17(4):287-91.

Chaudhuri A, Prasai A. Hyaluronidase in the reduction of prolapsed colostomy. Ann R Coll Surg Engl. 2003;85(3):209.

Chauí M. Introdução à história da filosofia: dos pré-socráticos a Aristóteles. São Paulo: Brasiliense; 1994.

Cheung MT, Chia NH, Chiu WY. Surgical treatment of parastomal hernia complicating sigmoid colostomies. Dis Colon Rectum. 2001;44(2):266-70.

Cheung YL, Molassiotis A, Chang AM. A pilot study on the effect of progressive muscle relaxation training of patients after stoma surgery. Eur $\mathrm{J}$ Cancer Care (Engl) 2001;10(2):107-14. 
Cianciarullo TI. Especialização: a contextualização do futuro da Enfermagem. In: Santos VLCG, Cesaretti IUR, coordenadoras. Assistência em estomaterapia: cuidando do ostomizado. São Paulo: Ateneu; 2000. p. 477-84.

Comb J. Role of the stoma care nurse: patients with cancer and colostomy. Br J Nurs. 2003;12(14):852-6.

Conde Redondo C, Estébanez Zarranz J, Rodríguez Tovez A, Amón Sesmero J, Alonso Fernández D, Martínez Sagarra JM. Estudio de la calidad de vida en pacientes sometidos a sustitución vesical ortotópica versus ileostomía cutánea. Actas Urol Esp. 2001;25(6):435-44.

Cordeiro F, Yamaguchi NH, Habr-Gama A, Cutait R, Reinan RJ, Asbramoff R, Perdicaris M, Moraes A, Quilici FA, Sugahara R, Valério F. Diagnóstico, estadiamento e tratamento cirúrgico e multidisciplinar do câncer colorretal, de 14 de agosto de 2001. In: Projeto Diretrizes AMB-CFM [online]. Disponivel em: http://www.projetodiretrizes.org.br. [Acesso em 30 jan 2006].

Costa IG, Maruyama SA. Implementação e avaliação de um plano de ensino para a auto-irrigação de colostomia: estudo de caso. Rev Lat Am Enferm. 2004;12(3):557-63.

Costa JA, Kreder KJ, Howe JR. Combined urinary and fecal diversion using a no bowel anastomosis technique. J Urol. 2003;169(2):621-2.

Cowan T, Hill AG. Ileostomy closure without contrast study is safe in selected patients. ANZ J Surg. 2005;75(4):218-9.

Craven ML, Etchells J. A review of the outcome of stoma surgery on spinal cord injured patients. J Adv Nurs. 1998;27(5):922-6.

Cruz EMTN. Especialidade: as complexidades da escolha. Ser Médico 1998; $1(3): 3-16$.

Cullen B, Thank you N. WOCN J. 1999;26(1):2.

Davenport R, Sica J. A new modern drainable appliance for people with ileostomies. Br J Nurs 2003;12(9):571-575.

Davis AJ. Las dimensiones éticas del cuidar en enfermería. Enferm Clín. 1999;9(1):21-7. 
Doughty D. Back to the future. WOCN J. 2000a;27(1):1-2.

Doughty D. Show me the data. WOCN J. 2000b;27(4):199-200.

Doughty D. Integrating advanced practice and WOC nursing education. WOCN J 2000c;27(1):65-8.

Doughty D. Principles of ostomy management in the oncology patient. $J$ Support Oncol. 2005;3(1):59-69.

Duchesne JC, Wang YZ, Weintraub SL, Boyle M, Hunt JP. Stoma complications: a multivariate analysis. Am Surg. 2002;68(11):961-6.

Ecker KW, Gierend M, Kreissler-Haag D, Feifel G. Reoperations at the ileostomy in Chron's disease reflect inflammatory activity rather than surgical stoma complications alone. Int J Colorectal Dis. 2001;16(2):76-80.

Edwards DP, Leppington-Clarke A, Sexton R, Heald RJ, Moran BJ. Stomarelated complications are more frequent after transverse colostomy than loop ileostomy: a prospective randomized clinical trial. Br J Surg. 2001;88(3):360-3.

El-Tawil AM. Reasons for creation of permanent ileostomy for the management of idiopathic chronic constipation. J Gastroenterol Hepatol. 2004;19(8):844-6.

Faller N. ET nursing: a clinical specialty. World Counc Enterostom Ther J. $1997 ; 17(4): 16-24$.

Ferreira MCT, Souza DMST, Resende MMC, Santos VLCG, Silva AC. A autoestima de pessoas portadoras de ostomia com o uso de peça íntima com bolso acoplado, para suporte da bolsa coletora [resumo]. Rev Estima. 2005;3(n. esp):32.

Floruta CV. Dietary choices of people with ostomies. WOCN J. 2001; 28(1):2831.

Foulkes B. El papel de la enfermera en el cuidado del estoma. In: Breckman B. Enfermería del estoma. Madrid: Interamericana;1987. p. 213-8. 
Gallagher SM. The historical context of business ethics: implicatons for choices and challenges in wound care. Ostomy Wound Manage. 1999; 45(8):12-4.

Gard D. Remembering norma. World Counc Enterostom Ther J. 1999;19(1):34.

Gastinger I, Marusch F, Steinert R, Wolff S, Koeckerling F, Lippert H; Working Group Colon/Rectum Carcinoma. Protective defunctioning stoma in low anterior resection for rectal carcinoma. Br J Surg. 2005;92(9):1137-42.

Gilligan C. In a different voice: psychological theory and women's development. Massachussets: Harvard University Press; 1993.

Gill-Thompson N Enterostomal therapy: from the bible until today. World Counc EnterostomTher J. 1990;10(3):30-4.

Gooszen AW, Geelkerken RH, Hermans J, Lagaay MB, Gooszen HG. Quality of life with a temporary stoma: ileostomy vs. colostomy. Dis Colon Rectum. 2000; 43(5):650-5.

Grant M, Ferrell B, Dean G, Uman G, Chu D, Krouse R. Revision and psychometric testing of the City of Hope Quality of Life - Ostomy Questionnaire. Qual Life Res. 2004;13(8):1445-57.

Gray M, Ratliff C, Mawyer R. A brief history of advanced practice nursing and its implications for WOC advanced nursing practice. WOCN J. 2000;27(1):4854.

Gray M. Ostomy care? Show me the data! WOCN J. 1998; 25(1):2-4.

Gray M. The passage of an era: in memory of Norma Gill-Thompson. WOCN J. 1999a;26(1):3-4.

Gray M. Are we ignoring the lessons of the history? WOCN J. 1999b;26(4):16970.

Griffero REH. Encuesta sobre la calidad de vida de los ostomizados. Rev Argent Coloproctol. 1998;9:176-9. 
Guenaga K, Atallah AN, Castro AA, Matos DDM, Hill-Jorgensen P. Mechanical bowel preparation for elective colorectal surgery. Cochrane Database Syst Ver [database online]. 2006;(1). Available from: http://www.cochrane.org/reviews [Access at 27 jan 2006].

Guimarães GC, Terabe F, Rossi BM, Aguiar Júnior S, Ferreira FO, Nakagawa WT, Lopes AA. The double-barreled wet ileostomy: an alternative method for simultaneous urinary and intestinal diversion without intestinal anastomosis after total colectomy and pelvic exenteration. Int $\mathrm{J}$ Colorectal Dis. 2005;20(2):190-3.

Guthrie B. Nursing: a new perspective. Int Nurs Rev. 1999; 46(1):25-6.

Habr-Gama A, Araújo SEA. Estomas intestinais: aspectos conceituais e técnicos. In: Santos VLCG, Cesaretti IUR, coordenadoras. Assistência em estomaterapia: cuidando do ostomizado. São Paulo: Atheneu; 2000. p. 39-54.

Habr-Gama A, Santos VLCG, Sousa Jr AHS, Oya T, Pinotti HW. Importância do método de irrigação para o colostomizado [editorial]. Rev Bras Coloproctol. 1989;9(2):49-51.

Habr-Gama A, Santos VLCG, Sousa Junior AHS. Importance of the bowel irriogation method for the colostomized patient [editorial]. ABCD Arq Bras Cir Dig. $1991 ; 6(2): 31-2$.

Hampton BG, Bryant RA. Ostomies and continente diversions: nursing management. Saint Louis: Mosby; 1992.

Hamric AB. WOC nursing and the evolution to advanced nursing practice. WOCN J. 2000;27(1):46-47.

Hashimoto H, Guedes SL, Pereira VC, Santos VLCG, Kimura M, Sousa Junior AHS. O ostomizado e a qualidade de vida: abordagem fundamentada nas dimensões propostas por Flanagan [resumo]. Rev Bras Coloproctol. 1996;16 Supl 1:74-.

Hawthorne LD, Yurkovich NJ. Science, technology, caring and the professions: are they compatible? J Adv Nurs. 1995;21(6):1087-91.

Heidegger M. A questão da técnica. Cad Tradução. 1997;2:41-93. 
Hetzer FH, Schwizer W, Kuenzi W, demartines N. Experimental model of continent colostomy using rectus abdominus neosphincteroplasty. Br J Surg. 2003;90(10):1273-9.

Hodgson DC, Fuchs CS, Ayanian JZ. Impact of patient and provider characteristics on the treatment and outcomes of colorectal cancer. $\mathrm{J}$ Natl Cancer Inst. 2001;93(7):501-15.

Hodgson DC, Zhang W, Zaslavsky AM, Fuchs CS, Wright WE, Ayanian JZ. Relation of hospital volume to colostomy rates and survival for patients with rectal cancer. J Natl Cancer Inst. 2003;95(10):708-16.

International Ostomy Association (IOA). Estatutos. England: IOA; 1975.

Jackson BS, Broadwell DC Role of the enterostomal therapy practitioner. In: Broadwell DC, Jackson BS Principles of ostomy care. Saint Louis: Mosby; 1982. p. 8-13.

Jänes A, Cengiz Y, Israelsson LA. Preventing parastomal hernia with a prosthetic mesh. Arch Surg. 2004;139(12):1356-8.

Jeffery GM, Hickey BE, Hider P. Follow-up strategies for patients treated for non-metastatic colorectal cancer. Cochrane Database Syst Rev [dabase online].2006;(1). Available from: http://www.cochrane.org/reviews. [Access at 27 jan 2006].

Jones EG, Harbit M, Anderson R. Management of an ileostomy and mucous fistula located in a dehisced wound in a patient with morbid obesity. WOCN J. 2003;30(6):351-6.

Kaiser AM, Stein JP, Beart RW. T-pouch: a new valve design for a continent ileostomy. Dis Colon Rectum. 2002;45(3):411-5.

Kanaane R, Ortigoso SAF. Manual de treinamento e desenvolvimento do potencial humano. Rio de Janeiro: Qualitymarks; 2000.

Karadag A, Mentes BB, Uner A, Irkörücü O, Ayaz S, Ozkan S. Impact of stomatherapy on quality of life in patients with permanent colostomies or ileostomies. Int J Colorectal Dis. 2003;18(3):234-8. 
Kasperk R, Willis S, Klinge U, Schumpelick V. Update on incisional hernia. Parastomal hernia. Chirurg. 2002;73(9):895-8.

Kataoka H, Mori N, Nagasaka M, Harada T, Minami N, Kanazawa HKM, Kohzuki M. Generic and disease specific quality of life in Japanese colostomates [abstract]. Qual Life Res. 2003;12:820.

Keating J, Kelly EW, Hunt I. Save the skin and improve the scar: a simple technique to minimize the scar from a temporary stoma. Dis Colon Rectum. 2003;46(10):1428-9.

Keating JP. Sexual function after rectal excision. ANZ Surg. 2004;74(4):24859.

Kienle P, Weitz J, Benner A, Herfarth C, Schmidt J. Laparoscopically assisted colectomy and ileoanal pouch procedure with and without protective ileostomy. Surg Endosc. 2003;17(5):716-20.

Köhler LW, Pemberton JH, Zinsmeister AR, Kelly KA. Quality of life after proctocolectomy: a comparison of Brooke Ileostomy, Kock Pouch and ileal pouch-anal anastomosis. Gastroenterology. 1991;101:679-84.

Koperna T. Cost-effectiveness of defunctioning stomas in low anterior resections for rectal cancer: a call for benchmarking. Arch Surg. 2003; 138(12):1334-9.

Kostov DV, Temelkov TD, Dragnev NA, Kobakov GL, Ivanov KD. Smooth muscle sphincteroplasty in colostomy. Dis Colon Rectum. 2004;47(4):486-93.

Krasner D. Valuing diversity: a foundation stone of advanced wound caring. Ostomy Wound Manage. 1999;45(5):4-6.

Krasner DL. Following the Nightingale legacy. Ostomy Wound Manage. 2000; 46(6):6.

Kuijpers JH. Gastrointestinal surgery and gastroenterology. XI. Stomas and stoma surgery. Ned Tijdschr Geneeskd. 2001;145(24):1144-8.

Kuzu MA, Topçu O, Uçar K, Ulukent S, Unal E, Erverdi N, Elhan A, Demirci S. Effect of sphincter-sacrificing surgery for rectal carcinoma on quality of life in Muslim patients. Dis Colon Rectum. 2002;45(10):1359-66. 
La Fuente SG, Levin LS, Reynolds JD, Olivares C, Pappas TN, Ludwig KA, Mantyh CR. Elective stoma construction improves outcomes in medically intractable pressure ulcers. Dis Colon Rectum. 2003;46(11):1525-30.

Ladrière J. Os desafios da racionalidade. Petrópolis: Vozes; 1979.

Lasser P, Dubé P, Guillot JM, Elias D. Pseudocontinent perineal colostomy following abdominoperineal resection: technique and findings in 49 patients. Eur J Surg Oncol. 2001;27(1):49-53.

Law WL, Chu KW, Choi HK. Randomized clinical trial comparing loop ileostomy and loop transverse colostomy for faecal diversion following total mesorectal excision. Br J Surg. 2002;89(11):1480-1.

Le Blanc KA, Ballenager DE, Whitaker JM, Hausmann MG. Laparoscopic parastomal hernia repair. Hernia. 2005;9(2):140-4.

Lenneberg E Role of enterostomal therapist and stoma rehabilitation clinics. Cancer. 1971;28:266-9.

Lepistö AH, Järvinen HJ. Durability of Kock continent ileostomy. Dis Colon Rectum. 2003;46(7):925-928.

Lertsithichai P, Rattanapichart P. Temporary ileostomy versus colostomy: a meta-analysis of complications. Asian J Surg. 2004;27(3):202-10.

Litle VR, Barbour S, Schrock TR, Welton ML. The continent ileostomy: longterm durability and patient satisfaction. J Gastrointest Surg. 1999; 3:625-32.

Longman RJ, Thomson WH. Mesh repair of parastomal hernias: a safety modification. Colrectal Dis. 2005;7(3):292-4.

Lustosa SAS, Matos D, Atallah NA, Castro AA. Stapled versus handsewn methods for colorectal anastomosis surgery. Cochrane Database Syst Rev [database online].2006;(1). Available from: http://www.cochrane.org/reviews. [Access at 27 jan 2006].

Lyons AS. Ileostomy and colostomy support groups. Mt Sinai J Med. 2001; 68(2):110-2. 
Machado $\mathrm{MH}$, coordenador. Os médicos no Brasil: um retrato da realidade. Rio de Janeiro: FIOCRUZ; 1997.

Maeda K, Maruta M, Utsumi T, Sato H, Aoyama H, Katsuno H, Hultén L. Local correction of a transverse loop colostomy prolapse by means of a stapler device. Tech Coloproctol. 2004;8(1):45-6.

Mahoney JM. Guide to ostomy nursing care. Boston: Little Brown; 1976. p. 177-89.

Mancini GJ, Floyd L, Solla JA. Parastomal pyoderma gangrenosum: a case report and literature review. Am Surg. 2002;68(9):824-6.

Marquis P, Marrel A, Jambon B. Quality of life in patients with stomas: The Montreux Study. Ostomy Wound Manage. 2003;49(2):48-55.

Martins Junior A, Rocha JJR. Tipos de estomas intestinais. In: Crema E, Silva E Estomas: uma abordagem interdisciplinar. Uberaba: Ed. Pinti; 1997. p. 4164.

Martinsson ES, Josefsson M, Ek AC. Working capacity and quality of life after undergoing an ileostomy. J Adv Nurs. 1991;16(9):1035-41.

Mattingly M, Wasvary H, Sacksner J, Deshmukh G, Kadro OO. Minimally invasive, endoscopically assisted colostomy can be performed without general anesthesia or laparotomy. Dis Colon Rectum. 2003;46(2):271-3.

Matuliková AS, Hoch J. Colostomy and ileostomy and their complications. Rozhl Chir. 2001;80(10):517-20.

Mc Garity W The evolution of continence following total colectomy: part 1. World Counc Enterostom Ther J. 1993a;13(3):12-6.

Mc Garity W. The evolution of continence following total colectomy: part 2. World Counc Enterostom Ther J. 1993b;13(4):10-6.

McCance TV, McKenna HP, Boore JRP. Caring: dealing with a difficult concept. Int J Nurs Stud. 1997;34(4):241-8. 
McNamara DA, Parc R. Methods and results of sphincter-preserving surgery for rectal cancer. Cancer Control. 2003;10(3):212-8.

Meeberg GA. Quality of life: a conceptual analysis. J Adv Nurs. 1993;18(1):328.

Michelone APC, Santos VLCG. Qualidade de vida de adultos com câncer colorretal, com e sem ostomia. [resumo]. Rev Bras Coloproctol. 2002; 22 Supl $1: 6$.

Michelone APC, Santos VLCG. Qualidade de vida de adultos com câncer colorretal com e sem ostomia. Rev Lat Am Enferm. 2004;12(6):875-83.

Miller PR, Fabian TC, Croce MA, Magnotti LJ, Prichard EF, Minard G, Stewart RM. Improving outcomes following penetrating colon wounds: application of a clinical pathway. Ann Surg. 2002;235(6):775-81.

Mirhashemi R, Lamrbou N, Hus N, Salom E, Penalver MA, Averette HE. The gastrointestinal complications of the Miami Pouch: a review of 77 cases. Gynecol Oncol. 2004;92(1):220-4.

Moore KN. The patient at the center of care [editorial]. WOCN J. 2004;31(1):12.

Münch A, Söderholm JD, Wallon C, Ost A, Olaison G, Ström M. Dynamics of mucosal permeability and inflammation in collagenous colitis before, during, and after loop ileostomy. Gut. 2005;54(8):1126-8.

Murai HC, Prado SRLA, D`Amaral RKK, Armond JE. Sistema Único de Saúde: uma realidade em modelos assistenciais distintos. In: Cianciarullo TI, Silva GTR, Cunha ICKO, editores. Uma nova estratégia em foco: o Programa de Saúde da Família: identificando as suas características no cenário do SUS. São Paulo: Ícone; 2005. p. 43-54.

Nakamae DD. Novos caminhos da enfermagem. São Paulo: Cortez; 1987.

Nascimento Junior PG, Guimarães TMM. A relação médico-paciente e seus aspectos psicodinâmicos. Bioética 2003;11(1):101-12. 
Nelson R, Singer M. Primary repair for penetrating injuries. Cochrane Database Syst Rev [database online].2006;(1). Available from: http://www.cochrane.org/reviews. [Access at 27 jan 2006].

Nessar G, Remzi FH, Wu JS. Evolving technique for continent ileostomy: valveless pouch design. Tech Coloprotol. 2004;8(1):49-52.

Nielsen LF, Blume N, Romme T, Samuelsen P, Everland $H$, Ifversen $P$, Karlsmark T. Skin changes induced by a zinc oxide dressing compared with a hydrocolloid dressing in healthy individuals. Skin Res Technol. 2005; 11(2):140-51.

Nio $\mathrm{Y}$, Itakura $\mathrm{M}$, Yamaguchi $\mathrm{K}$, Hirahara N. Ileocecal valve-preserving ileostomy after total proctocolectomy: a novel technique for ileostomy. Dig Surg. 2004;21(1):7-9.

Nissinen MJ, Gylling H, Järvinen HJ, Miettinen TA. Ileal pouch-anal anastomosis, conventional ileostomy and ileorectal anastomosis modify cholesterol metabolism. Dig DFis Sci. 2004;49(9):1444-53.

Noddings N. Caring : a feminine approach to ethics and moral education. Berkeley: University of California Press; 1984.

Nogueira AS, Santos ER, Boccardo LM, Santos VLCG. Autocuidado do ostomizado: dificuldades percebidas após a alta hospitalar. Rev Esc Enferm USP. 1994;28(3):309-20.

Nordenfelt L. Concepts and measurement of quality of life in health care. Netherlands: Kluwer Academic Publishers; 1994.

Nunes WA. Do cuidar com tecnologia à tecnologia do cuidar [tese]. São Paulo: Escola de Enfermagem da USP; 1999.

O`Bichere A, Bossom C, Gangoli S, Green C, Phillips RK. Chemical colostomy irrigation with glyceryl trinitrate solution. Dis Colon Rectum. 2001;44(9):13247.

O`Bichere A, Green C, Phillips RK. Randomized cross-over trial of polyethylene glycol electrolyte solution and water for colostomy irrigation. Dis Colon Rectum. 2004;47(9):1506-9. 
O`Brian B, Baddi L, Benson A. Ostomy care: the added considerations for cancer patients. J Support Oncol. 2005;3(1):71-2.

O`Leary DP, Fide CJ, Foy C, Lucaroti ME. Quality of life after low resection with total mesorectal excision and temporary ileostomy for rectal carcinoma. Br J Surg. 2001;88(9):1216-20.

Oh NG, Son GM, Sin JY, Ding XZ, Adrian TE. Time-course of morphologic changes and peptide YY adaptation in ileal mucosa after loop ileostomy in humans. Dis Colon Rectum. 2005;48(6):1287-94.

Olbrisch ME. Development and validation of the Ostomy Adjustment Scale. Rehabil Psychol. 1983; 28(1):3-12.

Olmi S, Croce E, Magnone S, Mastropasqua E. Laparoscopic stoma creation. Chir Ital. 2002;55(6):897-902.

Oulton J. The future is ours. Int Nurs Rev. 1999;46(1):15-6, 26.

Pachler J, Wille-Jorgensen P. Quality of life after rectal resection for cancer,. with or without permanent colostomy. Cochrane Database Syst Rev [database online].2006;(1). Available from: http://www.cochrane.org/reviews. [Access at 27 jan 2006].

Paegle SO, Silva MJ. Análise da comunicação não verbal de pessoas portadoras de ostomia por câncer de intestino em grupo focal. Rev Lat Am Enferm. 2005;13(1):46-51.

Papachristou DN, Papachristou MD. Loop ileostomy without a rod. Ann Surg. 2004;70(1):89-90.

Paula RAB, Santos VLCG. Estudo retrospectivo sobre as complicações do estoma e da pele periestomal. Rev Bras Coloproctol. 1999a;19(3):155-63.

Paula RAB, Santos VLCG. Estudo retrospectivo sobre as complicações do estoma e da pele periestoma em ostomizados da cidade de São Paulo. Rev Esc Enferm USP. 1999b;33(n. esp):63-73.

Paula MAB, Santos VLCG. The significance of specialization for the enterostomal therapist nurse in Brazil. World Conc Enterostom Ther. J 2002; $22(4): 38-41$. 
Paula MAB, Santos VLCG. O significado de ser especialista para o enfermeiro estomaterapeuta. Rev Lat Am Enferm. 2003; 11(4):474-82.

Persson E, Hellström AL. Experiences of Swedish men and women 6 to 12 weeks after ostomy surgery. WOCN J. 2002;29(2):103-8.

Persson E, Gustavsson B, Hellström AL, Lappas G, Hultén L. Ostomy patients' perceptions of quality of care. J Adv Nurs. 2005;49(1):51-8.

Pessini L. A filosofia dos cuidados paliativos: uma resposta diante da obstinação terapêutica. Mundo Saúde 2003;27(1):15-32.

Platell C, Barwood N, Makin G. Clinical utility of a de-functioning loop ileostomy. ANZ J Surg. 2005;75(3):147-51.

Pringle W, Swan E. Continuing care after discharge from hospital for stoma patients. Br J Nurs. 2001;10(19):1275-88.

Probert CSJ, Jayanthi V, Mayberry JF. Quality of life after colectomy: a comparison of conventional ileostomy and sphincter saving continent procedures. Arq Gastroenterol. 1996;33(1):48-51.

Randell N, Lynch AC, Anthony A, Dobbs BR, Roake JA, Frizelle FA. Does a colostomy alter quality of life in patients with spinal cord injury? A controlled study. Spinal Cord. 2001;39(5):279-282.

Ratliff CR, Donovan AM. Frequency of peristomal complications. Ostomy Wound Manage 2001;47(8):26-9.

Reich WT. History of the notion of care. In: Reich WT, editor. Bioethics encyclopedia [CD-ROM]. 2nd ed. New York: Mac Millan Library; 1995.

Remzi FH, Oncel M, Hull TL, Strong AS, Lavery IC, Fazio VW. Current indications for blow-hole colostomy: ileostomy procedure. Int J Colorectal Dis. 2003;18(4):361-4.

Robertson I, Leung E, Hughes D, Spiers M, Donnelly L, Mackenzie I, Macdonald A. Prospective analysis of stoma-related complications. Colorectal Dis. 2005;7(3):279-85. 
Rodrigues P. Estomas urinários: aspectos conceituais e técnicos. In: Santos VLCG, Cesaretti IUR. Assistência em estomaterapia: cuidando do ostomizado. São Paulo: Atheneu; 2000. p. 55-68.

Rosito O, Nino-Murcia M, Wolfe VA, Kirati BJ, Perkash I. The effects of colostomy on the quality of life in patients with spinal cord injury: a retrospective analysis. J Spinal Cord Med. 2002;25(3):174-83.

Rullier E, Le Toux N, Laurent C, Garrelon JL, Parneix M, Saric J. Loop ileostomy versus loop colostomy for defunctioning low anastomoses during rectal cancer surgery. World J Surg. 2001;25(3):274-77.

Saclarides TJ, Hsu A, Quiros R. In situ mesh repair of parastomal hernias. Am Surg. 2004;70(8):701-5.

Sadler B, Froiland K. Obese patient with ileostomy management problems. WOCN J. 2002;29(3):164-9.

Safadi BY, Rosito O, Nino-Murcia M, Wolfe VA, Perkash I. Which stoma works better for colonic dysmobility in the spinal cord injured patients? Am J Surg. 2003;186(5):437-42.

Sailer M, Fein M, Fuchs KH, Bussen D, Grun C, Thiede AA. Morphologic changes of the anal sphincter musculature during and after temporary stool deviation. Langenbecks Arch Surg. 2001;386(3):183-7.

Saito N, Ono M, Sugito M, Ito M, Morihiro M, Kosugi C, Sato K, Kotaka M, Nomura S, Arai M, Kobatake T. Early results of intersphincteric resection for patients with very low rectal cancer: an active approach to avoid a permanent colostomy. Dis Colon Rectum. 2004;47(4):459-66.

Sakai Y, Nelson H, Larson D, Maidl L, Young-Fadok T, Ilstrup D. Temporal transverse coplostomy vs loop ileostomy in diversion: a case-matched study. Arch Surg. 2001;136(3):338-42.

Salom EM, Penalver MA. Pelvic exenteration and reconstruction. Cancer. 2003;9(5):415-24.

Sanchez-Crisol I. Estudio observacional para evaluar la efectividad de una nueva bolsa de colostomía. Rev Rol Enferm. 1998; 21(241):55-61. 
Santos VLCG. Estudo sobre o método de irrigação intestinal em colostomizados [nota prévia]. Rev Esc Enferm USP. 1984;18(1):93-4.

Santos VLCG. Relato da experiência no treinamento da irrigação intestinal de uma paciente colostomizada. Rev Paul Enferm. 1985;5(2):73-5.

Santos VLCG. Avaliação do equipamento disponivel para ostomizados. Rev Paul Enferm. 1986;6(3):116-9.

Santos VLCG, Silva MAT, Oya T, Gutierrez ECV. Previsão de equipamentos específicos para a assistência a pacientes portadores de estomas intestinais e urinários, no Hospital das Clínicas da faculdade de Medicina da Universidade de São Paulo. Rev Paul Enferm. 1986;6(2):60-6.

Santos VLCG. Estudo sobre os resultados da irrigação em colostomizados submetidos a um processo de treinamento sistematizado [dissertação]. São Paulo: Escola de Enfermagem da USP; 1989.

Santos VLCG, Koizumi MS. Processo de auto - irrigação em colostomizados: avaliação de resultados [resumo]. ABCD Arq Bras Cir Dig. 1990;5(2):11.

Santos VLCG, Sousa Jr AHS, Ribeiro AM, Schnitter MA, Baxter YC, Ferreira SHC, Oliveira DV. Núcleo de Assistência a Ostomizados: um relato de experiência [resumo]. Rev Med Reabil. 1991;1(29/30):16.

Santos VLCG. Reabilitação do ostomizado: em busca do ser saudável. Texto Contexto Enferm. 1992;1(2):180-90.

Santos VLCG, Habr-Gama A, Ribeiro AM, Roncaratti E, Sousa Junior AHS. Utilização do sistema oclusor de colostomia: resultados preliminares [resumo]. Rev Bras Coloproctol. 1992;12 Supl 1:59.

Santos VLCG, Koizumi MS. Sentimentos e sugestões manifestados por colostomizados que se auto-irrigam. Rev Esc Enferm USP. 1992a;26(2):16172 .

Santos VLCG, Koizumi MS. Estudo sobre os resultados da irrigação em colostomizados submetidos a um processo de treinamento sistematizado. Rev Esc Enferm USP. 1992b;26(3):302-14.

Santos VLCG. Buscando o lugar certo. Rev Paul Enferm. 1993;12(3)103-6. 
Santos VLCG, Habr-Gama A, Ribeiro AM, Nishida CSI, Roncaratti E, Sousa Junior AHS, Pinotti HW. Usage of colostomy plug system: preliminary results. ABCD Arq Bras Cir Dig. 1993;8(1):16-21.

Santos VLCG, Sousa Jr AHS. Estomaterapia: uma especialidade que emerge para a enfermagem brasileira. Rev Esc Enferm USP. 1993;27(1):9-14.

Santos VLCG, Sousa Jr AHS, Habr-Gama A. Enfermeiros estomaterapeutas (ETs) no Brasil. In: Resúmen del $8^{\circ}$ Congresso Latino Americano de Coloproctologia e $3^{\circ}$ Congreso Venezoelano de Coloproctologia; 1993 Set. 1923; Isla de Margarita; Venezuela; 1993. p.9-10.

Santos VLCG. Como eu trato as dermatites periestoma. Rev Esc Enferm USP. 1994;28(1):67-71.

Santos VLCG, Sousa Junior AHS. Trends in the teaching and research of stomal therapy in Brazil. World Conc Enterostom Ther J. 1994;14(4):29-35.

Santos VLCG, Sousa Junior AHS. Ensino especializado de estomaterapia no Brasil:1990-1995 [resumo]. Rev Bras Coloproctol. 1996;16 Supl 1:75.

Santos VLCG, Cezareti IUR, Ribeiro AM, Filippin MJ, Lima SRS. Métodos de controle do hábito intestinal em estomizados: auto-irrigação e sistema oclusor. In: Crema E, Silva R, organizadores. Estomas: uma abordagem interdisciplinar. Uberaba: Ed. Pinti; 1997. p.145-62.

Santos VLCG. Cuidados avançados em estomaterapia: vislumbrando o 3० milênio. Rev Esc Enferm USP. 1999;33(n. esp):1-3.

Santos VLCG. A estomaterapia através dos tempos. In: Santos VLCG, Cesaretti IU, coordenadoras. Assistência em estomaterapia: cuidando do ostomizado. São Paulo: Atheneu; 2000a. p. 1-17.

Santos VLCG. Fundamentação teórico-metodológica da assistência aos ostomizados na área da saúde do adulto institucionalizado. Rev Esc Enferm USP. 2000b;34(1):59-63.

Santos VLCG. Representações do corpo e a ostomia: estigma. In: Santos VLCG, Cesaretti IUR, coordenadoras. Assistência em estomaterapia: cuidando do ostomizado. São Paulo: Atheneu; 2000c. p. 89-102. 
Santos VLCG. The cancer patient: some reflections about the interface between rehabilitation and quality of life. World Counc Enterostom Ther J. 2000d;20(3):30-38.

Santos VLCG, Cesaretti IUR, Ribeiro AM. Métodos de "controle" intestinal em ostomizados: auto-irrigação e sistema oclusor. In: Santos VLCG, Cesaretti IUR, coordenadoras. Assistência em estomaterapia: cuidando do ostomizado. São Paulo: Atheneu; 2000. p. 245-62.

Santos VLCG, Kimura M. Qualidade de vida e a reabilitação do ostomizado. In: Santos VLCG, Cesaretti IUR, coordenadoras. Assistência em estomaterapia: cuidando do ostomizado. São Paulo: Atheneu; 2000. p. 453-75.

Santos VLCG, Sawaia BB. A bolsa na mediação "estar ostomizado" - "estar profissional": análise de uma estratégia pedagógica. Rev Lat Am Enferm. 2000; $8(3): 40-50$.

Santos VLCG, Sawaia BB. The pouch acting as a mediator between "being a person with an ostomy" and "being a professional": analysis of a pedagogical strategy. J WOCN. 2001;28(4):206-14.

Santos VLCG. Estomias abdominais. In: Velasco IT, editor. Propedêutica na emergência. São Paulo: Atheneu; 2003. p. 607-12.

Santos VLCG, Cesaretti IUR. Dermatites periestoma: da prevenção ao tratamento. In: Jorge SA, Dantas SRPE, organizadores. Abordagem multiprofissional no tratamento de feridas. São Paulo: Atheneu; 2003. p. 299308.

Santos VLCG, Kimura M, Chaves EC. Qualidade de vida e coping de pessoas com ostomias provisórias e definitivas [resumo]. Rev Bras Coloproctol. 2003a; 23 Supl 1:44.

Santos VLCG, Kimura M, Chaves EC. Quality of life and coping of people with temporary and permanent stomas [abstract]. Qual Life Res. 2003b;12(7):821.

Santos VLCG. Humanization of specialized care and the evolution of technology. In: Proceedings of the $15^{\text {th }}$ Biennial Congress of the World Council of Enterostomal Therapists and $5^{\circ}$ Brazilian Congress of Enterostomal Therapy; 2004 May 16-19; Florianópolis; Santa Catarina; 2004a. 
Santos VLCG, Oliveira ACB. Qualidade de vida e auto-estima de adultos jovens com ostomias [resumo]. Rev Bras Coloproctol. 2004;24 Supl 1:64.

Sato T, Konishi F, Endoh N, Uda H, Sugawara Y, NMagai H. Long-term outcomes of a neo-anus with a pudendal nerve anastomosis contemporaneously reconstructed with an abdominoperineal excision of the rectum. Surgery. 2005;137(1):8-15.

Saver C. Nursing in the new millennium. NSNA Imprint. 1999;46(1):32-6.

Scarpa M, Barollo M, Keighley MR. Ileostomy for constipation: long-term postoperative outcome. Colorectal Dis. 2005;7(3):224-7.

Schultz JM. Preparing the patient for colostomy care: a lesson well learned. Ostomy Wound Manage. 2002;48(10):22-5.

Schwenk W, Haase O, Neudecker J, Müller JM. Short term benefits for laparoscopic colorectal resection. Cochrane Database Syst Rev [database online].2006;(1). Available from: http://www.cochrane.org/reviews [Access at 27 jan 2006].

Secoli S. Perfil epidemiológico do câncer no adulto: panorama brasileiro. Âmb Hosp. 2005; 17(171):59-62.

Secretaria de Estado da Saúde de São Paulo. Proposta Básica para Assistência aos Ostomizados do SUS-SP. São Paulo: Secretaria da Saúde; 1993.

Seidel SA, Newman M, Sharp KW. Ileoanal pouch versus ileostomy: is there a difference in quality of life? Am Surg. 2000;66(6):540-6.

Shibuya T, Uchiyama K, Kokuma M, Shioya T, Watanabe Y, Moriyama Y, Matsumoto K, Yokosuka I. Metachronous adenocarcinoma occurring at a colostomy site after abdominoperineal resection for rectal carcinoma. $J$ Gastroenterol. 2002;37(5):387-90.

Silva ED, Arruda MEM, Martins SS, Santos VLCG. Colostomia e irrigação: significados psicológicos atribuídos por colostomizados. Rev Esc Enferm USP. 1999;33(n. esp):55-62.

Silva MA, Ratnayake G, Deen KI. Quality of life of stoma patients: temporary ileostomy versus colostomy. World J Surg. 2003;27(4):421-4. 
Singer MA, Nelson RL. Primary repair for penetrating injuries: a systematic review. Dis Colon Rectum. 2002;45(12):1579-87.

Smits S. President's message: dialogue of change. World Counc Enterostom Ther J. 2005;25(4):3.

Solomon MJ, Pager CK, Keshava A, Findlay M, Butow P, Salkeld GP, Roberts $\mathrm{R}$. What do patients want? Patient preferences and surrogate decision making in the treatment of colorectal cancer. Dis Colon Rectum. 2003;46(10):1351-7.

Sousa Junior AHS, Santos VLCG, Habr-Gama A. Curso de Especialização de Enfermagem em Estomaterapia: primeira experiência [resumo]. Rev. Bras Coloproctol. 1990;10 Supl 1:56-.

Sousa Junior AHS, Santos VLCG, Mileo LF, Delatorre GA, Nahas P, Pinotti HW, Habr-Gama A. Equipe multiprofissional no cuidado de ostomizados: 164 casos seguidos no Núcleo de Assistência a Ostomizados [resumo]. Rev Bras Coloproctol. 1989;9 Supl 1:56.

Souza DM, Santos VLCG. Quality of life of children with continent urinary stomas: a comparative study with healthy children. In: Programme and Abstracts Book of the 15th Biennial Congress of the World Council of Enterostomal Therapists; 2004 May 16-19; Florianópolis; SC, Brazil. p.73.

Souza DMST, Serpa LF, Rodrigues NHP, Santos VLCG. Thesis and dissertations in thematic areas regarding to Brazilian enterostomal therapy. In: Programme and Abstracts Book of the 15th Biennial Congress of the World Council of Enterostomal Therapists; 2004 May 16-19; Florianópolis, SC, Brazil. p.94.

Souza MTM, Lemonica L. Paciente terminal e médico capacitado: parceria pela qualidade de vida. Bioética 2003;11(1):83-100.

Sredl D, Wilhite M. The enterostomal therapist: a new breed of nurse. Superv Nurs. 1980;11(1):51-2.

Swain BT, Ellis CN. Laparoscopic-assisted loop ileostomy: an acceptable option for temporary fecal diversion after anorectal surgery. Dis Colon Rectum. 2002;45(5):705-7.

Szczepkowski M. Do we still need a permanent colostomy? Acta Chir Iugosl. 2002;49(2):45-55. 
Tan HT, Morton D, Connoly AB, pringle W, White M, Keighley MRB. Quality of life after pouch excision. Brit J Surg. 1997;85:249-51.

Tennant SM. Nursing to care or caring to nurse: a qualitative investigation of perceptions of new recruits. Nurse Educ Today. 1999;19(3):239-45.

Thompson JM. Quality of life after conventional ileostomy in NSW. World Counc Enterostom Ther J. 1990;10(1):8-14.

Tichy J. Somatognosis, body schema and the phenomena of somatic and visceral phantoms and phantom pain. Cas Lek Cesk. 2003;142(6):331-4.

Tocchi A, Mazzoni G, Miccini M, Bettelli E, Cassini D. Use of ileostomy and colostomy as temporal derivation in colorectal surgery. G Chir. $2002 ; 23(1 / 2): 48-52$.

Towler BP, Irwig L, Glasziou P, Weller D, Kewenter J. Screening for colorectal cancer using the faecal occult blood test, Hemoccult. Cochrane Database Syst Rev [database online]. 2006;(1). Available from: http://www.cochrane.org/reviews. [Access at 27 jan 2006].

Tseng HC, Wang HH, Hsu YY, Weng WC. Factors related to stress in outpatients with permanent colostomies. Kaohsiung J Med. 2004;20(2):70-7.

Turnbull RW, Turnbul, GB The history and current status of paramedical support for the ostomy patient. J ET Nurs. 1993; 20(3):102-4.

Turnbull GB. The dollars and sense of patient teaching. Ostomy Wound Manage 1999a;45(3):16-7.

Turnbull GB. The new bottom line. Ostomy/ Wound Manage. 1999b;45(8):810.

Turnbull GB. Does age bring wisdom? The coming of age of managed care. Ostomy Wound Manage. 1999c;45(1):16-7.

Turnbull GB, Erwin-Toth P. Ostomy care: foundation for teaching and practice. Ostomy Wound Manage. 1999;45 Suppl 1A:23S-30S. 
Turnbull GB. Managing oversight of colostomy irrigation in long term-care. Ostomy Wound Manage. 2003;49(10):13-4.

Turnbull GB. The issue of oral medications and a fecal ostomy. Ostomy Wound Manage. 2005;51(3):14-6.

Turns D. Psychosocial issues: pelvic exenterative surgery. J Surg Oncol. 2001;76(3):224-236.

Van Rijswijk L. Clinical practice guidelines: moving into the $21^{\text {st }}$ century. Ostomy Wound Manage. 1999a;45(1A):47S-53S.

Van Rijswijk L. Challenging the status quo: lessons from Norma Gill. Ostomy Wound Manage. 1999b;45(1):4.

Van Rijwisjk L. Looking back on 20 years: change is constant..but there are exceptions. Ostomy Wound Manage 2000; 46(1):6-9.

Viana NM, Moritaka L, Pelicia R, Roncaratti E, Marx LC, Santos VLCG. Técnica da demarcação do local do futuro estoma: determinante da adaptação do ostomizado [resumo]. Rev Bras Coloproctol. 1995;15 Supl 1:101.

Vukovich VC, Grubb RD. Care of the ostomy patient. 2nd ed. Saint Louis: Mosby; 1977.

Weakley FL. A historical perspective of stomal construction. WOCN J. 1994; 21(2):59-75.

Wedderburn A, Lee RS, Denny A, Steinbrecher HA, Koyle MA, Malone PS. Synchronous bladder reconstruction and antegrade continence enema. J Urol. 2001;165(6 Pt 2):2392-3.

Weingarten MA, Zalmanovici A, Yaphe J. Dietary calcium supplementation for preventing colorectal cancer and adenomatous polyps. Cochrane Database Syst Rev [database online].2006;(1). Available from: http://www.cochrane.org/reviews. [Access at 27 jan 2006].

White M, Berg K. A new flangeless adhesive coupling system for colostomy and ileostomy. Br J Nurs. 2005;14(6):325-8. 
Winnie CSW. Adapting a quality of life scale for those with a colostomy in Hong Kong: a preliminary study. World Counc Enterostom Ther J. 2001; 21(1):21-9.

Wong KS, Remzi FH, Arrigain S, Church JM, Preen M, Fazio VW. Loop ileostomy closure after restorative proctocolectomy: outcome in 1504 patients. Dis Colon Rectum. 2005;48(2):243-50.

World Council of Enterostomal Therapists (WCET). History [online]. Available from: www.wcetn.org. [Access at 20 fev 2006].

World Council of Enterostomal Therapists (WCET). Members' Handbook. Ontario, Canada: World Council of Enterostomal Therapists; 2005.

Wound Ostomy Continence Nursing Society (WOCNS). WOCN position statement: stoma site marking [online]. 2006a. Available from: www.wocn.org. [Access at $16 \mathrm{fev}$ 2006].

Wound Ostomy Continence Nursing Society (WOCNS). WOCN position statement. White paper: minimal and optimal skill set for the person with a new ostomy - self care procedures [online]. 2006b. Available from: www.wocn.org. [Access at $16 \mathrm{fev} 2006$ ].

Wound Ostomy Continence Nursing Society (WOCNS). WOCN position statement. White paper: wear time of a fecal or urinary pouching system [online]. 2006c. Available from: www.wocn.org. [Access at $16 \mathrm{fev}$ 2006].

Yamada BFA, Peres CSV, Santos VLCG. Granuloma em gastrostomia: uma alternativa inovadora de tratamento tópico. Rev Estima. 2005;3(n. esp):61.

Zampieri JC, Jatobá PP Histórico. In: Crema E, Silva E. Estomas: uma abordagem interdisciplinar. Uberaba: Ed. Pinti; 1997. p.13-8.

Zhan L. Quality of life: conceptual and measurement issues. J Adv Nurs. 1992;17(7):795-800.

Zherlov GK, Bashirov SR, Krasnoperov AV. Surgical creation of a reservoircolostomy with reflex evacuation. Vestn Khir Im I I Grek. 2002;161(3):75-7. 